\title{
Simulação de Mini-Ecossistemas Vegetais em Tempo Real
}

\author{
Luis Carlos Yano Endo
}

\author{
DISSER'TAÇÃO APRESENTADA AO \\ INSTITUTO DE MATEMÁTICA E EsTATÍSTICA \\ DA UNIVERSIDADE DE SÃO PAULO \\ COMO PARTE DOS REQUISITOS \\ PARA OBTENÇÃO DO GRAU DE \\ MESTRE EM CIÊNCIA DA COMPUTAÇÃo
}

Área de Concentração: Computação Gráfica

Orientador: Prof. Dr. Antonio Elias Fabris

- São Paulo - Dezembro de 2003 - 


\title{
Simulação de Mini-Ecossistemas Vegetais em Tempo Real
}

\author{
Este exemplar corresponde à redação final \\ da dissertação de mestrado devidamente \\ corrigida e defendida por \\ Luis Carlos Yano Endo \\ e aprovada pela comissão julgadora.
}

São Paulo, 26 de Abril de 2004

Banca examinadora:

- Prof. Dr. Antonio Elias Fabris (Orientador) - IME - USP

- Prof. Dr. Carlos Hitoshi Morimoto - IME - USP

- Prof. Dr. Márcio Lobo Netto - EP - USP

- Prof. Dr. Jorge Stolfi - IC - UNICAMP

- Prof. Dr. Eduardo Toledo Santos - EP - USP 
Aos meus pais Yoshibumi Endo e Sadako Yano Endo, minha irmã Ana Cristina Yano Endo e meu avô Shigetaka Yano. 


\section{Agradecimentos}

Meus sinceros agradecimentos ao meu orientador, Antonio Elias Fabris, por todos estes anos de dedicação, amizade e instrução. Agradeço à liberdade, incentivo e confiança que demonstrou durante à definição do tema deste trabalho.

Agradecimentos especiais ao professor Carlos Hitoshi Morimoto, cujas idéias, críticas e sugestões foram de fundamentais importância para elaboração desta dissertação.

Agradeço também a todos professores do instituto que participaram da minha formação. Em especial aos professores Carlos Eduardo Ferreira e Roberto Marcondes Cesar Jr pela excelente didática e apoio durante os cursos da graduação e pós-graduação neste instituto, e à professora Nina Sumiko Tomita Hirata pelas sugestões durante a leitura do texto de qualificação desta dissertação, o que evitou alguns deslizes.

Aos meus pais Yoshibumi e Sadako, que sempre me incentivaram, e cujo esforço e dedicação proporcionaram todas as condições necessárias para minha formação.

À minha irmã Ana pela amizade, apoio e cooperação.

À minha namorada Alessandra Nagatsu pela compreensão, carinho e incentivo.

À minha família e aos meus amigos, em especial Leonardo Inoue, Leonardo Pinho, Lívio Soares, Luciano Kubo, Marcelo Vinagreiro, Marcos Ottani e Shigueo Isotani pela companhia e colaboração durante todos estes anos. 


\section{Resumo}

Dos temas atuais de pesquisa em Computação Gráfica, dois chamam bastante atenção pelo número de aplicações que requerem as soluções: a renderização e animação de cenas complexas em tempo real e a simulação realista de fenômenos naturais.

Neste trabalho, apresentamos algumas técnicas relacionadas a estes problemas e propomos uma solução que visa satisfazer ambos da melhor forma possível. Este trabalho tem como principal objetivo a criação de um arcabouço capaz de gerar cenas que simulem, de forma realista, mini-ecossistemas vegetais em tempo real.

Para isto, foi necessário o estudo e desenvolvimento de diversas técnicas de modelagem, animação e interação que produzem resultados eficientes e realistas. Tais técnicas podem ser utilizadas, inclusive, por outras aplicações com o mesmo objetivo.

Palavras-Chave: Computação Gráfica, modelagem e renderização de fenômenos naturais, modelagem baseada em Física, animação com controles, nível de detalhes, renderização em tempo real. 


\begin{abstract}
Among all subjects of research on Computer Graphics, two of them draw people's attention because of the number of applications that require the solution: real time rendering and animation of complex scenes and natural phenomena realistic simulation.

In this work we present some techniques related to these problems and a solution is proposed to satisfy both the best way it is possible. The main purpose of this work is the creation of a framework that generates scenes that simulate, realistically, small plant ecossystems in real time.

To achieve this purpose, it was necessary the research and development of several techniques for modeling, animation and interaction that generate efficient and realistic results. These techniques can be also used for other applications with the same intention.
\end{abstract}

Keywords: Computer Graphics, Modeling and Rendering of Natural Phenomena, Physically Based Modeling, Animation with Constraints, Level of Details, Real time Rendering. 


\section{Conteúdo}

1 Introdução $\quad 1$

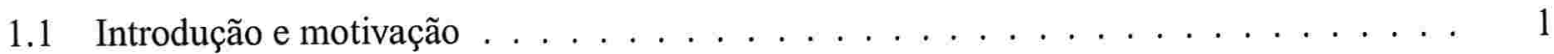

1.2 Problemas envolvidos . . . . . . . . . . . . . . . . . 3

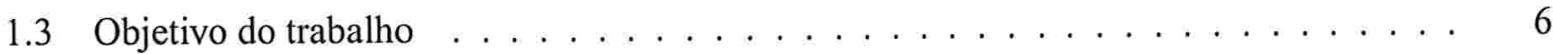

2 Fundamentos Teóricos $\quad 8$

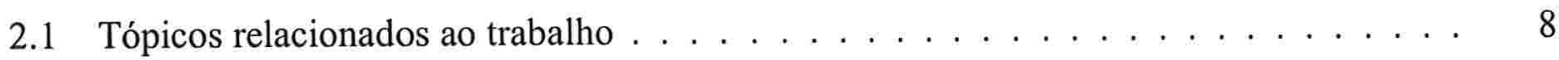

2.2 Modelagem . . . . . . . . . . . . . . . . . . . . 9

2.2 .1 Modelagem de sólidos . . . . . . . . . . . . . . . . . . . 9

Representação por varredura . . . . . . . . . . . . . . . . . . . . . . . 10

Representação CSG . . . . . . . . . . . . . . . . . . . 10

Representação pelas bordas . . . . . . . . . . . . . . . . . . . 11

2.2.2 Técnicas avançadas de modelagem . . . . . . . . . . . . . . . 12

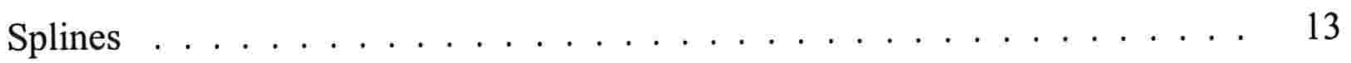

Modelos baseados em gramática . . . . . . . . . . . . . . . . . . . . . . . . . . .

Sistemas de partículas . . . . . . . . . . . . . . . . 15

2.3 Técnicas baseadas em Física $\ldots \ldots \ldots \ldots \ldots$

2.3 .1 Dinâmica do corpo rígido . . . . . . . . . . . . . . . . 17

2.3.2 Controles dinâmicos . . . . . . . . . . . . . . . . . . . 18

2.3.3 Controle para não penetração e detecção de colisão . . . . . . . . . . . . . . . 19

2.3.4 Modelos elasticamente deformáveis . . . . . . . . . . . . . . 20

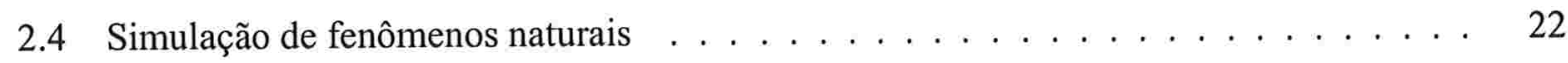


2.4.1 Modelagem de fenômenos naturais com sistemas de partículas . . . . . . . . . 22

2.4.2 Modelagem e animação de plantas . . . . . . . . . . . . . . . . 24

L-Systems . . . . . . . . . . . . . . . . . . . . 24

Modelagem de vegetação rasteira . . . . . . . . . . . . . . . . 28

2.4.3 Modelagem de outros fenômenos naturais . . . . . . . . . . . . . 28

2.4 .4 Simulação de ecossistemas . . . . . . . . . . . . . . . . . . . . . 30

2.5 Níveis de detalhes . . . . . . . . . . . . . . . . . . . . . . . . . . . . . 32

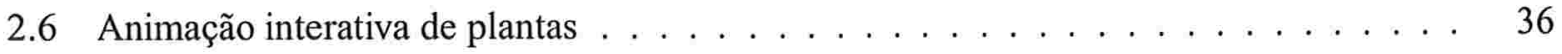

3 Simulador de Mini-Ecossistemas Vegetais $\quad 41$

3.1 Introdução . . . . . . . . . . . . . . . . . . . . . 41

3.2 Modelagem do terreno . . . . . . . . . . . . . . . . 42

3.2 .1 Descrição da solução . . . . . . . . . . . . . . . . . . . . . . 43

3.2 .2 Resultados obtidos e discussão . . . . . . . . . . . . . . . . . . . . . 43

3.3 Modelagem de plantas . . . . . . . . . . . . . . . . . . 45

3.3.1 Pré-computações e estrutura de dados . . . . . . . . . . . . . . . . 45

3.3.2 Modelo físico para componentes das plantas . . . . . . . . . . . . . . 47

Algoritmo para modelagem sobre ação da força de gravidade . . . . . . . . . . . . . . . . . . . . . .

Cálculo dos centros de massa . . . . . . . . . . . . . . . . . 49

Cálculo do ângulo de curvatura $\ldots \ldots \ldots \ldots$. . . . . . . . . 50

Resultados . . . . . . . . . . . . . . . . . . . . 51

3.3.3 Nível de detalhes para modelagem . . . . . . . . . . . . . . . 51

3.3.4 Resultados obtidos e discussão . . . . . . . . . . . . . . . . . 53

3.4 Campo de forças . . . . . . . . . . . . . . . . . . . 54

3.4 .1 Introdução . . . . . . . . . . . . . . . . . . 54

3.4 .2 Técnica de Quadtree . . . . . . . . . . . . . . . . . . 56

3.4.3 Nível de detalhes por distância e células visíveis. . . . . . . . . . . . . . . 58

3.4 .4 Resultados obtidos e discussão . . . . . . . . . . . . . . . . . . . 62

3.5 Animação de plantas . . . . . . . . . . . . . . . . . . . . . 62

3.5.1 Utilização dos modelos físicos pré-computados . . . . . . . . . . . . . . 63

3.5.2 Animação realista utilizando controles dinâmicos . . . . . . . . . . . . . 64 
3.5.3 Algoritmo de animação por aproximação baseado na técnica de controles dinâmicos 67

Passo 1: Simulação por tipo de planta e célula do campo de forças . . . . . . . 67

Passo 2: Animação dos componentes que foram alterados . . . . . . . . . 68

3.5.4 Resultados obtidos e discussão . . . . . . . . . . . . . . . . . . . . . 69

3.6 Distribuição de plantas . . . . . . . . . . . . . . . . . . . . . . . . . . . 69

3.6 .1 Descrição da solução . . . . . . . . . . . . . . . . . . . . . . 70

3.6 .2 Resultados obtidos e discussão . . . . . . . . . . . . . . . . . . 71

3.7 Modelagem de fenômenos naturais . . . . . . . . . . . . . . . . 72

3.7 .1 Modelagem do Vento . . . . . . . . . . . . . . . . . . . . . 72

3.7 .2 Animação rápida pela ação do Vento . . . . . . . . . . . . . . . . . . . 74

Fluxos . . . . . . . . . . . . . . . . . . . . . . 74

Tratamento do conjunto de fluxos . . . . . . . . . . . . . . . 75

Integração com o campo de forças . . . . . . . . . . . . . . . 76

Simulação da ação do vento nas células do campo de forças . . . . . . . . 78

3.7.3 Resultados obtidos e discussão . . . . . . . . . . . . . . . . . . . . . . 79

4 O Arcabouço $\quad 81$

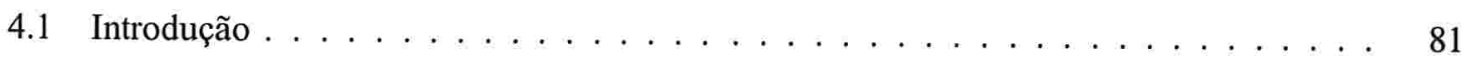

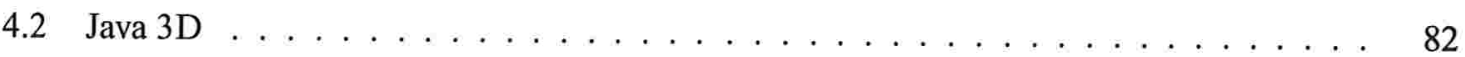

4.2 .1 Detalhes relevantes da API . . . . . . . . . . . . . . . . . 84

Grafo de uma cena Java 3D $\ldots \ldots \ldots \ldots$

Hierarquia básica de classes . . . . . . . . . . . . . . . . . . . . . . . 84

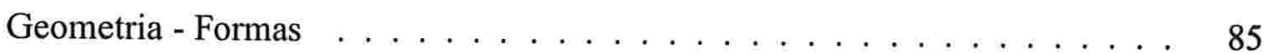

Comportamentos . . . . . . . . . . . . . . . . . 86

Animação . . . . . . . . . . . . . . . . . . . . . . 86

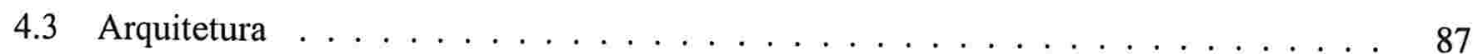

4.4 Análise do desempenho do arcabouço . . . . . . . . . . . . . . . 88

4.4.1 Análise de desempenho dada a complexidade geométrica dos objetos . . . . 89

4.4.2 Análise de desempenho dados os modelos geométricos dos objetos . . . . . 91

4.4.3 Análise de desempenho pela quantidade de modelos

pré-computados . . . . . . . . . . . . . . . . . . . . . . 92 
4.4.4 Análise do desempenho do campo de forças . . . . . . . . . . . . . . . . 92

4.4.5 Análise de desempenho do algoritmo de animação . . . . . . . . . . . . 93

4.4.6 Análise do desempenho do algoritmo de nível de detalhes . . . . . . . . . . 94

5 Conclusão $\quad 95$

5.1 Resultados . . . . . . . . . . . . . . . . . . . . . 96

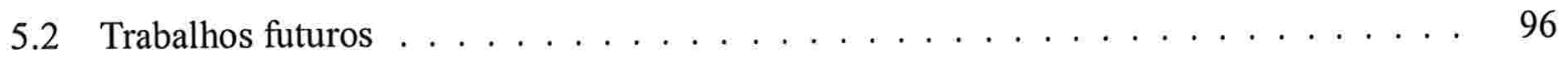

5.3 Considerações finais . . . . . . . . . . . . . . . . . . . . 99

A Detalhes da Arquitetura do Arcabouço $\quad 100$

A.1 Pacote ecosys terrain . . . . . . . . . . . . . . . . 101

A.2 Pacote ecosys.interaction . . . . . . . . . . . . . . 102

A.3 Pacote ecosys.plants . . . . . . . . . . . . . . 103

A.3.1 Pacote ecosys.plants. leaf . . . . . . . . . . . . . . 105

A.3.2 Pacote ecosys.plants.branch . . . . . . . . . . . . 105

A.3.3 Pacote ecosys.plants.flower . . . . . . . . . . . . . 107

A.3.4 Pacote ecosys.plants.animation . . . . . . . . . . . . 107

A.3.5 Pacote ecosys.plants.distribution . . . . . . . . . . . . 109

A.3.6 Pacote ecosys.plants. underbrush . . . . . . . . . . . . . . 110

A.3.7 Pacote ecosys.plants.bush . . . . . . . . . . . . . . . 111

A.4 Pacote ecosys.naturalphenomena . . . . . . . . . . . . . . . 112

A.4.1 Pacote ecosys.naturalphenomena. wind . . . . . . . . . . . 112

A.5 Pacote ecosys visualization . . . . . . . . . . . . . . . . 113

A.6 Pacote ecosys.ui . . . . . . . . . . . . . . . . . . . . . 114

A.6.1 Pacote ecosys.ui.gui . . . . . . . . . . . . . . . . . . . 114

A.6.2 Pacote ecosys.ui. parser . . . . . . . . . . . . . . 114

A.6.3 Pacote ecosys.ui.user . . . . . . . . . . . . . 116

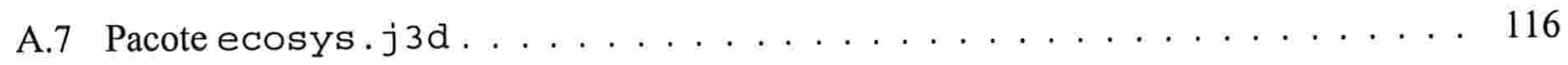

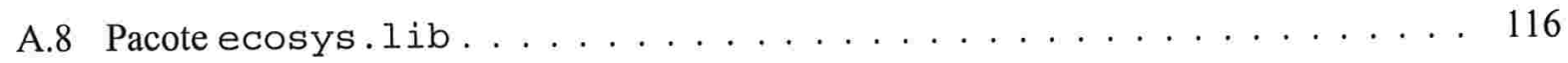

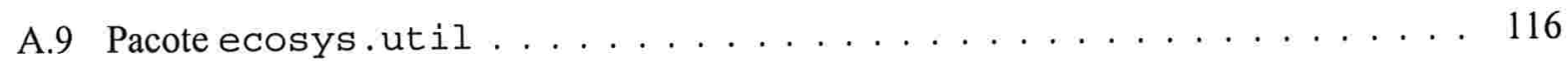


B ESL - A Linguagem de Descrição de Cenas $\quad 117$

B.1 Descrição da linguagem . . . . . . . . . . . . . . . . . . . . . . . . . 117

B.1.1 Tipos definidos . . . . . . . . . . . . . . . . . 118

B.1.2 Tags e atributos . . . . . . . . . . . . . . . . 118

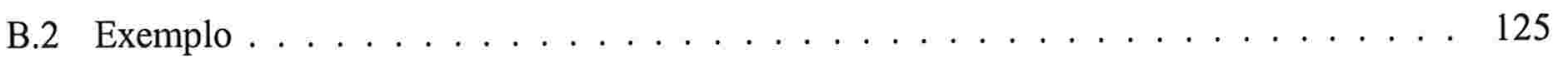




\section{Lista de Figuras}

2.1 Exemplo de B-rep + shading. . . . . . . . . . . . . . . . . 12

2.2 Comparação de modelagem por polígonos e splines. . . . . . . . . . . . . . . 14

2.3 Exemplo de modelagem por partículas. . . . . . . . . . . . . . . 16

2.4 Exemplo de modelagem baseada em Física. . . . . . . . . . . . . . . . . . 19

2.5 Exemplo de animação baseada em Física. . . . . . . . . . . . . . . 21

2.6 Modelagem de plantas e uma cachoeira utilizando sistemas de partículas. . . . . . . . 24

2.7 Exemplo de especificações e aplicações de produções de L-Systems. . . . . . . . . . . . 25

2.8 Aplicação das regras de produção em L-Systems. . . . . . . . . . . . . . . . . . . 27

2.9 Exemplos de simulação de ecossistemas. . . . . . . . . . . . . . . . . . 32

2.10 Criaturas modeladas utilizando 3 níveis de detalhes. . . . . . . . . . . . 33

2.11 Exemplo da utilização de diferentes técnicas para criação de níveis de detalhes. . . . . 34

2.12 Aproximação por pontos e linhas. . . . . . . . . . . . . . . . . . . . . . . . . . . . . . . . . .

2.13 Vegetação animada em tempo real. . . . . . . . . . . . . . . . . . . 37

2.14 Aproximação de uma árvore utilizando "Slicing". . . . . . . . . . . . . . . . . 38

2.15 Aproximação de um campo de grama utilizando a técnica de linhas e pontos. . . . . . 39

2.16 Resultados obtidos em trabalho semelhante. . . . . . . . . . . . . . . . . 39

3.1 Terreno e malha do terreno gerado pelo sistema . . . . . . . . . . . . . . . 44

3.2 Representação de componentes de planta por vetores . . . . . . . . . . . . . . . 46

3.3 Resultados de modelos pré-computados. . . . . . . . . . . . . . . . . 47

3.4 Figura considerando a ação das forças de gravidade $\left(\vec{F}_{g}\right)$ e elástica $\left(\vec{F}_{e l}\right)$ na modelagem. 48

$3.5 \mathrm{O}$ processo de curvamento devido à força de gravidade. . . . . . . . . . . . . . . . 49 
3.6 Resultados para o algoritmo de modelagem de plantas baseado em Física. . . . . . . 52

3.7 Resultados do algoritmo de Nível de detalhes para modelagem das plantas. . . . . . 53

3.8 Quatro diferentes espécies de plantas modeladas pelo sistema em três níveis de detalhes. 54

3.9 Representação simples de um campo de forças uniforme. . . . . . . . . . . . . . . 55

3.10 Esquema do campo de forças e seu algoritmo de nível de detalhes. . . . . . . . . . . 60

3.11 Simulação da força elástica de animação. . . . . . . . . . . . . . . . 64

3.12 Resultado do algoritmo de animação: Animação de um campo de grama. . . . . . . . . 69

3.13 Resultado do algoritmo de animação: Animação de um campo de flores. . . . . . . . . 70

3.14 Figura que ilustra a distribuição de plantas de acordo com a quantidade de nutrientes e a irrigação do terreno. . . . . . . . . . . . . . . . . . 72

3.15 Modelo do vento - utilização de partículas. . . . . . . . . . . . . . . 73

3.16 Tipos de fluxo definidos. . . . . . . . . . . . . . . . . 75

3.17 Simulação dos fluxos sobre o campo de forças . . . . . . . . . . . . . 77

3.18 Ação do vento sobre a vegetação. . . . . . . . . . . . . . . . . . 80

4.1 Grafo da cena de uma aplicação em Java 3D. . . . . . . . . . . . . . . . . 85

4.2 Cenas geradas para os testes. . . . . . . . . . . . . . . . . . 90

5.1 Mini-ecossistema animado em tempo real, pela ação do vento. . . . . . . . . . . . . 97

5.2 Continuação da animação... . . . . . . . . . . . . . . . . 98

A.1 Diagrama UML do pacote ecosys . terrain. . . . . . . . . . . . . . . 102

A.2 Diagrama UML do pacote ecosys. interation. . . . . . . . . . . . . . 103

A.3 Diagrama UML do pacote ecosys.plants. . . . . . . . . . . . . . . . . 104

A.4 Diagrama UML do pacote ecosys plants. leaf. . . . . . . . . . . . . 106

A.5 Diagrama UML do pacote ecosys . plants.branch. . . . . . . . . . . . . 107

A.6 Diagrama UML do pacote ecosys . plants.animation. . . . . . . . . . . 108

A.7 Diagrama UML do pacote ecosys.plant. distribution. . . . . . . . . . . 109

A.8 Diagrama UML do pacote ecosys.plant. underbrush. . . . . . . . . . 110

A.9 Diagrama UML do pacote ecosys. plant . bush. . . . . . . . . . . . 111

A.10 Diagrama UML do pacote ecosys . naturalphenomena . wind . . . . . . . . 113

A.11 Diagrama UML do pacote ecosys . visualization. . . . . . . . . . . . . . . 114 
A.12 Diagrama UML do pacote ecosys. ui parser. . . . . . . . . . . . . . . 115

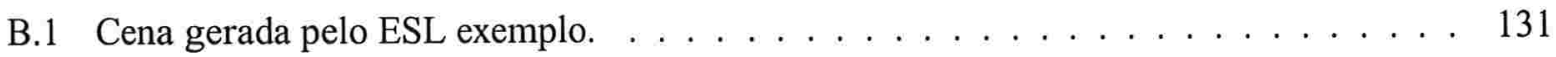




\section{Lista de Tabelas}

3.1 Tabela de complexidade dos modelos de uma flor em diferentes níveis de de-

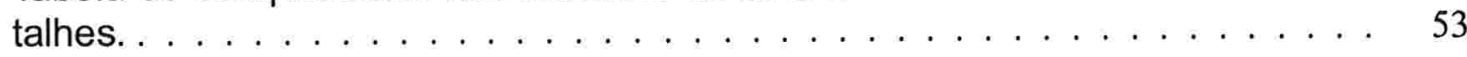

4.1 Dados da complexidade das plantas utilizadas para os testes de desempenho. 88

4.2 Tabela de informação dos níveis de detalhes utilizados nos testes. . . . . . . . 89

4.3 Tabela que descreve as cenas utilizadas para os testes. . . . . . . . . . . 89

4.4 Tabela de análise de desempenho $x$ complexidade geométrica da cena. . . . . 90

4.5 Tabela de análise de desempenho $\times$ modelos geométricos. . . . . . . . . . . . 91

4.6 Tabela de medida do desempenho do campo de forças. . . . . . . . . . . . . 92

4.7 Tabela de análise de desempenho do algoritmo de animação baseado em controles dinâmicos. . . . . . . . . . . . . . . . . . 93

4.8 Tabela de análise de desempenho dado o algoritmo de nível de detalhes de modelagem. . . . . . . . . . . . . . . . . . . . 94 


\section{Capítulo 1}

\section{Introdução}

\subsection{Introdução e motivação}

No decorrer dos últimos anos, a evolução da Computação Gráfica pôde ser acompanhada analisando-se alguns resultados apresentados em diversas aplicações como filmes, jogos eletrônicos, programas de realidade virtual e simuladores diversos. Os avanços obtidos nesta área foram tantos que, atualmente, podemos encontrar cenas geradas com auxílio do computador, onde nem mesmo especialistas podem perceber a sua utilização.

Entretanto, ao se fazer um estudo da evolução da Computação Gráfica podemos verificar que os primeiros modelos tridimensionais eram bastante rudimentares, gerando imagens pouco realistas. Para resolver este problema, foram desenvolvidas diversas técnicas de renderização ${ }^{~}$ que aliadas ao desenvolvimento de novos "hardwares", capazes de processar uma quantidade maior de informação em um menor tempo, possibilitaram a geração de cenas mais realistas.

No início da década de 90, já era bastante comum a utilização da Computação Gráfica como recurso para criação de objetos tridimensionais virtuais em diversos filmes, com resultados realistas. Porém, a utilização desses recursos ainda era baixa, os poucos objetos tridimensionais utilizados eram geralmente incluídos em uma cena real.

Foram surgindo, então, alguns filmes, séries de TV e jogos onde a produção era inteiramente baseada

${ }^{1}$ Utilizaremos neste texto o termo "renderizar" com o significado de sintetizar a imagem descrita por modelo computacional. Apesar de cometermos este anglicismo, acreditamos que esta seja a forma mais clara e completa de se expressar o significado do termo inglês "render". 
em Computação Gráfica. Os resultados obtidos, em geral, exibiam cenas estáticas e com um número reduzido de objetos. Além disso, o cenário modelado era geralmente futurista com ambientes fechados e metálicos. Quando se encontrava modelagem de cenas naturais, o que geralmente se via eram terrenos montanhosos ou desérticos, isto dado à dificuldade para a criação de cenas naturais realistas no computador.

Após o início do estudo da renderização de fenômenos naturais, o realismo na modelagem de tais fenômenos foi aumentando, como pode ser observado em filmes mais recentes. Porém, esta afirmação ainda não é válida, em geral, para aplicações em tempo real. Fato devido, principalmente, à utilização de técnicas extremamente caras computacionalmente para geração de cenas realistas. O problema é ainda mais evidente em casos de animação de uma grande quantidade de objetos. O custo computacional para uma animação realista torna difícil sua execução em tempo real, mesmo utilizando-se computadores capazes de processar milhões de polígonos por segundo.

Analisando estes fatos, observamos que o próximo passo na evolução deste ramo da Computação Gráfica é a renderização e simulação de cenas complexas em tempo real.

Com o objetivo de gerar uma pequena contribuição para o atual estágio de evolução desse tópico, será desenvolvido um trabalho focado à modelagem e animação eficiente de cenas contendo uma grande variedade de espécies vegetais. O objetivo deste trabalho é a criação de um sistema capaz de simular mini-ecossistemas vegetais de forma realista e em tempo real. Esse tema envolve três tópicos principais e bastante complexos: a simulação de fenômenos naturais, animação realista e geração de resultados em tempo real. A proposta de realismo e rapidez na animação aumenta a complexidade do sistema, visto que são conceitos antagônicos.

A escolha da simulação de vegetação como tema da dissertação foi devida ao fato deste possuir uma grande diversidade de aplicações práticas para sua utilização, além de representar bem o problema exposto por definir cenas complexas. É de grande interesse que o projeto seja estendido posteriormente para tratar problemas mais específicos, como sugerimos nesta seção. Com este objetivo o sistema foi arquitetado de modo que seja facilmente expandido.

O trabalho pode ser utilizado em diversas aplicações que requerem animação de plantas em tempo real. Jogos, simuladores e aplicações de realidade virtual podem ter cenas visualmente mais ricas e realistas utilizando o sistema. Outra possível aplicação para o trabalho seria o auxílio no estudo de Ecologia e Botânica. O sistema permitiria a simulação de mini-ecossistemas vegetais, além do estudo e da comparação de comportamentos simulados no computador com os reais observados na natureza.

Jogos são aplicações onde a animação em tempo real é indispensável. A utilização do sistema em jogos contribuiria muito com o aumento do realismo dos mesmos. Por exemplo, em jogos atuais, lutadores tridimensionais podem se mover de forma bastante semelhante a pessoas reais, porém a interação 
destes com a cena é mínima. Poderíamos construir uma cena com um campo de grama e arbustos que interferissem na luta. Em jogos de automobilismo, a vegetação ao redor da pista poderia se mover devido ao vento gerado quando os carros passam por elas. Estes são apenas alguns exemplos de como o sistema pode aumentar a interação e o realismo de jogos.

Aplicações de realidade virtual poderiam ser criadas utilizando cenas com vegetação. Estas aplicações são geralmente executadas em tempo real, para possibilitar a interação com o usuário. O sistema proporcionaria uma opção para incrementar a cena visualizada. No caso de realidade virtual estendida, poderíamos acrescentar vegetais virtuais em cenas reais em tempo real, permitindo inclusive que estes vegetais interagissem com as condições ambientais. Por exemplo, a planta virtual poderia ser animada considerando dados recebidos da medição de correntes de ar no local.

Ao se criar um sistema onde é possível definir plantas através de diversos parâmetros botânicos, este pode ser utilizado no estudo do desenvolvimento de um certo vegetal em diversos ambientes e em uma grande variedade de condições climáticas. Além disso, o sistema permitiria a simulação de miniecossistemas que podem representar um ecossistema real. Assim, o biólogo poderia fazer simulações de introdução de espécies de um ecossistema diferente em sistemas em equilíbrio, verificando as consequências desta ação para a vegetação nativa.

Ainda neste capítulo discutimos os problemas relacionados e a descrição formal do que o sistema se propõe a realizar.

\subsection{Problemas envolvidos}

Como foi citado na introdução, a proposta do trabalho envolve pelo menos três grandes áreas de pesquisa na Computação Gráfica: a simulação de fenômenos naturais, a animação realista de cenas complexas e o desenvolvimento de sistemas em tempo real. Para garantir que as soluções propostas satisfaçam da melhor forma possível todos esses objetivos, primeiramente foram estudadas soluções com um forte embasamento teórico para garantir o realismo necessário para simulação. Tais soluções são tipicamente muito caras computacionalmente e para obter o desempenho necessário para geração de resultados em tempo real, soluções mais eficientes foram desenvolvidas ou adaptadas.

Nesta seção discutimos alguns problemas que cada um destes tópicos apresentam. Veremos que muitos destes problemas afetam diretamente um dos objetivos do sistema, fato que será destacado. $\mathrm{O}$ capítulo 2 descreve muitas técnicas já desenvolvidas e que resolvem alguns problemas citados nesta seção. Porém, é importante levantar questões que envolvem os três tópicos para analisarmos se tal solução é apropriada para o problema proposto.

A Modelagem e Simulação de Fenômenos Naturais ("Natural Phenomena Simulation”) é um tema 
que vêm sendo estudado há muito tempo na área de Computação Gráfica. Muitas soluções foram apresentadas, inclusive para modelagem e animação de vegetação. Uma nova linha de pesquisa que vem atraindo interesse, é o desenvolvimento de soluções em tempo real para geração de cenas com vegetação semelhante a paisagens naturais. No entanto, muitas plantas tem uma complexa estrutura de galhos, o que dificulta sua renderização em tempo real. Mesmo no caso de plantas de modelagem simples, como gramíneas ou ervas, o número de elementos que podem compor uma cena pode impactar no desempenho do sistema.

Além dos problemas citados acima, a modelagem de vegetação é complexa por envolver estudos relacionados à Biologia, mais particularmente, à área de Ecologia. Conceitos como ciclo de nutrientes, equilíbrio de populações, entre outros, tem grande importância na distribuição e no comportamento das espécies vegetais modeladas. Um estudo aprofundado de conceitos de Ecologia é importante a fim de gerar um modelo computacional próximo ao real, além de possibilitar que o sistema seja utilizado como um simulador para estudos relacionados a esta área.

No próximo capítulo serão descritos trabalhos relacionados à Simulação de fenômenos naturais. Podemos então analisar porque algumas técnicas já desenvolvidas, que geram imagens realistas, não são apropriadas para aplicações em tempo real.

Técnicas baseadas em Física ("Physically Based Graphics") são conhecidas por gerar as animações e modelagens mais próximas às reais dentre todas técnicas utilizadas na Computação Gráfica. As soluções que utilizam estas técnicas implementam modelos físicos, o que proporciona o realismo obtido. Porém, estas técnicas também não são apropriadas para animação em tempo real, pois dependem de cálculos de complexas equações diferenciais e modelos físicos.

Com o intuito de se utilizar técnicas realistas em aplicações em tempo real, podemos utilizar dois artifícios que podem gerar boas aproximações de um modelo real. Um deles é permitir uma simplificação no modelo, de modo que a modelagem e os resultados obtidos não sejam comprometidos. Porém, simplificar um modelo físico sem que haja grandes perdas nas informações que o mesmo descreve não é uma tarefa simples.

O outro artifício que pode ser utilizado são pré-computações dos modelos reais. Nesta aproximação, alguns valores relativos ao modelo são calculados antes do início da animação, sendo futuramente utilizados na sua geração. Entretanto, modelos restritos a valores pré-calculados podem gerar uma animação repetitiva ou brusca, caso poucos valores tenham sido armazenados. Porém, também não podemos guardar uma grande quantidade de informações para evitar a utilização da memória do sistema, que será necessária para renderização da cena.

Diversas técnicas baseadas em Física vêm sendo desenvolvidas desde a introdução destas, em meados da década de 80. Algumas destas técnicas serão apresentadas na seção 2.3. 
Técnicas em tempo real para animação de cenas complexas são baseadas, de modo geral, em aproximações de modelos mais complexos. Estas técnicas tendem a iludir o observador utilizando uma aproximação bem mais simples do que o modelo original. Dentre as técnicas de aproximação de modelos, as técnicas baseadas em imagem ("Image Based Rendering") estão entre as mais utilizadas para esta finalidade. Estas técnicas aproximam modelos tridimensionais por modelos bidimensionais e texturas.

Técnicas baseadas em Níveis de detalhes ("Level of Details") também são bastante utilizadas a fim de obter modelagem e animação em tempo real. Nestas técnicas, diferentes tipos de modelos ou representações são utilizados para descrever o mesmo objeto. A técnica que é utilizada para modelagem do objeto depende da distância deste para o observador. Caso o objeto esteja próximo ao observador uma técnica mais exata e realista é utilizada, caso contrário, uma técnica menos realista, porém mais eficiente, é utilizada.

Sabemos que o realismo e a precisão das imagens geradas depende muito da eficiência do algoritmo, é nisso que a técnica de nível de detalhes está baseada. Um dos desafios do trabalho é determinar o grau de realismo que pode ser obtido em um sistema em tempo real

Considerando que uma cena gerada neste sistema pode ter um grande número de vegetais das mais diversas formas e aparências, temos que implementar uma solução cuja modelagem seja a mais realista possível e, além disso, gere uma quantidade de quadros suficiente para que a animação seja suave. Temos ainda que criar simplificações nos modelos complexos de forma que elas não comprometam o realismo da modelagem e das animações.

A seguir listamos alguns itens a serem considerados na implementação do sistema, a fim de que estes problemas sejam levantados durante o estudo da teoria relacionada. Isto facilitará a análise das soluções, descritas no capítulo 3.

- Definição da estrutura de dados mais adequada para modelar a vegetação.

- Propor a modelagem das plantas de forma realista e eficiente.

- Implementação da aproximação para animação de plantas em tempo real.

- Definição de atributos que definem a distribuição das plantas e composição da cena.

- Estudo das vantagens e desvantagens de se utilizar níveis de detalhes para modelagem ou animação.

- Utilização de alguma técnica de modelagem ou animação baseada em Física. Considerando o impacto no desempenho do sistema em caso de utilização. 
- Simplificação máxima de cada componente do sistema, para não impactar no desempenho do sistema.

\subsection{Objetivo do trabalho}

Identificados o problema e os assuntos relacionados a este, nosso objetivo é analisar as possíveis soluções e desenvolver aproximações capazes de resolver da melhor forma possível os problemas, sem comprometer outras partes do sistema. Nesta seção, descrevemos os objetivos deste trabalho e como este poderá ser utilizado em aplicações que requerem simulação de plantas em tempo real.

O objetivo principal do trabalho é a criação de um arcabouço capaz de criar cenas que simulem, de forma realista, mini-ecossistemas vegetais em tempo real.

Este arcabouço deve disponibilizar métodos para modelagem de diferentes tipos de vegetação e, além disso, permitir que sejam adicionados facilmente outros modelos de plantas mais específicos posteriormente. Desta forma, o trabalho pode ser adaptado a muitas aplicações específicas futuramente. Para isto, o arcabouço deve disponibilizar classes, métodos e interfaces que sejam de fácil adaptação às necessidades de cada aplicação, de modo que, se uma determinada aplicação necessitar de mais detalhes, estes possam ser implementados de acordo com a necessidade da mesma, aproveitando outras funções disponibilizadas pelo sistema.

Os módulos do sistema devem ser independentes, porém interligados, o que permite a alteração ou substituição de algumas técnicas sem comprometer as outras partes do sistema. Assim, podemos comparar o desempenho de diferentes técnicas implementadas e integradas ao sistema.

Para criação de um arcabouço reutilizável por outras aplicações, com uma modelagem moderna e confiável, utilizaremos o paradigma de Orientação a Objetos. A programação orientada a objetos permite a utilização de diversos conceitos como abstração, encapsulamento, herança, agregação, associação, generalização, entre outros, que podem ser muito úteis na criação de uma boa arquitetura para o sistema.

Considere, por exemplo, que definimos folha como um componente do sistema. As plantas são compostas por folhas (agregam folhas) e estas também devem ser animadas em tempo real. Seria muito interessante implementar uma abstração de folha que definisse todas as regras necessárias para que o sistema disponibilizasse dados para que esta seja animada em tempo real. As folhas que seriam implementadas, herdariam desta abstração os dados que o sistema gera. Este é um exemplo do nível de organização que o arcabouço deve ter. 
O arcabouço deve ser parametrizado, ou seja, receber do usuário diversas informações necessárias para criação e simulação de cada objeto do sistema. A cena final gerada deve refletir o que os parâmetros definirem. O sistema deve se certificar que as informações sejam passadas de forma simples e exata. Os parâmetros são muito importantes para descrição da cena, voltando ao exemplo da folha, ela poderia receber como parâmetros informações como: formato, cor, textura, massa, entre outros, para uma modelagem realista.

Parâmetros que representam informações relevantes sobre clima e propriedades do ambiente e do solo devem ser considerados para que possamos simular ecossistemas reais. Estes parâmetros serão tão importantes para a modelagem dos objetos quanto para distribuição das plantas sobre o terreno modelado.

Deve ser implementado um sistema genérico de interação com objetos do sistema, que pode ser utilizado por vários mecanismos de geração de interação. Este sistema implementa e encapsula toda interação com as plantas, ou seja, elementos externos só interagem com as plantas através deste componente. Uma modelagem do vento será implementada para servir de agente de interação com o sistema.

Além da animação das plantas, o usuário também poderá se mover livremente sobre a cena utilizando o teclado do computador. O sistema deve se certificar que a animação e as interações continuem sendo executadas em tempo real, mesmo neste caso, em que há mudança da posição da câmera.

Exemplos de mini-ecossistemas devem ser gerados para comprovar o funcionamento do sistema. Os exemplos devem deixar explícito que o sistema pode ser facilmente adaptado a outros ecossistemas não modelados. Uma análise de desempenho é feita ao final do projeto, onde se avalia o realismo e quantidade de objetos que podem ser representados com animação realista em tempo real.

No capítulo 2, discutimos soluções relacionadas e os resultados obtidos pelas mesmas, para cada tópico relacionado ao trabalho. O capítulo 3 descreve a solução proposta neste trabalho. São apresentadas as idéias e as teorias nas quais a solução foi baseada, além das aproximações necessárias para obtenção de resultados em tempo real. O arcabouço implementado para simulação de vegetação é discutido no capítulo 4, a arquitetura do sistema e informações úteis para utilizá-lo e expandi-lo são listadas. O capítulo 5 apresenta a conclusão dos estudos e do trabalho desenvolvido, onde os resultados obtidos são por fim analisados e discutidos. 


\section{Capítulo 2}

\section{Fundamentos Teóricos}

\subsection{Tópicos relacionados ao trabalho}

Neste capítulo serão discutidos quatro tópicos fundamentais para este trabalho: modelagem, técnicas baseadas em Física, simulação de fenômenos naturais e níveis de detalhes. Além desses quatro tópicos, a seção 2.6 descreve outros trabalhos que propõem técnicas para Animação de plantas em tempo real.

O tópico Modelagem foi subdividido em dois assuntos: a modelagem de sólidos e o estudo de técnicas avançadas de modelagem. Na seção 2.2.1 são descritas algumas técnicas básicas de modelagem de objetos com forma bem definida. Na seção 2.2.2 são descritos modelos procedurais mais avançados, que podem ser utilizados para uma modelagem mais realista. Estas técnicas permitem a modelagem de objetos que não podem ser representados por técnicas básicas de modelagem de sólidos por terem forma não definida. Muitos fenômenos naturais podem ser modelados utilizando as técnicas descritas neste tópico. A definição da técnica de modelagem mais adequada ao nosso problema tem grande impacto no desempenho do sistema.

A descrição das Técnicas baseadas em Física poderia ser incluída na seção 2.2, já que também representam técnicas de modelagem. Porém, como sua importância no trabalho é destacada, a discussão deste tema foi separada em uma seção própria. Por se tratar de um tópico onde muitas técnicas já foram desenvolvidas, descrevemos apenas alguns conceitos gerais básicos. Apenas técnicas diretamente relacionadas a este trabalho serão detalhadas.

A seção 2.4 destaca trabalhos focados à Simulação de fenômenos naturais, em especial os relacionados a plantas. Este tópico, descreve inúmeras técnicas diferentes para modelagem e animação de 
fenômenos naturais. Será dada ênfase na discussão sobre as vantagens e desvantagens de cada técnica apresentada, além da adequação das mesmas para proposta do sistema.

Artigos que utilizam representação por diferentes Niveis de detalhes serão apresentados na seção 2.5. Muitas das técnicas apresentadas nas seções anteriores podem ser utilizadas como um dos níveis definidos em uma aplicação.

\subsection{Modelagem}

\subsubsection{Modelagem de sólidos}

A modelagem trata do problema da criação, manipulação da geometria e topologia dos objetos gráficos no computador [GV98]. Diversas técnicas foram desenvolvidas nesta área, pois trata-se de uma das áreas precursoras na Computação Gráfica. O início da pesquisa, para o desenvolvimento do nosso trabalho, envolveu o estudo de técnicas de modelagem, a fim de se definir qual a mais apropriada para modelagem de plantas, que possa ser animada em tempo real.

Para podermos estudar técnicas avançadas de modelagem é importante ter o conhecimento de técnicas básicas de modelagem de sólidos. Estas técnicas já haviam sido estudadas na implementação de meu projeto de Iniciação Científica, Sistemas Gráficos 3D com Antialiasing ${ }^{1}$, realizado no IME-USP sob orientação do professor Antonio Elias Fabris, com duração de dois anos.

A modelagem de sólidos é uma forma de se representar um objeto tridimensional com certas propriedades desejadas. Requicha [Req80] assume a seguinte lista de propriedades desejáveis para representação de um sólido: O domínio da representação deve ser amplo o suficiente para permitir uma representação de um conjunto útil de objetos físicos. A representação não deve ser ambígua (representação completa), isto é, devemos saber exatamente o que está sendo representado, ou ainda, uma dada representação deve corresponder a um e apenas um sólido. Uma representação é única se o sólido pode ser gerado apenas de uma maneira. Uma representação precisa permite que o objeto seja representado sem aproximações.

A modelagem de sólidos atende muito bem ao problema de modelagem de objetos com uma forma bem definida. Em geral objetos manufaturados são bem modelados através destas técnicas. Objetos que não possuem uma geometria bem definida, como os relacionados a fenômenos naturais tais como nuvens, fogo, chuva etc., não podem ser bem modelados usando tais técnicas.

As técnicas de modelagem de sólidos são, em sua maior parte, antigas, divulgadas nas décadas de 70 e 80 , no entanto, continuam sendo bastante utilizadas em problemas de modelagem atuais. Daremos

\footnotetext{
${ }^{1}$ http://www.ime.usp.br/ lye/sg3d/
} 
uma breve descrição de algumas técnicas de modelagem de sólidos e suas principais características.

\section{Representação por varredura}

Nesta técnica, o objeto (curva, superfície ou volume) é definido pela trajetória do movimento de um objeto geométrico (como um ponto, curva, superfície ou volume) no espaço 3D. O movimento desta trajetória pode ser tanto uma translação ou uma rotação, ou ambas.

Os objetos são particularmente difíceis de se modelar de forma eficiente nesta técnica, pois dependem muito da equação da trajetória. Além disso, o problema de auto-intersecção da trajetória implica em ambiguidade de representação. Operações booleanas sobre objetos gerados nesta representação não geram um único objeto em representação por varredura, como acontece com a representação CSG, descrita na próxima subseção.

Os objetos gerados não são necessariamente tridimensionais, um objeto $2 \mathrm{D}$ movendo-se sobre o plano que o contém gera uma forma 2D. Isto é muito utilizado em técnicas de "stroking" (aumentar o tamanho do pincel utilizado para se desenhar uma curva).

\section{Representação CSG}

Este método de modelagem define sólidos complexos a partir da composição de sólidos simples (Primitivas) e operações booleanas definidas. No CSG ("Constructive Solid Geometry"), os objetos estão ordenados em uma árvore binária, onde as folhas são as primitivas, e os nós o resultado de uma operação booleana dos filhos. A raiz representa o objeto final obtido.

É uma técnica bastante simples de ser utilizada e implementada, porém o número de objetos que podem ser representados por esta técnica é bastante restrito. As primitivas mais comuns neste sistema são: cilindro, esfera, cone, toro e poliedros; e as operações booleanas mais utilizadas são: união, diferença e interseç̧ão.

Este método é a generalização da técnica de decomposição por células ("Cell Decomposition"), onde um sólido pode ser representado como soma ou união de um conjunto de células. Um caso mais específico desta técnica é a "Spatial-Occupancy Enumeration" onde o sólido é decomposto em células idênticas e arranjadas em um grid regular fixado. Esta técnica é bastante usada em aplicações biomédicas onde os dados são obtidos de tomografia computadorizada. A célula, neste caso, é denominada de voxel, em analogia ao pixel. O tipo de célula mais comum neste caso é o cubo. 


\section{Representação pelas bordas}

Na técnica conhecida por "B-Rep" ("Boundary Representation"), os objetos são descritos através da superfície de suas bordas. A borda de um sólido separa pontos interiores dos pontos exteriores deste, determinando a aparência do objeto, com propriedades como forma, cor e textura.

Para se determinar a borda, são necessárias informações sobre os vértices, arestas e faces da superficie de fronteira. Requicha [Req80] sugere as seguintes condições mínimas sejam satisfeitas na representação por bordas:

- Número de faces finito

- A união de todas as faces de um objeto define sua borda

- Uma face deve ter área finita e ser homogênea

A borda de um objeto pode ser segmentada em faces, arestas e vértices de formas ilimitadas, não há uma representação única da borda. Por exemplo, um cubo pode ser representado por seis quadrados, vinte e quatro quadrados, ou até em faces triangularizadas. É necessária uma estrutura com informações suficientes para que não haja confusão na representação do objeto.

Se representarmos cada face como uma lista de vértices, estaremos duplicando informações em locais onde duas faces compartilham uma aresta. Utilizando uma representação chamada Winged-Edge evitamos algumas duplicações de coordenadas compartilhadas por duas faces. Nesta estrutura de dados cada aresta A1 é representada com ponteiros para seus dois vértices (V1 e V2), para suas duas faces (F1 e F2) e para as outras quatro arestas que saem dos vértices (A2, A3, A4 e A5). As duas arestas que estão em sentido horário com relação a $\mathrm{A} 1$ (considerando a orientação $V 1 \rightarrow V 2$ ) pertencem a face $\mathrm{F} 1 \mathrm{e}$ as duas arestas em sentido anti-horário pertencem a F2.

Podemos representar praticamente qualquer objeto utilizando esta técnica. Porém, não se trata de uma representação exata, mas sim de uma aproximação do objeto. Quanto maior o número de polígonos utilizados nesta aproximação, mais próxima é a representação do objeto de sua aparência real. Porém, quanto maior o número de polígonos maior é também a utilização de memória e tempo de geração da imagem.

Utilizando-se algoritmos de "shading" (distribuição de cores sobre um polígono, para suavização das diferenças de cores entre polígonos adjacentes) obtemos imagens bastante realistas com poucos polígonos por objeto. Aliando esta técnica à grande capacidade de geração de polígonos por segundo das placas aceleradoras de vídeo atuais, a técnica pode ser utilizada para geração de objetos realistas de 
forma eficiente. Isto faz com que a B-Rep seja uma técnica bastante utilizada nos sistemas atuais. Um exemplo da modelagem utilizando B-Rep e "shading" pode ser visto na Figura 2.1.
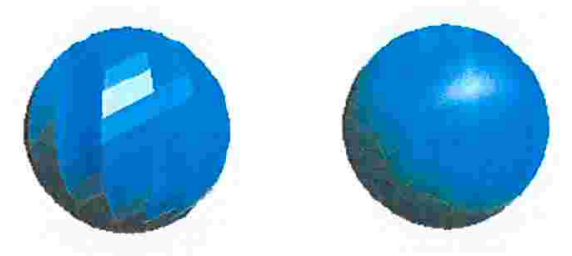

Figura 2.1: Exemplo uma esfera modelada utilizando apenas "B-Rep" (à esquerda) e "B-rep" + "shading" (à direita). A esfera é modelada utilizando poucos polígonos e resultado próximo a um modelo real. Fonte: [jav].

Observação: Como bibliografia complementar no estudo de técnicas de Modelagem de Sólidos foram consultados os livros de Foley et al. [FvDFH97], Watt [Wat93], Gomes e Velho [GV98] e Mantyla [Man88], além dos artigos de Green [Gre] e Requicha [Req80].

\subsubsection{Técnicas avançadas de modelagem}

As técnicas apresentadas na seção anterior funcionam perfeitamente em um mundo de objetos geométricos e de formas bem definidas. Porém, muitos fenômenos naturais não podem ser modelados de forma eficiente e satisfatória utilizando tais modelos geométricos.

Vamos descrever agora técnicas avançadas capazes de representar uma classe de objetos mais ampla, pois a maioria delas foi desenvolvida para modelos dinâmicos ao invés de modelos estáticos, o que possibilita a modelagem do crescimento e mudança da forma dos objetos. A geração de imagens em sequência, combinadas, produz naturalmente uma animação do objeto.

As técnicas avançadas de modelagem tentam ir além do que pode ser representado pela modelagem geométrica, permitindo a modelagem simples de fenômenos complexos. Desta forma, pode-se representar uma grande quantidade de objetos por um modelo simples, que por sua vez, pode ser ajustado facilmente e intuitivamente alterando-se alguns parâmetros. [FvDFH97]

Serão descritos nesta seção três modelos avançados de modelagem: splines, modelagem baseada em gramática e sistemas de partículas. Os modelos foram escolhidos por estarem mais relacionados, ou já terem sido utilizados, para modelagem de plantas. Em geral, a principal característica destes modelos, como já foi mencionado, é que mudanças simples na especificação e definição dos parâmetros podem resultar em mudanças drásticas na forma. Além disso, os modelos geralmente são procedurais, isto é, descrevem objetos que podem interagir com eventos externos ou com o ambiente para se auto 
modificarem. Uma descrição geral das técnicas avançadas de modelagem podem ser encontradas em [Ebe96] e [FvDFH97].

\section{Splines}

Splines são curvas paramétricas que são definidas através de pontos de controle, muito estudadas em cursos básicos de Computação Gráfica e Análise Numérica. Uma malha ("mesh") de curvas pode gerar uma superfície tridimensional.

Esta técnica é capaz de gerar resultados impressionantes, o objeto final é uma união de vários patches de splines, podendo ser renderizados utilizando métodos convencionais de renderização (ex: ray-tracing).

A modelagem do objeto deve ser feita alterando-se os pontos de controle que definem as curvas splines. Pode-se criar mais pontos de controle a partir dos já existentes para melhorar a modelagem do objeto.

Pode-se modelar praticamente qualquer forma definida com esta técnica de interpolação, porém, os pontos de controle devem ser definidos manualmente para geração da forma desejada. Outro problema é o tempo de geração da imagem, pois as curvas podem ser tão complexas quanto quisermos.

Esta técnica também é bastante utilizada para modelagem de plantas, trabalhos que enfatizam a modelagem realista de plantas utilizam Splines para renderizar as imagens. Podemos ver exemplos de plantas modeladas utilizando Splines em diversos trabalhos de Prusinkiewicz e Deussen [DHL*98, Pru93, PHHM96b, FPB92]. A quantidade de pontos de controle impactam no tempo de renderização, a alteração da quantidade de pontos que representam um objeto pode ser utilizado em técnicas de Níveis de detalhes que utilizem esta técnica de renderização. Para isto basta representar o objeto utilizando um número menor de pontos de controle para objetos distantes do observador. Um exemplo disto pode ser visto na Figura 2.2 do trabalho de Tankard [Tan01].

\section{Modelos baseados em gramática}

Os modelos baseados em gramática foram inicialmente criados para descrever a estrutura de certas plantas na década de 80 , baseados em uma técnica descrita por Lindenmayer em 1968. Tais modelos passaram a ser conhecidos como L-Systems, técnica muito utilizada para algoritmos de ramificação de plantas, como apresentamos em detalhes na seção 2.4.2.

A idéia básica dos modelos baseados em gramática é desenvolver linguagens, descritas por uma gramática, que consistem de uma coleção de regras de produção, que são aplicadas na construção de 


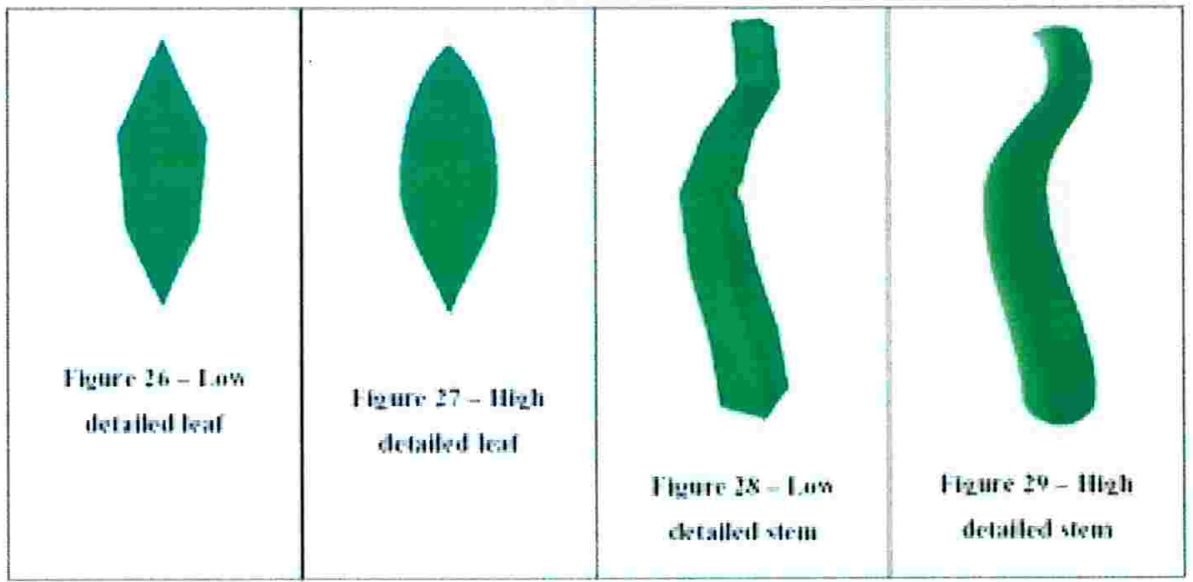

Figura 2.2: Comparação da modelagem de componentes de uma planta (folha e galho): à esquerda representação por polígonos, à direita os mesmos objetos modelados utilizando splines. Fonte [Tan01].

objeto.

Para melhor ilustrar a técnica vamos criar um exemplo. Seja uma gramática com o alfabeto A, B, [, ] e duas regras de produção:

regra 1: $A \rightarrow A A$

regra 2: $B \rightarrow A[B] A A[B]$

A cada passo do algoritmo estas regras são aplicadas para todos elementos da cadeia inicial. O exemplo abaixo ilustra a aplicação das regras dado um passo inicial somente com o elemento B.

iteração $0: B$

iteração 1: $A[B] A A[B]$

iteração 2: $A A[A[B] A A[B]] A A A A[A[B] A A[B]]$

Se considerarmos A como sendo um galho com direção vertical e B um galho de direção horizontal, verificamos que a partir do passo inicial B, obtemos um crescimento de uma árvore ou arbusto, se a cada iteração aplicamos as regras 1 e 2, na árvore anterior.

Embora o melhor exemplo de aplicação desta técnica seja o de modelagem de plantas, qualquer domínio onde os objetos sejam modelados exibindo regularidade, pode ser adaptado ao modelo baseado em gramática. Prusinkiewicz [PHM] utiliza este modelo para modelar formas de vegetais complexas, e conchas de caramujos. 


\section{Sistemas de partículas}

Técnica introduzida por Reeves, no artigo Particle Systems - A Technique for Modeling a Class of Fuzzy Objects [Ree83], o Sistema de partículas, descreve um método para se modelar objetos sem aspecto definido.

Trata-se de uma técnica bastante utilizada para se modelar objetos cujo comportamento não pode ser descrito em termos de sua superfície. A modelagem dos objetos é feita utilizando-se uma nuvem de partículas primitivas, que juntas definem o volume e aspecto de um objeto nebuloso. Essas partículas seguem uma certa regra: são geradas, mudam de característica ao longo do tempo e se extinguem. As partículas também podem se mover de acordo com alguma lei estocástica definida. Desta forma, o modelo é capaz de representar movimento, mudanças de forma e dinâmica dos objetos.

A dinâmica proporcionada pela técnica de sistemas de partículas, não era possível com métodos clássicos de modelagem, baseados em representação de superfícies. Este sistema é amplamente utilizado na modelagem de fogo, neblina, fogos de artifício, árvores, grama, explosões e fluidos em geral.

O modelo básico de um sistema de partículas pode ser descrito pelos passos:

- Geração da Partícula

- Definição dos atributos (velocidade, posição, cor, forma, etc.)

- Alteração na dinâmica (mudança de cor, direção do movimento, tamanho, etc.)

- Extinção

A cada quadro da sequência gerada em uma animação, devem ser seguidos os seguintes passos:

1. Geração de novas partículas pelo sistema.

2. Associação de parâmetros individuais a cada nova partícula recém gerada.

3. Extinção das partículas que completaram seu "tempo de vida".

4. Movimentação de transformação das partículas restantes de acordo com a dinâmica descrita nos seus atributos.

5. Renderização do novo estado do sistema de partículas. 
Para a animação das partículas, deve-se considerar variáveis como: tipo, idade, eixo espiral, cor, opacidade e tamanho. Outras informações podem ser: velocidade inicial, tempo de vida, aceleração, entre outros. Para maior realismo, as partículas podem ser dotadas de propriedades físicas.

Para se renderizar um modelo de partículas deve-se utilizar uma técnica não convencional. A utilização de técnicas como o ray-tracing seria bastante ineficiente, visto que cada raio traçado para renderização de um pixel poderia interceptar milhares de partículas. As partículas devem ser renderizadas apenas adicionando seu ponto de iluminação, ou segmento de reta caso esteja em movimento, na imagem final. Cada pixel acumula valores de cada partícula logo todas as partículas são responsáveis pela imagem final obtida. Observe que a renderização desta forma é bastante cara computacionalmente. É uma técnica poderosa, mas para cada nova aplicação uma nova técnica de renderização pode vir a ser necessária.

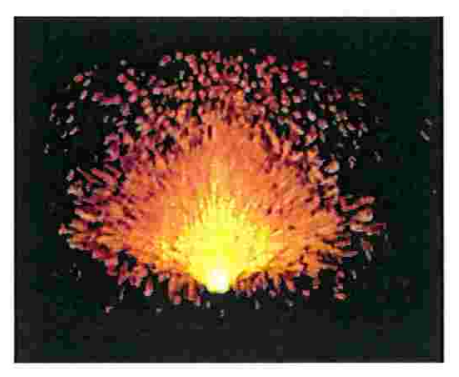

Figura 2.3: Fogo modelado utilizando sistemas de partículas. Fonte: [Ree83]

\subsection{Técnicas baseadas em Física}

Nesta seção são descritas técnicas que utilizam propriedades e definições da teoria da Física para determinar o aspecto, forma e movimento dos objetos. Os objetos gerados apresentam comportamentos descritos por leis da Física, o que proporciona maior realismo ao movimento do corpo. Porém, a matemática complexa descrita pelas fórmulas físicas faz com que, em geral, estas técnicas tenham um alto custo computacional.

Vamos analisar um exemplo simples, que descreve a animação de uma bola de plástico e utiliza técnicas com modelos baseados em Física, para ilustrarmos o poder e complexidades destas. Suponha que a bola seja lançada com uma certa velocidade inicial e por ação da força da gravidade vai caindo até tocar no chão. A detecção da colisão e a deformação do formato da bola devido ao contato, devem ser tratadas pelo sistema. Após o contato, a bola deve ter a capacidade de retomar seu formato original. Além disso, o sistema deve determinar como a trajetória da bola foi afetada devido ao contato, de modo 
que o movimento prossiga de forma natural. A animação segue até que a velocidade da bola seja zero e seu movimento termine.

Apesar de ser uma cena de descrição e entendimento bastante simples, a implementação desta requer estudos de teorias complexas, que serão descritas nesta subseção. Neste exemplo da bola não temos nenhuma utilidade prática (a não ser o estudo de movimento em Física), porém podemos usar esta técnica para fazer simulações realistas e úteis por utilizarmos conceitos da Física. Por exemplo, pode ser feita a simulação de uma colisão de um carro contra uma parede, ou com outro carro, e analisar o que acontece com os objetos dentro do carro; a técnica também pode ser aplicada no estudo de lançamentos de objetos, teste de resistência de materiais, animação realista de objetos flexíveis e elásticos, entre outros.

Estas técnicas geram, em geral, animações bastante realistas, porém com alto custo computacional, já que para gerarmos um movimento fisicamente correto é necessária a aplicação de inúmeras equações complexas. Além disso, esses sistemas requerem um dispositivo para resolução de equações diferenciais, para resolver as equações físicas. Além deste dispositivo ser de difícil implementação, ele também é pouco eficiente para podermos utilizá-lo, de forma satisfatória, em aplicações em tempo real onde a animação de muitos objetos é requerida.

Na próxima subseção, serão descritos alguns conceitos de Dinâmica de corpo rígido que mostram o poder desta técnica. Os conceitos foram retirados do curso da SIGGRAPH'97, Physically Based Modeling: Principles and Practice de Witkin e Baraff [WB]. Na subseção 2.3.2 será descrita a técnica de controles dinâmicos, que define regras de controle para animação e modelagem de objetos. Esta técnica tem grande importância na definição da animação do sistema que desenvolvemos. Nas subseções subsequentes serão discutidos conceitos como penetração de objetos, deteç̧ão de colisão e Dinâmica de corpos não rígidos (deformáveis), ilustrando ainda mais possibilidades de aplicação desta teoria.

\subsubsection{Dinâmica do corpo rígido}

A Dinâmica do corpo rígido relaciona-se a conceitos da Dinâmica de Newton aplicadas na modelagem de objetos. Os conceitos básicos abaixo, podem ser implementados e utilizados em um sistema com animação de objetos baseados em Física.

- Posição e orientação - A posição em que um certo corpo rígido se encontra em relação a cena, em um período de tempo $t$, é definida pela função $x(t)$. O objeto também pode ter uma orientação, definida por uma matriz $3 \times 3, R(t)$, de rotação, que indica para onde este tende a se mover.

- Velocidade linear e angular - Os objetos podem ter uma velocidade linear, descrita pela função $v(t)=\dot{x}(t)=\frac{d}{d t} x(t)$, e uma velocidade angular (função $w(t)$ ), em um certo período $t$. 
- Massa do corpo e centro de massa - Supondo que um corpo rígido seja composto por uma grande quantidade de pequenas partículas. Seja $m_{i}$ a massa e $r_{i}$ a localização da i-ésima partícula do corpo rígido, a massa total do corpo, $M$, é dada por: $\sum_{i=1}^{N} m_{i}$. O centro de massa do mesmo é definido pela fórmula $\frac{\Sigma m_{i} r_{i}(t)}{M}$.

- Força e torque - Seja $F_{i}(t)$ a força externa e $\tau_{i}(t)=\left(r_{i}(t)-x(t)\right) \cdot F_{i}(t)$ o torque externo agindo sobre a i-ésima partícula no período de tempo $t$. A força externa total agindo no corpo é definida por: $F(t)=\Sigma F_{i}(t)$, enquanto o torque externo total é definido similarmente por: $\tau(t)=\Sigma \tau_{i}(t)=$ $\Sigma\left(r_{i}(t)-x(t)\right) \cdot F_{i}(t)$. O torque é, intuitivamente, o eixo em que o corpo gira devido à força externa.

\subsubsection{Controles dinâmicos}

A técnica de "Dynamic Constraints", desenvolvida por Barzel e Barr [BB88] no artigo A Modeling System Based On Dynamic Constraints, é capaz de alterar a posição dos objetos para que estes satisfaçam as restrições ou controles ("constraints") definidos, utilizando para isso algumas forças auxiliares ("constraint forces").

$\mathrm{O}$ artigo discute o fato de modelagem baseada em Física ser uma técnica difícil de implementar, controlar e lenta, daí a necessidade das restrições para melhor controlar os objetos gerados. É feita uma descrição da mecânica Newtoniana utilizada e definição de corpos primitivos com parâmetros próprios, como raio, comprimento, etc.

As forças de controle podem ser definidas como forças internas que fixam pontos do objeto. Também é definido o conceito de Dinâmica Inversa, que define forças que determinam o comportamento de um certo objeto. Este problema consiste em se definir as forças que levam o objeto satisfazer a restrição e após isso, manter esta restrição satisfeita. Podemos ver um exemplo da utilização de controles na Figura 2.4.

Abaixo são descritos alguns exemplos de possíveis controles:

- Ponto de controle - Um ponto de controle é fixado em um local do objeto fazendo com que este fique preso neste ponto. (ex: Pêndulo)

- Ponto a ponto - Dois corpos têm movimentos livres, mas estão sempre juntos, ligados por um ponto.

- Ponto a caminho - Um ponto do objeto deve seguir um caminho especificado.

- Dinâmica inversa - Dados um corpo e um ponto de controle, a Dinâmica inversa consiste em: 

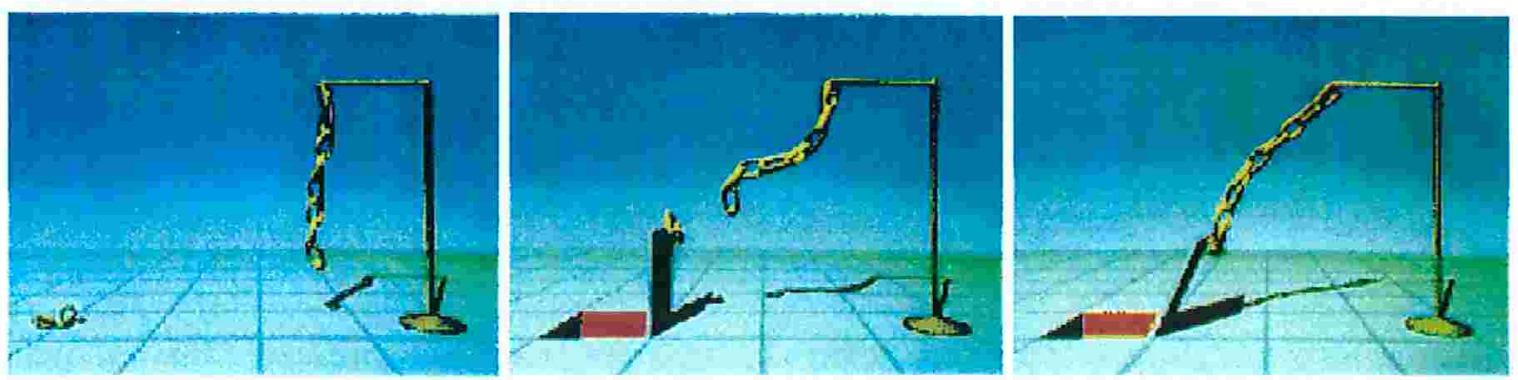

Figura 2.4: Uma força leva a corrente para a haste, para isto deve levantar um alçapão. A força de gravidade é considerada sobre todos os corpos na simulação. Fonte: [BB88].

1. determinar as forças que levam o corpo ao ponto de controle.

2. quando o corpo se encontra no local que o ponto de controle define, determinar as forças que mantém o controle satisfeito. Isto é, determinar as forças que vão se opor a outras forças que tentem mover o corpo do local que o ponto de controle determina.

Sistemas baseados em controle permitem ao usuário especificar uma coleção de controles ou restrições que as partes do modelo devem satisfazer. Nestes tipos de sistema a prioridade da restrição deve ser especificada, assim restrições mais importantes podem ser satisfeitas antes.

A especificação de controles é complexa, podendo ser dada por um conjunto de igualdades ou desigualdades matemáticas ou físicas. A especificação do controle pode ser do tipo "Energy Constraint", sistema onde as restrições são representadas por funções que são não negativas em todos os lugares exceto onde a restrição é satisfeita.

No artigo Energy Constraints on Parameterized Models de Witkin, Fleischer e Barr [WFB87] é dada uma definição para "Energy Constraints", que se comportam como forças que puxam e deformam partes do modelo para uma configuração desejada. Quando isto ocorre, as forças continuam agindo para que a mesma seja mantida. Os controles são utilizados como funções de energia, que se anulam quando a restrição é satisfeita. Alguns controles úteis são catalogados no artigo: anexação de um objeto a um ponto fixo, atração entre superfícies, cálculo de colisão sem calcular intersecções entre superfícies (a idéia é utilizar forças, em um campo de repulsão, como restrições), fixação de restrição em uma linha, entre outros.

\subsubsection{Controle para não penetração e detecção de colisão}

Em corpos rígidos não deve haver interpenetração de objetos. Para problemas que requerem este tipo de restrição devem ser considerados dois casos: 


\section{- Colisão com mudança de velocidade abrupta}

Como não há penetração em corpos rígidos, após a colisão, deve-se calcular a nova velocidade e as forças que vão descrever o movimento, que dependem diretamente das forças que evitam a interpenetração.

A detecção de colisão pode ser determinada utilizando-se o conceito de "bounding regions", que são volumes que envolvem o corpo e podem ser utilizados para representar a forma do corpo. A principal idéia envolvida é representar um objeto de forma complexa por um mais simples, de modo a facilitar a definição de sua posição ou volume que este ocupa.

O conceito pode ser utilizado com diversas formas. Dentre as mais conhecidas está a "bounding box", que define um cubo para representar um objeto, porém, podemos utilizar outras formas geométricas que forem convenientes em cada caso, como por exemplo um esfera.

A utilização de "bounding regions" para se aproximar a detecção de colisão de objetos de forma complexa, facilita e torna o processo mais eficiente. Por exemplo, se representarmos dois objetos por suas "bounding boxes", quando estas se sobrepõem temos a indicação de que ocorreu um contato. Algoritmos estudados em Geometria Computacional resolvem o problema de sobreposição de "bounding boxes" de forma eficiente.

- Corpos em repouso

Para o contato em repouso entre dois corpos rígidos, ou seja, o caso em que um corpo está sobre o outro e ambos não estão em movimento, devemos considerar três condições:

1. As forças normais de contato devem evitar a interpenetração.

2. As forças de contato devem ser repulsivas entre si.

3. A força no ponto de contato deve ser nula caso os corpos comecem a se separar.

Além disso, as forças de contato devem evitar que o objeto entre em movimento sem motivo, isto é sem aplicação de nenhuma força durante o repouso do objeto.

\subsubsection{Modelos elasticamente deformáveis}

A teoria de elasticidade descreve materiais deformáveis como borracha, tecidos, papel e metais flexíveis. Ao aplicarmos uma força em um objeto deformável, deve-se calcular se a força foi suficiente para provocar uma deformação na forma, caso isto ocorra deve-se determinar sua nova forma. Outras características podem ser consideradas, como por exemplo, se o objeto tiver a característica de 
restituição da forma antiga, ele deve voltar à forma anterior, quando a força que o levou a se deformar para agir. Os objetos devem responder de forma natural às forças aplicadas.

Em Elastically Deformable Models, Terzopoulos, Platt, Barr e Fleischer [TPBF87] aplicam a teoria da elasticidade para construir equações diferenciais que modelam o comportamento de superfícies e sólidos não rígidos. Modelos elasticamente deformáveis são ativos, pois respondem de forma natural a forças aplicadas e controles. Simulando propriedades físicas como tensão e rigidez, podemos modelar formas estáticas como objetos deformáveis. Incluindo massa e amortecimento simulamos a dinâmica nestes objetos.

A modelagem é feita utilizando-se Splines e Dinâmica. São descritas, também, algumas forças aplicadas para deformação dos modelos elásticos, como por exemplo, força gravitacional e colisão destes com objetos fixos e impenetráveis. A implementação da deformação é baseada em equações diferenciais descritas no artigo. Os resultados são exibidos no final do artigo, como podemos ver na figura 2.5.
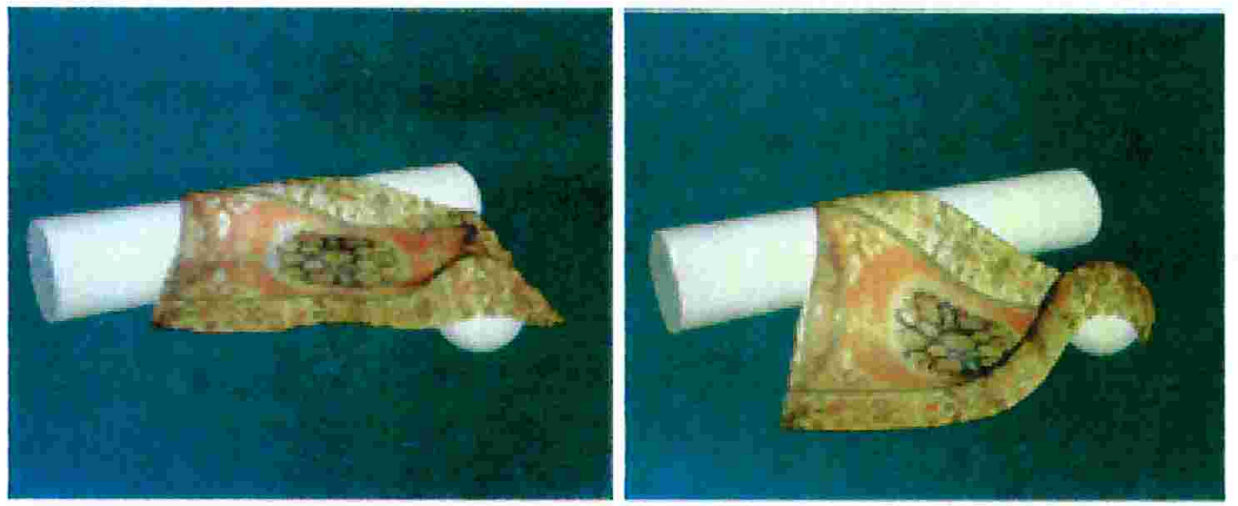

Figura 2.5: O tapete cai devido à ação do peso, sobre obstáculos fixos e sofre deformação. Fonte: [TPBF87]

No artigo Dynamic Deformation of Solid Primitives with Constraints [MT92], Metaxas e Terzopoulos utilizam os conceitos de controle e deformação. São descritas primitivas sólidas comuns como esfera, cilindro, cones, quádricas, que são deformadas globalmente ou localmente para geração de novas formas. Conceitos como elasticidade e flexibilidade são discutidos e algumas fórmulas Físicas definidas para deformação dos objetos. Após a deformação, a distribuição de massa no objeto deformado deve estar coerente. $\mathrm{O}$ artigo também discute um método baseado em controles para conectar as novas primitivas geradas para criação de modelos articulados.

Atualmente, com computadores de alto desempenho, pode-se obter a animação interativa de mo- 
delos deformáveis como podemos ver em [FGL03]. Em geral, o que se faz para obtenção de taxas interativas para animação em técnicas baseadas em Física, é evitar a utilização de equações diferenciais, substituindo-as por aproximações e controles de modo a se obter modelos plausíveis para gerar resultados em tempo real.

\subsection{Simulação de fenômenos naturais}

A modelagem e simulação de fenômenos naturais são geralmente tarefas árduas, visto que tais fenômenos, na maioria dos casos, não tem forma bem definida ou regular. Além disso, as cenas geradas costumam ser complexas e com um grande número de elementos, o que dificulta sua criação e animação em tempo real.

Nesta seção vamos concentrar o estudo em artigos relacionados à simulação de fenômenos naturais, detalhando técnicas que viabilizam a execução em tempo real deste tipo de aplicação. Abordamos com detalhes a modelagem de plantas com o objetivo de analisar algumas técnicas que podem ser utilizadas em nosso simulador de mini-ecossistemas vegetais. Diversas técnicas são descritas, destacando as vantagens e desvantagens de cada uma delas.

São descritas técnicas que produzem imagens bastante realistas como no artigo de Deussen et al. [DHL*98], porém que são muito caras computacionalmente. Por outro lado, também estudamos diversas técnicas que produzem imagens de forma eficiente, utilizando aproximações dos modelos reais, como na técnica de "Slicing" de Jakulin [Jak00]. Estas técnicas, porém, geralmente apresentam menor qualidade e realismo nas imagens geradas.

Além de descrever técnicas para modelagem de plantas, são estudadas técnicas para simulação de outros fenômenos naturais como, por exemplo, modelagem do vento e de ecossistemas. Para modelagem de plantas estudamos técnicas muito utilizadas para modelagem de vegetação rasteira e árvores, como L-System e Slicing. Também estudamos artigos relacionados à simulação de ecossistemas diversos, inclusive reais, para aprofundarmos nosso conhecimento deste assunto, bastante relacionado ao tema da tese.

\subsubsection{Modelagem de fenômenos naturais com sistemas de partículas}

O modelo de sistemas de partículas, descrito na seção 2.2.2, pode ser utilizado para modelagem de muitos fenômenos naturais, inclusive plantas. O próprio Reeves, no artigo Approximate and Probabilistic Algorithms for Shading and Rendering Structured Particle Systems [RB85], descreve como utilizar sua técnica para modelagem de plantas, mostrando que os sistemas de partículas podem ser utilizados inclusive para modelagem de objetos complexos e estruturados. 
Reeves detalha uma técnica de modelagem estocástica, "shading", sombreamento e texturas utilizada nos sistemas de partículas, para geração de árvores, grama e outros vegetais. As partículas utilizadas para modelar fenômenos naturais como árvores e grama não são independentes como no caso de fogo e água por exemplo. Para um campo de gramas cada folha é descrita pela trajetória de uma partícula.

As árvores são geradas a partir do tronco com um algoritmo de construção de galhos ("branching") recursivo. Os galhos gerados a cada passo da recursão herdam os parâmetros de seus pais, sendo feito um controle para que os "sub-galhos" sejam mais finos e próximos ao pai. O algoritmo termina quando os galhos gerados tem uma certa espessura determinada, folhas são adicionadas a galhos que não tem filhos.

Uma árvore gerada por esta técnica, tem cerca de um milhão de partículas, logo o tempo de construção de uma árvore é elevado. A modelagem de folhas de grama é gerada utilizando partículas com parâmetros como posição, orientação, área, densidade e tipo. As partículas e suas trajetórias geram cada folha de um tufo de grama. O artigo descreve técnicas para "shading" e determinação de superfícies visíveis para melhorar o desempenho do sistema e a aparência das cenas geradas. A modelagem do vento para a animação também é descrita, porém deixamos esta discussão para a seção 2.4.3. A Figura 2.6 mostra os resultados obtidos por Reeves.

O sistema de partículas permite a modelagem de muitos outros fenômenos naturais, tais como cachoeiras, fogo, chuva e neve utilizando esta técnica. Uma aplicação desta técnica para simulação de fenômenos naturais pode ser vista no artigo de Sims [Sim90], Particle Animation and Rendering Using Data Parallel Computation. Este artigo desenvolve um sistema de animação e renderização de sistemas de partículas em computadores paralelos. No sistema de partículas cada partícula é animada isoladamente, encorajando a implementação deste sistema em aplicações paralelas ou distribuídas.

A animação baseada em Física com a utilização de forças geram resultados complexos e realistas, porém torna o sistema ainda mais lento. Para animação são definidas operações de posição, velocidade e aceleração das partículas, Sims deixa claro que utiliza aproximações para se evitar as equações complexas da Física. Para renderização, Sims define a cabeça e o rabo da partícula, a posição cabeça é animada enquanto a posição rabo segue a cabeça com a função de "borrar" um rastro da partícula na imagem. O artigo mostra a animação de neve, vento, água e fogo utilizando os operadores descritos, onde pode-se ver a alteração dos atributos das partículas no decorrer do tempo, assim como alguns operadores definidos por Sims como amortecimento (neve ao tocar no chão) e saltos (água ao atingir um obstáculo). 

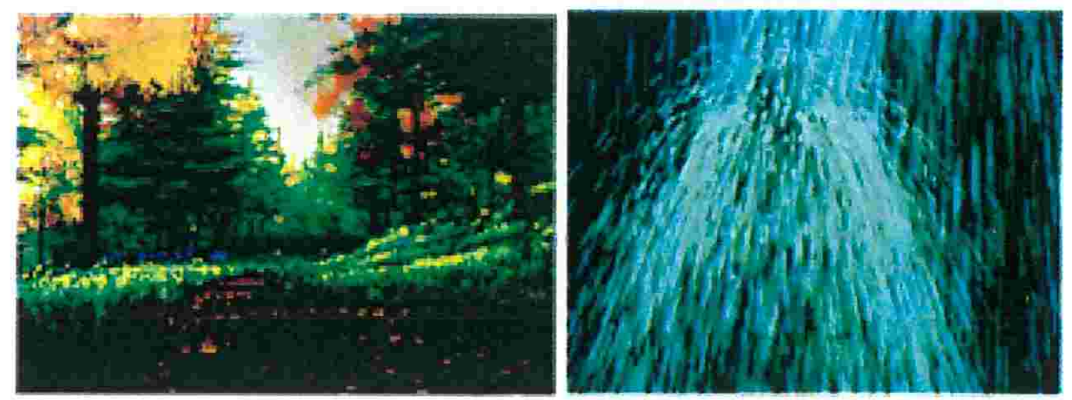

Figura 2.6: Modelagem de plantas e uma cachoeira utilizando sistemas de partículas. Fontes: [RB85] e [Sim90]

\subsubsection{Modelagem e animação de plantas}

\section{L-Systems}

Sistemas de Lindenmayer, os L-Systems, são mecanismos para escrita baseados em gramáticas ("string rewriting mechanisms"), originalmente desenvolvidos por Lindenmayer como uma teoria matemática para a descrição de desenvolvimento de plantas. Originalmente, os L-Systems modelavam o desenvolvimento de organismos multicelulares simples (como por exemplo algas), em termos de divisão, crescimento e morte de células individuais. Porém, sua utilização logo foi estendida a plantas maiores com estruturas de galhos complexas.

Prusinkiewicz et al., em L-SYSTEMS: FROM THE THEORY TO VISUAL MODELS OF PLANTS [PHHM96a], descreve detalhadamente a técnica, mostrando como esta se originou, foi desenvolvida e é utilizada. $\mathrm{O}$ artigo ainda discute aspectos relacionados ao ambiente que possam influir na modelagem de plantas, o que implica em uma discussão sobre tópicos básicos de Ecologia. São descritos padrões para geração e desenvolvimento de galhos e raízes de plantas de acordo com a concentração de nutrientes no vegetal. Além disso, é feita uma simulação de um ataque da planta por insetos, o que impede a transmissão dos nutrientes para galhos na parte superior a parte atacada, fazendo os galhos murcharem. O artigo também descreve o comportamento das plantas ao se efetuar podas em alguns galhos gerados, verificando como isto influi no crescimento e desenvolvimento do vegetal. O desenvolvimento de plantas utilizando esta técnica também pode ser encontrado mais recentemente em $A$ Global Signal Propagation Technique for the Modeling of Plants [VF03].

Os L-Systems demonstraram adequação para modelar objetos naturais, particularmente modelos botânicos e celulares. Esta técnica usa o princípio de "database amplification", que indica a possibilidade da geração de estruturas complexas a partir de conjunto de dados compactos. 
A idéia do desenvolvimento é reescrever o sistema que substitui paralelamente módulos pais, individualmente, por configurações dos filhos, como nas técnicas de modelagem baseadas em gramática já citadas. Todos os módulos devem pertencer a um alfabeto finito de tipos, e o comportamento dos módulos podem ser especificados utilizando-se um conjunto finito de regras ou produções. A figura 2.7 indica três exemplos de aplicações destas produções.

a)

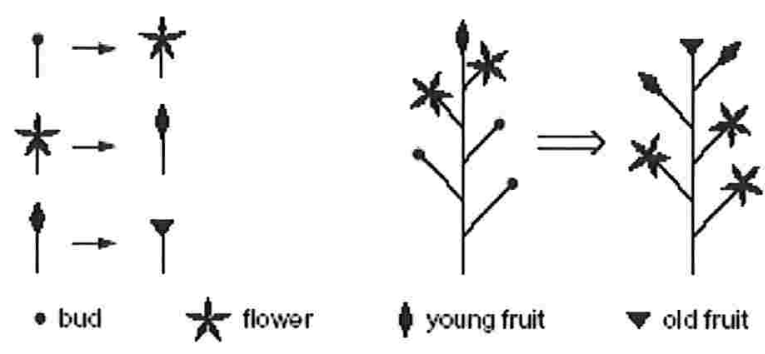

b)

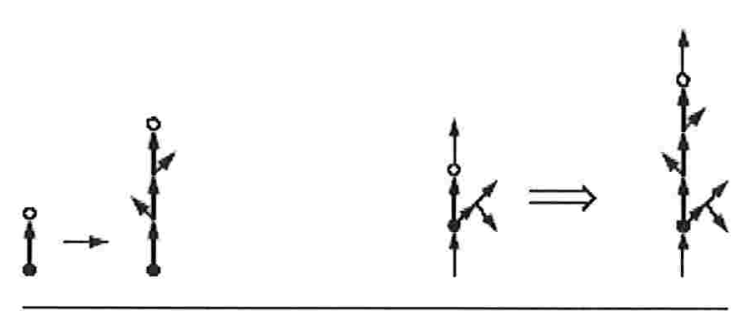

c)
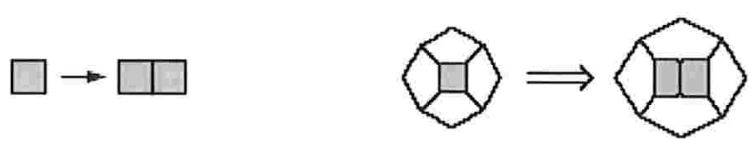

Figura 2.7: Exemplo de especificações e aplicações de produções de L-Systems. (a) o desenvolvimento de uma planta, com flores e frutos em diferentes fases, (b) a simulação da ramificação de um galho e (c) a divisão de uma célula. Fonte: [PHHM96a].

As produções podem ser aplicadas sequencialmente, um módulo por vez, ou em paralelo, com todos módulos sendo reescritos simultaneamente a cada passo da recursão. A escrita paralela é mais apropriada para modelagem de desenvolvimento de vegetais, pois o desenvolvimento ocorre simultaneamente em todas partes do organismo.

L-Systems paramétricos tem módulos indicados por letras associados a parâmetros. Essas letras pertencem a um alfabeto $V$, e os parâmetros pertencem ao conjunto dos números reais $\Re$. Vamos citar algumas notações utilizadas em L-Systems paramétricos, e que utilizamos nos exemplos citados.

Um módulo $A \in \Re$ com parâmetros $a_{1}, a_{2}, \ldots, a_{n}$ é denotado por $A\left(a_{1}, a_{2}, \ldots, a_{n}\right)$. Expressões podem ser criadas utilizando-se os parâmetros e números constantes combinados com os operadores 
aritméticos $+,-, *, /$; exponencial $\wedge$; relacionais $<,<=,>,>=,==$; logicos !, \&\&, \|, e parênteses (), além de outras funções matemáticas, como por exemplo logaritmo, seno, entre outras.

Os símbolos : e $\rightarrow$ são utilizados para separar os três componentes da produção: predecessor, condição e sucessor. Uma produção segue o seguinte formato:

predecessor:condição $\rightarrow$ sucessor.

Um L-system paramétrico é basicamente definido pelos elementos:

- V, o alfabeto do sistema.

- Um conjunto de parâmetros formais.

- Um axioma, $\omega$

- Um conjunto de produções.

Um exemplo de um L-System paramétrico é mostrado abaixo.

$\omega: B(2) A(4 ; 4)$

p1 : $A(x ; y): y<=3 \rightarrow A(x * 2 ; x+y)$

p2: $A(x ; y): y>3 \rightarrow B(x) A(x / y ; 0)$

p3 : $B(x): x<1 \rightarrow C$

$\mathrm{p} 4: B(x): x>=1 \rightarrow B(x-1)$

A figura 2.8 mostra a aplicação das regras de produção definidas acima. Assume-se que o módulo se substitui por si mesmo quando nenhuma produção definida satisfaz suas propriedades.

Para facilitar o entendimento podemos supor que este L-System descrito representa o crescimento de um certo vegetal. Partindo do axioma $\omega$ que contém parâmetros iniciais, por exemplo, umidade e iluminação, as regras de produção p1, p2, p3 e p4 são aplicadas para simular o desenvolvimento deste vegetal em tais condições definidas pelos parâmetros.

Podemos definir uma regra de produção com contextos, isto é, que só é aplicada quando aparece em um determinado contexto. A produção passa a ter o seguinte formato:

left-context $<$ predecessor $>$ right-context:condição $\rightarrow$ sucessor. 


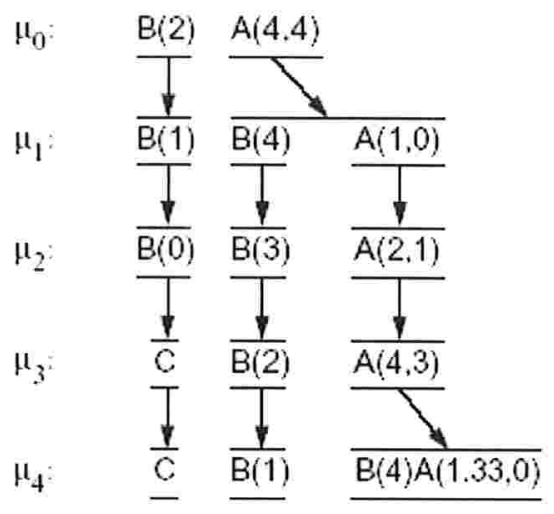

Figura 2.8: Aplicação das regras de produção. Fonte: [PHHM96a].

Uma regra de produção como por exemplo: $A(x)<B(y)>C(z): x+y+z>10 \rightarrow E(x+$ y) $F(y+z)$ só seria aplicada caso a regra em um certo passo de iteração seja, por exemplo, da forma ...A(5)B(4)C(3)...

Várias formas de interpretação das regras geradas pelo L-System foram criadas. A interpretação chamada "turtle interpretation" descreve uma série de símbolos para utilização e alteração da geometria do objeto criado. Alguns símbolos definidos na "turtle interpretation" são descritos abaixo.

@ $O(r)$ Desenha uma esfera de raio $r$ na posição atual.

$+(\theta)$ Rotaciona para esquerda por um ângulo $\theta$ ao redor do eixo vertical do objeto.

$\wedge(\theta)$ Incrementa em $\theta$ o ângulo com o eixo horizontal.

L-Systems estocásticos definem uma probabilidade para uma regra ser substituída por outra regra. A notação $A(x) \rightarrow^{0.5} A(x) B(x)$ indica que a produção tem $50 \%$ de chances de ser aplicada.

Timed L-Systems atribuem tempo de vida a cada módulo em uma regra de produção. A produção $(A(x), 5) \rightarrow(A(x), 0.5)(B(x), 0)$ indica que o módulo $A$ tem vida de 5 segundos. Quando $A$ atinge a idade de 5 segundos a regra de produção é aplicada. Um novo módulo $A$ é gerado com idade 0.5 segundos e um novo módulo $B$ é gerado com idade 0 segundos.

Um estudo sobre a evolução dos L-Systems é feito por McCormack em Interactive Evolution of LSystem Grammars for Computer Graphics Modeling [McC93]. Neste artigo é apresentada uma evolução da técnica, citando contribuições dadas por diversos pesquisadores, explicando brevemente L-Systems 
paramétricos, estocásticos e por tempo. O artigo aplica o princípio da evolução, proposta por Charles Darwin, nas gramáticas criadas utilizando-se L-Systems onde as regras podem sofrer mutação e passar pelo processo de seleção.

As regras e parâmetros fariam o papel de genótipo, que contém as informações genéticas de cada indivíduo. As mutações podem alterar regras, módulos, parâmetros e funções utilizadas nas regras. Uma probabilidade para mutação deve ser especificada. Podemos ter, por exemplo, mutações em que um módulo é removido, adicionado ou alterado por outro módulo em uma regra. Para mutações sobre parâmetros basta aplicar operadores aritméticos e funções matemáticas.

\section{Modelagem de vegetação rasteira}

Não há muitos trabalhos específicos sobre modelagem de vegetação rasteira. Perbet e Cani [PC01], em Animating Prairies in Real-Time, descrevem uma forma de se modelar e animar campos de grama em tempo real utilizando a técnica de Níveis de detalhes, que será descrita na próxima seção. Como além de tratar a animação de vegetação rasteira este artigo está bastante relacionado ao trabalho deixamos a discussão para a seção 2.6.

Encontramos muitos artigos que descrevem como modelar vegetação rasteira utilizando a técnica que estão desenvolvendo, este é o caso dos artigos de Reeves [RB85] e Deussen et al. [DHL*98]. Ambas as técnicas apresentam excelentes resultados, porém como o tempo de criação e alteração da cena é alto, não poderíamos utilizá-las para gerar animações em tempo real.

Um dos principais problemas de geração de imagens de vegetação rasteira é o número de instâncias que uma cena pode conter. Apesar de certos objetos, como folhas de grama, serem de simples modelagem e animação, o número de instâncias dos mesmos, que são geralmente necessárias nas cenas que os contém, tornam o sistema bastante caro computacionalmente, caso alguns cuidados não venham a ser tomados.

Por fim, o nosso trabalho, Real-time Animation of Underbrush [EMF03], apresenta uma técnica para animação rápida e realista de vegetação rasteira. Descrevemos a técnica desenvolvida no capítulo 3.

\subsubsection{Modelagem de outros fenômenos naturais}

A modelagem do vento pode ser utilizada para animação de vários outros fenômenos naturais, como geração de ondas em um lago, movimentação do fogo ou de vegetais.

$\mathrm{O}$ vento pode ser modelado definindo-se áreas de influência do vento como no artigo de Giacomo et al. [GCF01]. Nesta aproximação, todos os objetos dentro desta área de influência definida são afetados por uma força definida nesta área. A área pode ter o formato desejado pelo usuário. 
Em Animation Aerodynamics [WH91], Wejchert e Haumann criaram um método baseado em aerodinâmica para animação, simulação de controle do movimento de objetos sob ação do vento. Ao invés de criar um fluxo numericamente, os autores definem um conjunto de primitivas de fluxo, que descrevem campos de velocidade do fluido. Ao interceptar objetos, o fluxo aplica nas superfícies destes uma força para deslocamento dos mesmos.

As primitivas podem gerar diversos tipos básicos de fluxos:

- fluxos uniformes e unidirecionais;

- fluxos que dispersam ou atraem objetos a um ponto definido;

- fluxos em formato espiral.

A união de diferentes tipos de fluxos pode gerar fluxos complexos. Obstáculos podem ser modelados com primitivas fortes o suficiente para alterar a direção de um fluxo. Em muitos casos isto pode ser mais eficiente que determinar a detecção de colisão, além de permitir movimento natural e suave do fluxo.

A força aplicada no objeto dentro do fluxo é proporcional à área e a posição deste em relação ao fluxo. Ao se calcular os efeitos do vetor de velocidade na superfície do objeto, este vetor é separado em uma componente normal e outra tangencial, que representam a pressão e viscosidade do fluido, respectivamente. Como exemplo foi mostrada a animação de folhas de árvores soltas sendo carregadas pelo vento e colidindo com obstáculos fixos.

Stam e Fiume [SF93] modelaram campos de ventos utilizando processos estocásticos e turbulência baseada em Física, no artigo Turbulent wind fields for gaseous phenomena. Eles assumiram que um campo de vento era separado em dois componentes, um de alta escala, composto por campos de ventos simples, e outro de baixa escala, definido por um campo aleatório. Simulações do vento em tempo real foram apresentadas, assumindo-se que os dois componentes são independentes e não se afetam.

Chuva, neve e fumaça também são fenômenos naturais modelados em diversos trabalhos. Em geral, para estes fenômenos é utilizada a técnica de sistemas de partículas. Um exemplo da aplicação de partículas pode ser encontrado no trabalho de O' Brien e Hodgins [OH95], Dynamic simulation of splashing fluids. Neste artigo, gotas de água se espalham quando um objeto cai sobre a superfície do fluido. As propriedades físicas das partículas fazem com que a animação seja realista. Entretanto, a utilização de muitas partículas pode tornar a animação custosa.

Uma modelagem de neve utilizando outra forma de modelagem foi proposto por Nishita et $\mathrm{Al}$. [NIDN97], em $A$ modeling and rendering method for snow by using metaballs. A neve foi definida 
por campos de densidade, modelados utilizando a técnica de "metaballs". O modelo foi proposto para geração de imagens foto-realísticas, os flocos de gelo na neve são modelados utilizando prismas, que são utilizados para reflexão, criando uma renderização de cenas com objetos cobertos com neve bastante realistas.

Outra aproximação proposta, apresentada por Masselot and Chopard [MC95], no artigo Cellular automata modeling of snow transport by wind, é baseada em autômatos celulares, que são utilizados para o transporte de neve. O vento foi modelado como um fluido definido por um autômato celular composto por muitas partículas elementares seguindo as leis Físicas e de movimento de fluidos. A neve se move no mesmo reticulado das partículas de vento, seu movimento é definido pela gravidade e forças do vento. Algumas simulações realizadas levaram vários minutos ou horas para serem executadas.

\subsubsection{Simulação de ecossistemas}

Artigos relacionados à simulação de ecossistemas descrevem o comportamento de espécies animais ou vegetais em determinadas condições no ambiente em que vivem.

Muitos dos trabalhos estudados, apresentam um estudo de problemas de ecossistemas específicos, tais como: Insect Population Simulation [BFWS78], The Digital Simulation of River Plankton Population Dynamics [Cla75] e SIMPLE: A Simplified Ecosystem Model for Lake George, New York [Kil78]. Estes artigos tratam de assuntos como controle de população de insetos e plâncton em lagos. São realizados estudos que ajudam a fazer projeções da população destes seres no futuro, em função dos nutrientes, poluição ou inseticida que são encontrados nos ambientes que estes vivem.

O estudo de tais trabalhos, foi de grande importância para o entendimento de conceitos relacionados a ecossistemas, assim como para entender o foco de interesse deste tipo de pesquisa. Além disso, as discussões sobre alguns conceitos como ciclo de população e competição por nutrientes são extremamente valiosas para definição da distribuição da vegetação no nosso trabalho.

A modelagem de um ecossistema complexo requer um sistema bastante poderoso para simular a interação dos seres. Deve ser tratado também, o controle e a estabilização das populações de animais e vegetais, levando-se em conta, competição por espaço, alimento e outros recursos disponíveis. Além de Computação Gráfica este tipo de sistema pode até mesmo utilizar conceitos de inteligência artificial, como veremos no artigo de Terzopoulos ainda nesta seção.

Em Realistic Modeling and Rendering of Plant Ecosystems, Deussen et al. [DHL*98] descreve diversos problemas relacionados à renderização de cenas naturais com grande número de plantas. No texto são descritos algoritmos de geração de terrenos e especificação de populações de plantas.

A definição do terreno e da distribuição das plantas pode ser feita por especificação explícita, onde 
o usuário intervém na descrição da cena, ou por geração procedural, onde a distribuição é realizada simulando interações em modelos ecológicos, ou mesmo por ambas as técnicas. $\mathrm{O}$ algoritmo que gera a distribuição das plantas de diferentes espécies requer parâmetros como:

1. O número de novas plantas adicionadas por passo de simulação.

2. O tamanho máximo das plantas.

3. O crescimento médio das plantas.

4. A probabilidade de uma planta sobreviver em caso de competição com outra planta com vantagens naturais.

5. A preferência por áreas úmidas ou secas.

Todas as plantas deste sistema são modeladas utilizando L-Systems e Splines, o que explica o realismo das imagens obtidas, e também o tempo de renderização extremamente elevado para cenas muito populadas.

Terzopoulos et al. [TTG94], em Artificial Fishes: Autonomous Locomotion, Perception, Behavior, and Learning in a Simulated Physical World, trata a simulação de ecossistemas aquáticos, descrevendo um ambiente marinho habitado por algumas espécies de peixes artificiais.

A modelagem dos peixes é feita utilizando-se Splines. Texturas de fotos de peixes reais são mapeadas sobre o modelo para geração de peixes parecidos com os reais, poupando o trabalho de se modelar propriedades como cor, escamas dos peixes, entre outros.

$\mathrm{O}$ artigo faz um estudo sobre a anatomia e comportamento dos peixes. O modelo e a locomoção dos peixes são baseados em Física e teoria de hidrodinâmica. O estudo de anatomia é aplicado para simulação dos músculos, utilizados para realização do movimento dos peixes, e da visão dos peixes, que é modelada de forma realista, com bases em estudos de Visão Computacional. Algoritmos de aprendizagem são utilizados para que os peixes aprendam a nadar, utilizando os músculos modelados.

Algumas rotinas para sobrevivência dos peixes são implementadas, dentre elas: comer, acasalar, perambular, fugir, aprender e como evitar a colisão com obstáculos estáticos e outros peixes. Dois tipos de peixes são definidos: os predadores e presas. As presas aprendem a evitar os predadores, enquanto estes devem perseguir as presas para se alimentarem.

A complexidade de modelagem de sistemas que simulam ambientes com seres vivos é enorme, como pode ser observado neste exemplo de simulação de ambientes com peixes. A simulação em tempo real e realista para tais sistemas é, certamente, um dos grandes desafios atuais na área de Computação Gráfica. 

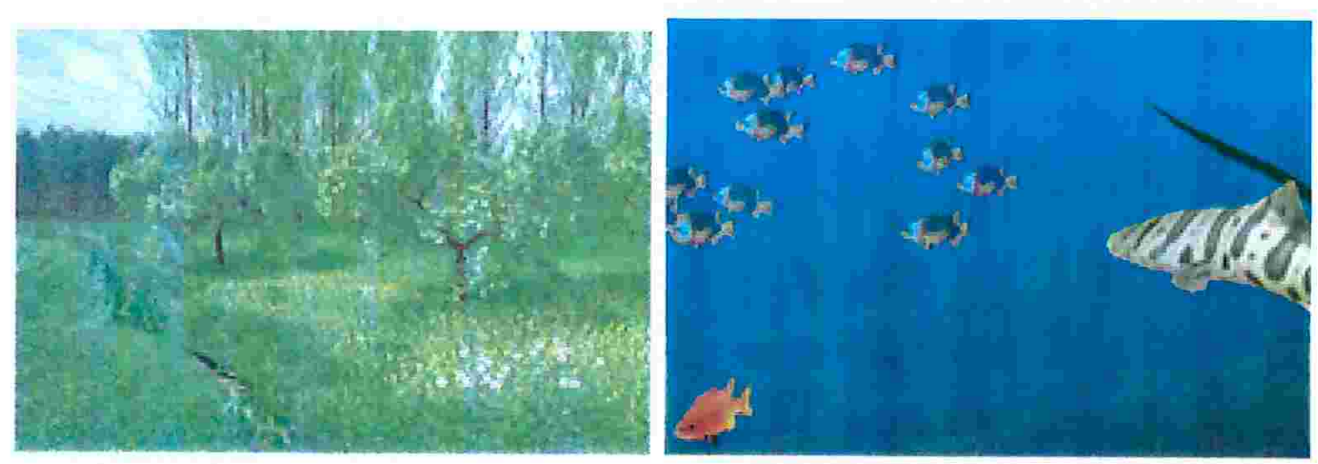

Figura 2.9: Ecossistemas vegetais e marinhos apresentados nos artigos de Deussen e Terzopoulos. Fontes: [DHL*98] e [TTG94]

\subsection{Níveis de detalhes}

Nesta seção descrevemos a utilização de uma técnica conhecida por Níveis de detalhes, ou método de representação hierárquica. Diversas aproximações já foram propostas utilizando esta técnica, inclusive, algumas criadas especificamente para representação de fenômenos naturais.

Nesta técnica, os objetos são representados por diferentes modelos ou técnicas. Certos modelos são mais precisos e exatos, porém caros computacionalmente, enquanto outros são menos realistas, porém mais eficientes. Com o objetivo de melhorar o desempenho do sistema, os modelos mais precisos são utilizados apenas para representar os objetos próximos em relação ao observador, enquanto os mais eficientes são utilizados para aproximar os objetos, quando estes estão distantes do observador.

Diversos artifícios podem ser utilizados com este intuito como por exemplo, a representação do mesmo objeto utilizando menos polígonos ou primitivas mais simples. Para se obter o resultado esperado podem ser utilizadas, inclusive, diferentes técnicas de modelagem para os objetos que compõem a cena, de modo que a distância destes com o observador determina a técnica que será utilizada. Detalhamos a seguir alguns trabalhos que tratam especificamente deste tópico.

Esta técnica é muito utilizada em sistemas interativos, aproveitando-se de uma característica da visão humana, que não pode distinguir bem pequenas diferenças em objetos muito distantes. Além disso, em casos de distribuição uniforme de uma grande quantidade de objetos na cena, o número de objetos visíveis aumenta à medida que a distância destes em relação ao observador vai aumentando. Logo uma técnica eficiente é necessária para renderizar objetos distantes, em maior número, em sistemas que requerem animação em tempo real. No caso de objetos próximos ao observador, um modelo mais realista é necessário, pois este objeto pode ser visto com detalhes pelo observador. Além disso, este objeto pode cobrir diversos outros mais distantes, fato que pode ser aproveitado para evitar que estes 
sejam renderizados.

Um dos primeiros trabalhos publicados utilizando a técnica de Níveis de detalhes em animação foi o de Carlson e Hodgins [CH97]. Este trabalho também é interessante por utilizar modelos dinâmicos. Neste artigo são criadas criaturas de uma perna só, que se movimentam pulando e tentando evitar a colisão entre elas mesmas e com a parede. Três níveis de detalhes são utilizados: um baseado em Dinâmica ("Rigid Body Dynamics"), um modelo híbrido entre Cinemática e Dinâmica e um modelo "Point-mass". A Figura 2.10 mostra uma imagem deste trabalho.

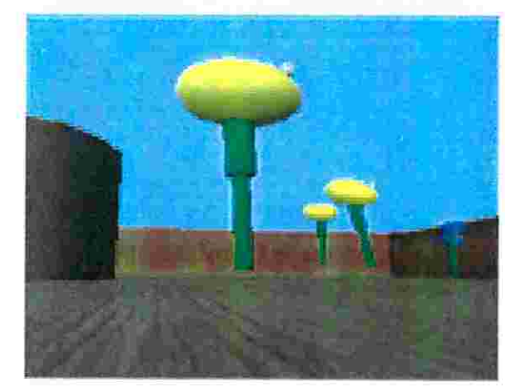

Figura 2.10: Criaturas modeladas utilizando 3 níveis de detalhes. Fonte: [CH97]

Neste artigo os modelos geométricos são os mesmos para os três níveis, a técnica de animação, no entanto, é alterada em cada nível. Este artigo tem outros pontos interessantes que merecem ser citados:

- Poucas criaturas podem ser representadas por cena (cerca de doze), para que seja gerada uma animação em tempo real.

- A modelagem baseada em Física é cara e simplificações foram feitas para melhorar o desempenho da animação neste caso.

- O tempo gasto no cálculo dos dados para animação utilizando o modelo dinâmico é cem vezes maior que o método híbrido, que por sua vez, é dez vezes mais lento que o sem nenhuma dinâmica.

- Deve se tomar um cuidado especial na implementação das transições de níveis de detalhes, isto é, quando um objeto passa a ser representado por outra técnica. Mesmo que a modelagem geométrica não seja alterada, a transição deve ser feita de forma suave, de modo a não afetar a qualidade visual e o comportamento do movimento.

Em Simulation Level-Of-Detail, Chenney [Che01] discute outros aspectos para realizar simulações com um custo computacional menor. Técnicas como, por exemplo, animar somente os objetos visíveis 
("clipping") são citadas. Isto é feito de modo eficiente utilizando-se a técnica de "bounding volumes", apresentada também em [WB] e na seção 2.3.3, para determinar se o objeto é visível ou não. No caso de uma simulação, deve-se reconstituir a posição, comportamento e movimento dos objetos que não estavam sendo renderizados por estarem "escondidos", quando estes voltam a ser visíveis.

Artigos que tratam de animação de fenômenos naturais em tempo real, frequentemente, utilizam esta técnica para atingir taxas interativas de quadros por segundo na animação. Alguns deles relacionados, inclusive, à animação de plantas, como os artigos de Perbet e Cani [PC01] e de Giacomo, Capo e Faure [GCF01]. Discutiremos estes trabalhos na próxima seção, que trata especialmente deste assunto. Nesta seção nos limitamos a descrever as soluções de níveis de detalhe adotadas nestes artigos.

Perbet utiliza três níveis de detalhes para animação de um campo de grama em tempo real. O nível mais próximo ao observador utiliza modelos tridimensionais (3D). O modelo intermediário (a média distância) é modelado utilizando-se uma técnica baseada em imagem, que mapeia uma textura de grama em um plano 3D, este nível é ilustrado na Figura 2.11. O último nível trata-se apenas de uma textura bidimensional (2D) mapeada sobre o terreno. A animação da grama foi implementada utilizando cálculos da posição da grama com modelagem baseada em Física, realizados antes do início de execução do programa. Os autores não especificam qual técnica baseada em Física foi utilizada.

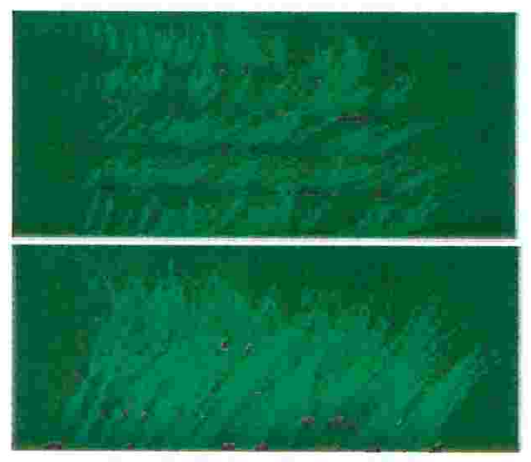

Figura 2.11: Nível de detalhe intermediário para simulação de um campo de grama. Perbet utiliza planos com texturas de gramas. A figura acima ilustra a visão aérea enquanto a abaixo a visão lateral. Fonte: [PC01]

O trabalho de Giacomo modela uma floresta virtual, utilizando apenas dois métodos de modelagem combinados. Um método procedural trata a maioria das árvores eficientemente. Para árvores próximas ao observador, um método com modelagem baseada em Física é utilizado, e permite a interação do usuário com as árvores modeladas.

A técnica também é utilizada no artigo de Markosian et al. [MMK*00] para renderização de dese- 
nhos animados, “Art-based Rendering”. Desenhos de árvores, pêlo e grama são feitos utilizando técnicas de "stroking" para que eles tenham aparência de desenhos feitos a mão.

A aproximação por pontos e linhas, para objetos distantes, também é uma técnica de nível de detalhe que vem sendo bastante utilizada. Nesta técnica objetos são substituídos por pontos e linhas a partir de uma certa distância em relação ao observador. Deussen et al. [DCSD02] substitui folhas e flores por pontos, e galhos e folhas compridas por linhas para objetos a uma longa distância. A figura 2.12 mostra os resultados obtidos.

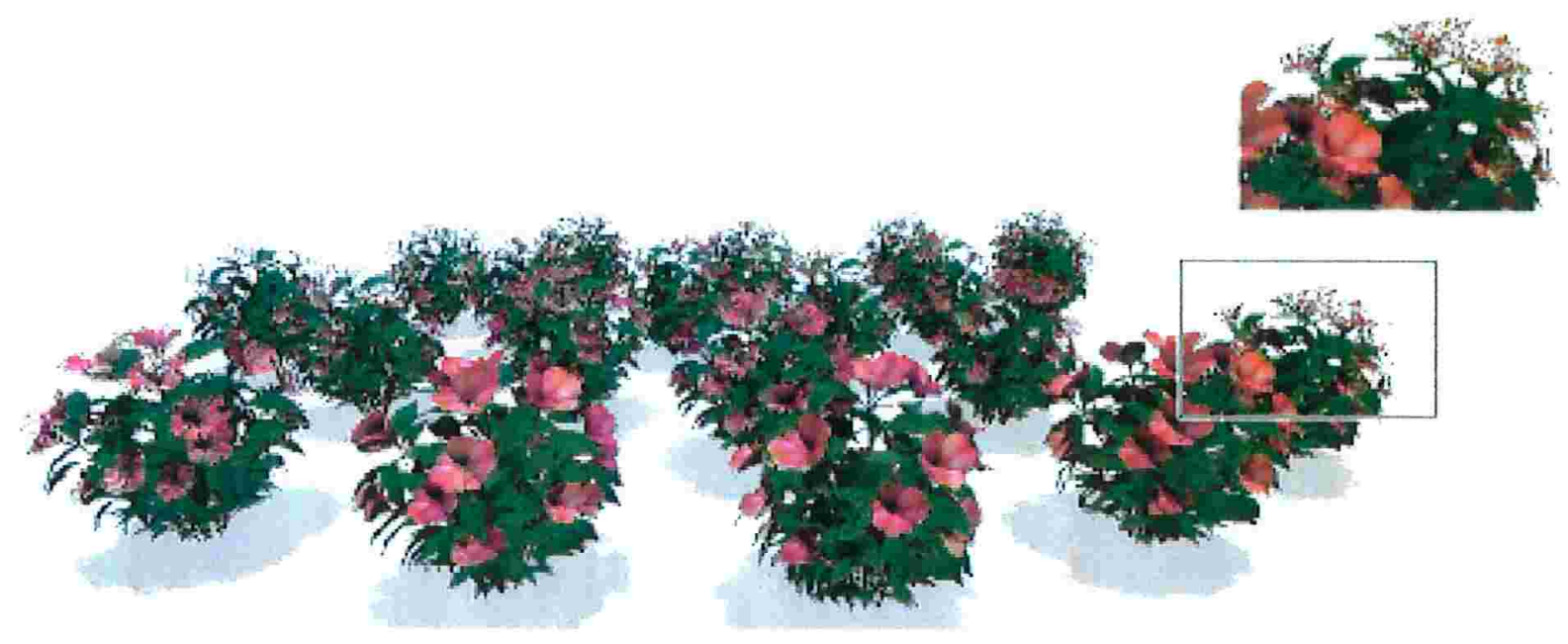

Figura 2.12: A aproximação de Deussen utiliza pontos para modelagem das flores distantes, como pode ser observado no destaque da figura. Fonte: [DCSD02]

A aproximação de objetos por pontos ou linhas para objetos a longa distância faz com que a renderização seja muito mais rápida, visto que é a renderização destas primitivas é mais eficiente do que a de um ou mais triângulos que descrevem um objeto. Esta aproximação difere das demais apresentadas, por fazer a aproximação por alteração das primitivas utilizadas.

Muitas bibliotecas gráficas têm funções de nível de detalhes já implementadas. Dentre as mais comuns estão a de "billboard" e a de redução automática do número de polígonos utilizados para renderização de um objeto dependendo da distância deste em relação ao observador.

A técnica de "billboard" representa um objeto visualmente, com alta velocidade de renderização. Esta técnica utiliza um objeto planar poligonal combinado a uma textura, que representa uma imagem do mesmo, mapeada em sua superfície e podem ser do seguinte tipo:

- "Single billboards" - utiliza apenas um objeto planar perpendicular ao solo. 
- "Double billboards" - utiliza dois objetos planares perpendiculares entre si e com o solo.

- "Triple billboards" - utiliza três objetos planares ortogonais entre si, sendo um deles paralelo ao solo.

Também pode ser encontrada uma aproximação desta técnica que rotaciona o polígono de modo que este esteja sempre "de frente" para o observador. É claro que a "farsa" é percebida facilmente para objetos próximos ao observador, mas esta pode ser uma técnica importante para modelagem rápida de objetos distantes. A eficiência do algoritmo é decorrente da drástica redução na quantidade de polígonos utilizados na renderização dos objetos.

\subsection{Animação interativa de plantas}

Nesta seção, descrevemos alguns trabalhos que tratam a animação interativa de plantas. São feitas análises das técnicas propostas, apontando pontos positivos e negativos. Podemos utilizar, como base para o trabalho, as idéias que consideramos interessantes, adaptando-as ao nosso sistema, assim como, propor novas soluções para problemas mal resolvidos até o momento. Isto possibilita comparações de resultados em relação à solução que propomos na próxima seção, e, deste modo, avaliar a contribuição apresentada pelo trabalho.

Uma observação importante é que a maior parte dos trabalhos que serão discutidos são recentes, visto que, é um problema que pôde começar a ser resolvido de forma eficiente, e relativamente realista, apenas recentemente. Outra característica interessante, que pode ser observada, é a utilização de aproximações e simplificações de modelos complexos a fim de possibilitar a renderização e animação das cenas em tempo real.

No artigo Animating Prairies in Real-Time, Perbet e Cani [PC01] descrevem uma forma de se modelar e animar campos de grama em tempo real, utilizando a técnica de Níveis de detalhes. Diversos problemas que devemos resolver, são também o objetivo de estudo deste artigo. Portanto, este artigo será bastante importante para comparações dos resultados e desempenho obtido, apesar de tratar apenas de renderização de grama.

Como já foi comentado, um dos principais problemas para animação de vegetação rasteira em tempo real é o número de instâncias de plantas que cenas deste tipo podem apresentar. Mesmo se considerando que as instâncias são de modelagem relativamente simples, a quantidade destas torna muitos algoritmos proibitivos em termos de desempenho, caso cuidados não venham a ser tomados. A solução descrita no artigo de Perbet e Cani considera este problema, que também será tratado em nosso trabalho.

Uma aproximação bastante interessante, que é utilizada neste artigo, é a pré-computação de dados 
sobre as posições que as folhas devem ter quando dobradas por ação de uma força. Folhas de grama têm geometria bastante similar uma das outras, o que possibilita esta abordagem. A animação é produzida utilizando-se rajadas de ventos com ações ou formatos pré-estabelecidos seguindo as idéias descritas por Wejchert e Haumann [WH91], trabalho descrito na seção 2.4.3.

Do mesmo grupo de pesquisa, iMAGIS-GRAVIR ${ }^{2}$, o artigo An Interactive Forest, de Giacomo, Capo e Faure [GCF01], descreve o problema de interação do usuário com árvores, em uma cena que simula uma floresta. A aproximação de Níveis de detalhes e interação utilizando um método baseado em Física, apenas onde é necessário, também é seguida neste artigo.

O fato que chama atenção neste artigo, é a utilização de áreas de influência. Todas as árvores ou galhos dentro de uma certa área são afetados por uma mesma força de ação. São tratadas e descritas, também, as equações para o movimento das árvores, assim como a transição de níveis de detalhes.
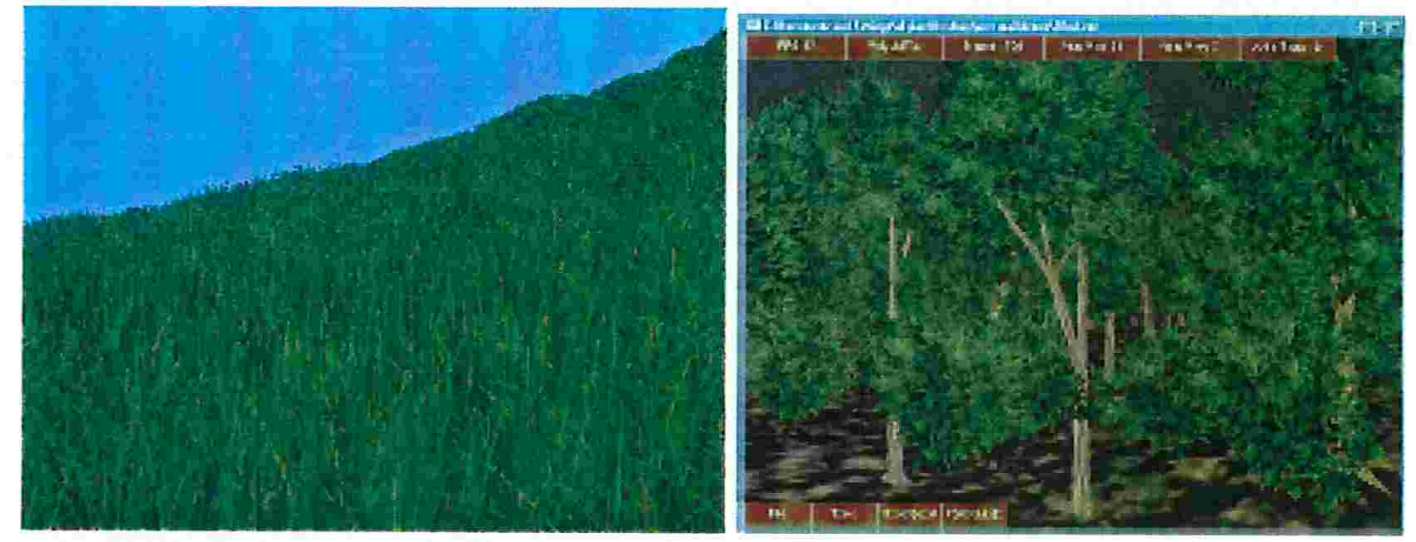

Figura 2.13: Um campo de grama e uma floresta animada em tempo real pelo grupo iMAGIS-GRAVIR. Fontes: [PC01] e [GCF01]

Outra aplicação que tenta solucionar o problema da renderização de plantas em tempo real é a técnica de "Slicing", proposta por Jakulin [Jak00] em 2000, no artigo Interactive Vegetation Rendering with Slicing and Blending. Diferentemente das duas anteriores, esta técnica não utiliza níveis de detalhes, mas uma aproximação utilizando renderização baseada em imagem. Os resultados para objetos próximos do observador são bastante pobres, no entanto trata-se de uma técnica a ser considerada para renderizar plantas distantes do observador.

A técnica proposta por Jakulin representa uma árvore modelando seu tronco com uma técnica simples baseada em malha de polígonos. As partes "esparsas" da árvore são modeladas por um conjunto

\footnotetext{
${ }^{2}$ http://www-imagis.imag.fr/index.gb.html
} 
de "cortes" ("slices"). Um "slice" é uma camada plana onde imagem das folhas e galhos são mapeadas, semelhante ao segundo nível de detalhe do artigo de Perbet e Cani [PC01]. Um conjunto de "slices" pa- ralelos é chamado de "Slicing". Dois "slicings" são colocados perpendicularmente, em relação ao outro, para representação das folhas. Cada primitiva, é mapeada então, no "slice" mais próximo. Jakulin desenvolve também uma técnica de "blending", que faz com que as primitivas que se sobrepõem sejam unidas em uma única imagem, cujo coeficiente de cor é maior e o de transparência menor para o "slice" mais próximo ao observador.

Podem ser utilizados "slices" em várias direções, inclusive com planos colocados de forma que circulem completamente a árvore. Quanto maior o número de "slices" maior a qualidade da imagem gerada, porém, o custo para sua geração também aumenta. Podemos dizer que se trata de uma técnica de "billboard" mais elaborada. A animação se restringe ao movimento do usuário, as folhas das árvores não são animadas por ação de forças externas. Resultados são exibidos na Figura 2.14.

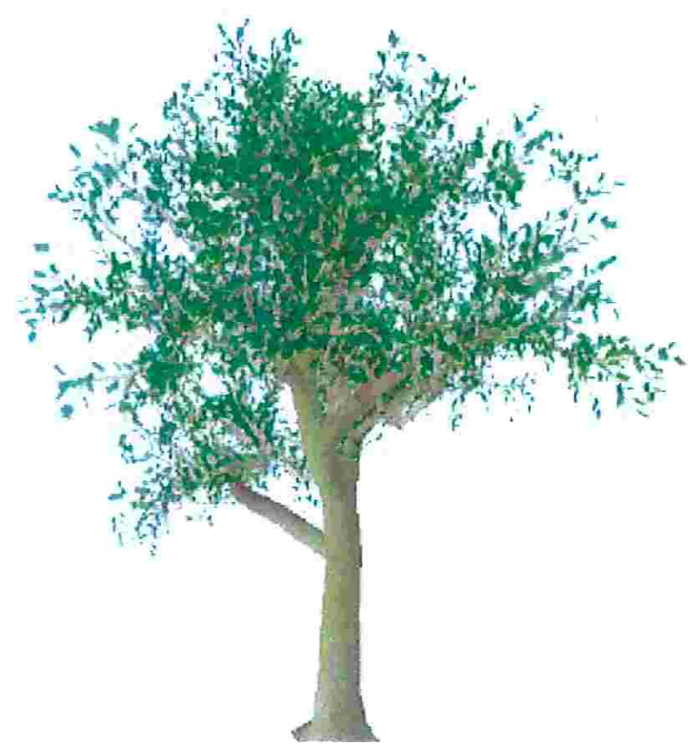

Figura 2.14: Aproximação de uma árvore utilizando "Slicing". Fonte: [Jak00].

A aproximação por pontos e linhas, citada na seção 2.5 , é uma técnica de renderização interativa que vem sendo muito utilizada em cenas compostas por uma grande quantidade de vegetação. Porém, a animação de milhões de pontos em tempo real, de forma realista, é bastante difícil de ser gerada.

Outra aproximação feita em [MFAC97] se baseia na técnica de decomposição por células, descrita na seção 2.2.1. Tetraedros são utilizados como primitivas para representação das plantas. $\mathrm{O}$ artigo 

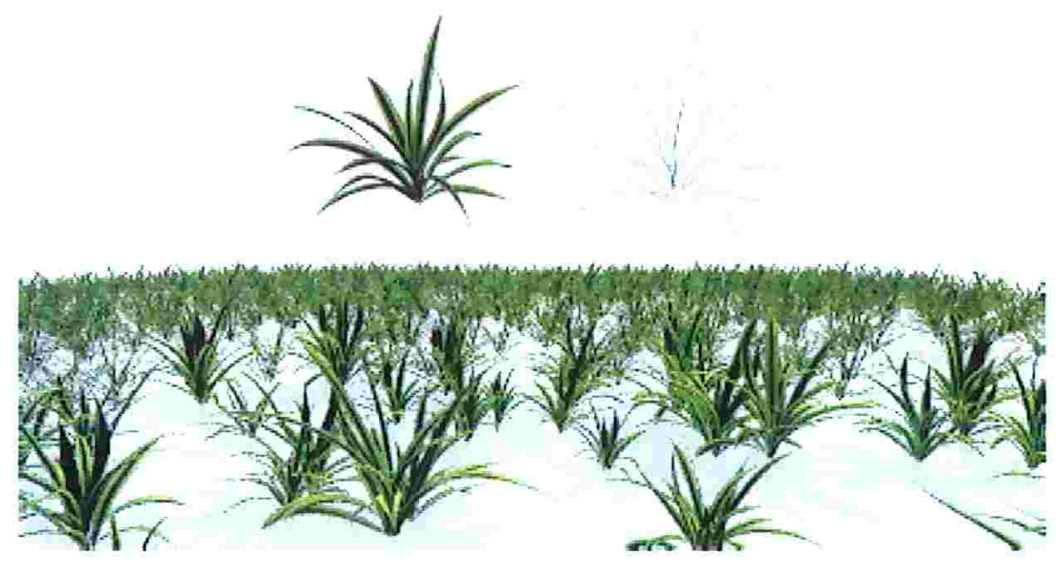

Figura 2.15: Aproximação de um campo de grama utilizando dois níveis de detalhes (Splines e a técnica de linhas e pontos). Fonte: [DCSD02].

cita as vantagens da utilização do tetraedro como primitiva, como a facilidade de subdivisão, o que é importante para algoritmos de multiresolução. Os resultados obtidos não são muito realistas, apesar de apresentar uma idéia interessante e diferente das demais.

O trabalho de Tankard [Tan01] é bastante semelhante à proposta apresentada neste trabalho. Tankard criou um sistema para modelagem de plantas e animação em tempo real. Foram desenvolvidos uma interface gráfica para criação de plantas, assim como um interpretador simples para L-Systems. Os resultados para uma pequena quantidade de plantas são satisfatórios, como pode ser observado na Figura 2.16 .

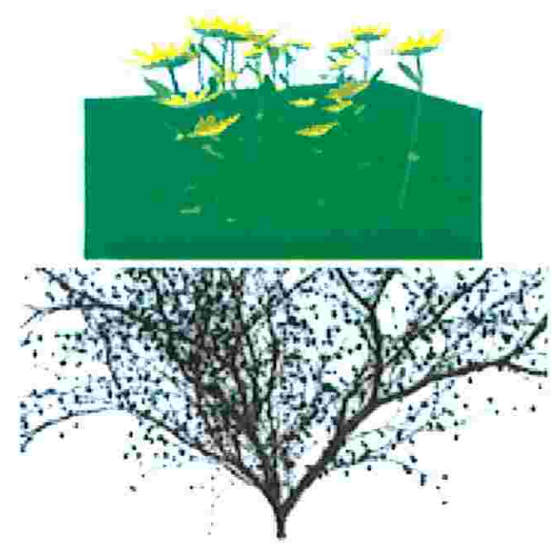

Figura 2.16: Resultados obtidos por Tankard em trabalho semelhante. Fonte [Tan01]. 
Neste capítulo apresentamos diversas idéias que podem ser aproveitadas ou estendidas no desenvolvimento de nosso sistema. O próximo capítulo descreve o sistema implementado, que certamente teve as idéias bastante influenciadas por técnicas descritas neste capítulo de fundamentos teóricos. 


\section{Capítulo 3}

\section{Simulador de Mini-Ecossistemas Vegetais}

\subsection{Introdução}

O estudo de problemas relacionados à simulação de um mini-ecossistema vegetal, realizado no capítulo anterior, ilustra alguns dos desafios propostos pelo tema da dissertação. Nesta seção, descrevemos a solução proposta neste trabalho. Muitas das soluções apresentadas até o momento não têm como objetivo principal a geração de animação e interação em tempo real. Assumimos que uma aplicação é executada em tempo real caso esta seja capaz de gerar uma taxa superior a 15 quadros por segundo (fps - "frames per second") na animação das cenas renderizadas pela mesma.

Na seção 2.6 apontamos diversas técnicas interessantes e adequadas para solução do nosso problema. Em muitos casos, faremos uma adaptação destas técnicas para solução de problemas específicos de uma parte do sistema. Quando isso ocorrer, citaremos a técnica que estamos utilizando como base e explicaremos as adaptações necessárias para sua utilização no sistema. Além disso, discutimos as consequências da utilização da mesma no desempenho do sistema.

Dentre as técnicas citadas, utilizamos: pré-computações de modelos, animação por área de influência, modelos baseados em Física simplificados, animação somente de objetos visíveis, entre outras, que chamaram atenção por se adequarem bem ao nosso problema.

As principais idéias das técnicas introduzidas ou adaptadas devem ser explicadas, de modo a justificar sua utilização, comparando-as com outras já existentes na literatura, discutindo as suas vantagens e desvantagens em relação a estas.

Optamos por utilizar os mesmos modelos geométricos para representação das plantas em diferen- 
tes distâncias. No entanto, os modelos podem ser representados utilizando um número menor ou até diferentes primitivas de acordo com sua distância em relação ao observador. Isto implica em menor complexidade no tratamento das transições de níveis de detalhes, pois o modelo é mantido, o que evita a mudança brusca da forma. Técnicas que utilizam diferentes tipos de modelagem, em cada nível de detalhe, dificilmente geram resultados cujas mudanças, durante as transições dos modelos, não são perceptíveis.

Desenvolvemos uma técnica de interação, para a animação das plantas, que também utiliza uma técnica de Nível de detalhes. Esta técnica executa a animação mais detalhada em locais onde há maior concentração de plantas ou estão mais próximos ao observador. Locais esparsos ou distantes do observador são animados utilizando uma quantidade menor de informações geradas, o que implica em uma maior eficiência.

Este capítulo foi dividido em assuntos que compõem o sistema. Cada um desses assuntos possuem características individuais onde foram necessárias implementações de abordagens próprias. Apesar disso, todos os assuntos estão devidamente interligados, como veremos a seguir. Iniciamos a descrição do trabalho descrevendo a modelagem do terreno. A seção 3.3 descreve a técnica utilizada para a modelagem dos componentes das plantas. A técnica desenvolvida para interação com nível de detalhes é apresentada na seção 3.4. A seção 3.5 discute a aproximação criada para implementação da animação realista e eficiente das plantas. A seção 3.6, por sua vez, introduz a técnica utilizada para distribuição das plantas, baseada na teoria de Ecologia. Por fim, a seção 3.7 descreve a modelagem do vento que pode afetar ou interagir com as plantas.

Na maioria destas seções, é feita uma discussão dos resultados obtidos e de possíveis melhorias que podem ser futuramente implementadas, lembrando-se que o arcabouço foi projetado para ser extensível. Diversas sugestões para se expandir o sistema ou utilizá-lo em conjunto com outro sistema existente são citadas. Naturalmente a integração com outros sistemas só é possível caso algumas regras definidas pelo arcabouço sejam satisfeitas.

\subsection{Modelagem do terreno}

A modelagem de terreno é um assunto bastante estudado, que dispõe de inúmeras publicações, muitas, inclusive, utilizando níveis de detalhes, com ótimos resultados gerados em tempo real. Por não se tratar de um dos temas principais deste trabalho, foi desenvolvida uma técnica bastante simples para modelagem do terreno.

O terreno em si, é utilizado apenas para representar o solo onde as plantas estão apoiadas. A informação que mais interessa ao trabalho é que cada porção do terreno tem propriedades ecológicas 
definidas. Estas propriedades serão utilizadas pelo algoritmo de distribuição das plantas como veremos em 3.6.

\subsubsection{Descrição da solução}

O terreno foi implementado utilizando uma malha ("mesh") de triângulos, dispostos lado a lado. Para simplificar, os pontos dos triângulos da malha, distam um tamanho fixo uns dos outros, sendo esta distância um dos parâmetros para gerar o terreno.

Como os pontos são equidistantes, podemos imaginar o terreno como sendo uma matriz que define a altura do terreno em cada ponto da malha. $\mathrm{O}$ algoritmo de geração de terreno, recebe o número de linhas e colunas desta matriz e um ponto inicial que determina o local que o terreno começará a ser gerado. O algoritmo utilizado para geração das alturas é bastante simples, utilizando um valor aleatório dada a variação máxima que um ponto pode ter em relação a outro adjacente.

Além dos parâmetros para modelagem da forma do terreno, devem ser definidos valores relativos às características ecológicas do terreno. Foram definidos apenas dois atributos, um relacionado à irrigação do solo e outro à sua fertilidade (quantidade de nutrientes). Devem ser passados para o sistema valores médios e uma variação máxima para estes atributos. O algoritmo de geração de terreno associa um valor para irrigação e quantidade de nutrientes para cada ponto do modelo.

Desta forma criamos uma modelagem simples e parametrizada para o terreno. O algoritmo de geração do terreno é executado antes do início da animação, na fase de pré-computação. Logo este não afeta o desempenho do sistema em tempo de execução.

No entanto, caso seja definida uma malha que contenha muitos triângulos a animação pode ser comprometida. Além disso, o terreno estaria consumindo memória que poderia estar sendo utilizada para modelagem de mais plantas. Portanto, os parâmetros especificados devem ser coerentes com a qualidade da cena a ser gerada e com a capacidade do computador que está sendo utilizado para sua criação. Outro fato, que pode ser considerado na decisão da especificação dos parâmetros, é que o terreno, geralmente, se encontra praticamente coberto em cenas com uma grande quantidade de plantas concentradas. Logo, não é necessária a utilização de muitos triângulos para sua representação.

\subsubsection{Resultados obtidos e discussão}

Os resultados obtidos com este algoritmo simples são exibidos na Figura 3.1.

Como o terreno tem uma dimensão definida e o sistema permite que o usuário se movimente sobre a cena, ele pode chegar a um ponto onde o mesmo termina. Para que isto não ocorra poderia ser implementado um algoritmo que trate este caso e crie a continuação do terreno. Porém, este comportamento 

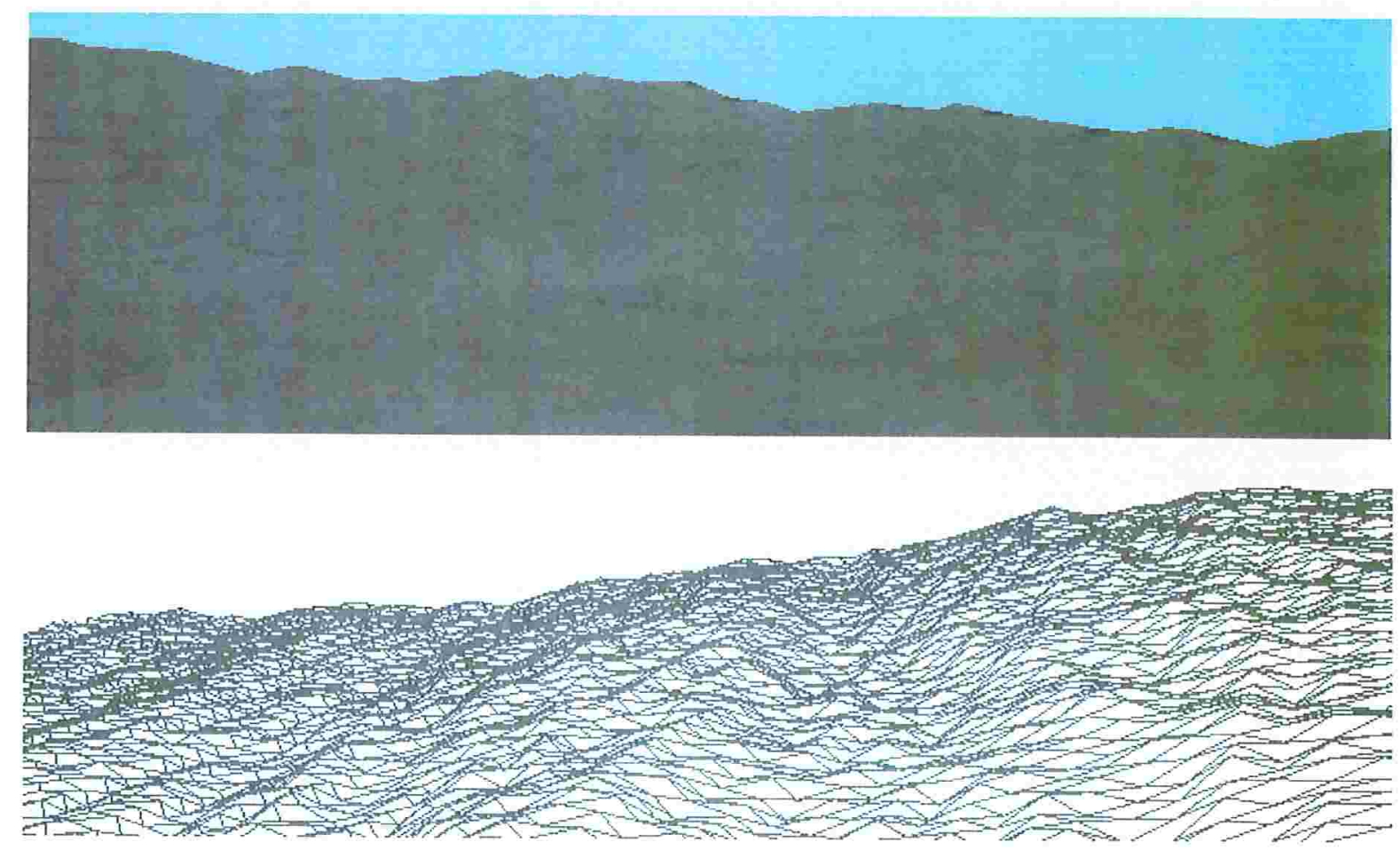

Figura 3.1: Imagens do terreno e da malha que representa a geometria do terreno, em um diferente ângulo de observação, geradas pelo sistema.

não foi implementado neste sistema. Observe que esta aproximação teria influência no desempenho do sistema em tempo de execução, pois seria necessária a geração automática do terreno, e o pior, das plantas e distribuição destas sobre o terreno.

Um algoritmo de Nível de detalhes poderia ser implementado para geração de terreno, para melhorar o desempenho do sistema. Isto geraria terrenos mais realistas em locais próximos ao observador e até poderia utilizar menos triângulos. Porém, como foi verificado que a modelagem do terreno não impacta muito no desempenho do sistema, pois o terreno é estático (não se movimenta), este dispositivo não foi implementado.

Como o arcabouço permite a substituição de diversos componentes do sistema, caso seja necessário, o usuário pode utilizar outras técnicas, adaptando-as às regras definidas pelo arcabouço, descrito no próximo capítulo. Por exemplo, pode-se alterar o algoritmo descrito, por um que utiliza o GIS ("Geographical Information System”) para obtenção de informações sobre o terreno. Aproximações envolvendo, inclusive, estudo e análise do desempenho de algoritmos relacionados à modelagem de terreno, podem utilizar este arcabouço para avaliar o desempenho de suas técnicas considerando animação de 
plantas sobre o terreno.

\subsection{Modelagem de plantas}

Nesta seção, descrevemos as técnicas implementadas para modelagem das plantas e seus componentes. Nosso modelo foi projetado para que tenha um bom desempenho, seja de fácil adaptação para um algoritmo de Nível de detalhes e possa representar a planta utilizando parâmetros físicos, para um maior realismo.

Para modelagem das plantas, consideramos três primitivas básicas: galhos, folhas e flores. Toda planta do sistema é composta por um agrupamento destas primitivas. Outra característica importante é que apenas os galhos podem se conectar a outras primitivas, inclusive outros galhos, formando assim a estrutura básica de uma planta. No restante do texto nos iremos nos referir às primitivas da planta como componentes da planta.

A subseção 3.3.1 descreve a estrutura de dados implementada para modelagem de plantas, assim como o modo de se utilizar as pré-computações dos modelos criados para agilizar tanto a modelagem e quanto a animação. A criação dos modelos utilizando parâmetros físicos é descrita na subseção 3.3.2. O algoritmo de Nível de detalhes para modelagem de plantas do sistema é descrito na subseção 3.3.3. Resultados obtidos e discussões relevantes à modelagem são exibidas na subseção 3.3.4.

\subsubsection{Pré-computações e estrutura de dados}

Em uma cena contendo muitas instâncias de plantas, qualquer cálculo que puder ser evitado na modelagem e animação em tempo de execução, significa um aumento considerável no desempenho do sistema.

Em geral, em cenas compostas por plantas temos muitas instâncias de folhas e flores geometricamente semelhantes. Aproveitando-se desta característica, podemos reutilizar alguns cálculos realizados por algumas instâncias na modelagem de outras, melhorando assim o desempenho do sistema. Para isso, devemos implementar uma estrutura de dados capaz de armazenar informações que possam ser reaproveitadas para modelar componentes semelhantes.

Um conjunto de coordenadas é utilizado para descrever cada componente da planta. Para armazenar as coordenadas, de modo a permitir o reaproveitamento destas, utilizamos um conjunto de vetores. A escolha de vetores como estrutura de dados básica dos modelos se deve à facilidade na alteração de suas propriedades, além de possuírem operações básicas já definidas. Um conjunto de vetores pode ser utilizado para representar diversas formas. Esta característica é aproveitada para o algoritmo de Nível 
de detalhes descrito em 3.3.3.

Os componentes da planta são representados por três conjuntos de vetores $C_{1}, C_{2}$ e $C_{3}$. O conjunto $C_{1}$ define o eixo principal do componente representado. Seja $n$ o número de pontos utilizados para definir o eixo principal do componente, os pontos que pertencem ao eixo principal, $\left\{P_{1}, P_{2}, \ldots, P_{n}\right\}$, de um componente são criados definindo-se um ponto inicial, $P_{i n i}$, e adicionando a este os vetores de $C_{1}$.

Os outros dois conjuntos de vetores $C_{2}$ e $C_{3}$, representam a superfície do componente à esquerda e à direita do eixo principal. Seja $m$ o número de pontos utilizados para definir a superfície lateral do componente. Os conjuntos de vetores laterais definem os pontos $L_{j}^{i}$ e $R_{k}^{i}$, para $0<j<m$ e $0<k<m$, sobre o eixo lateral à direita e à esquerda, respectivamente, dos pontos $P_{i}$, para $0<i<n$.

A Figura 3.2 mostra os conjuntos de vetores que representam uma folha e um galho. A flor é representada por um conjunto de pétalas cuja representação é bastante semelhante à da folha.

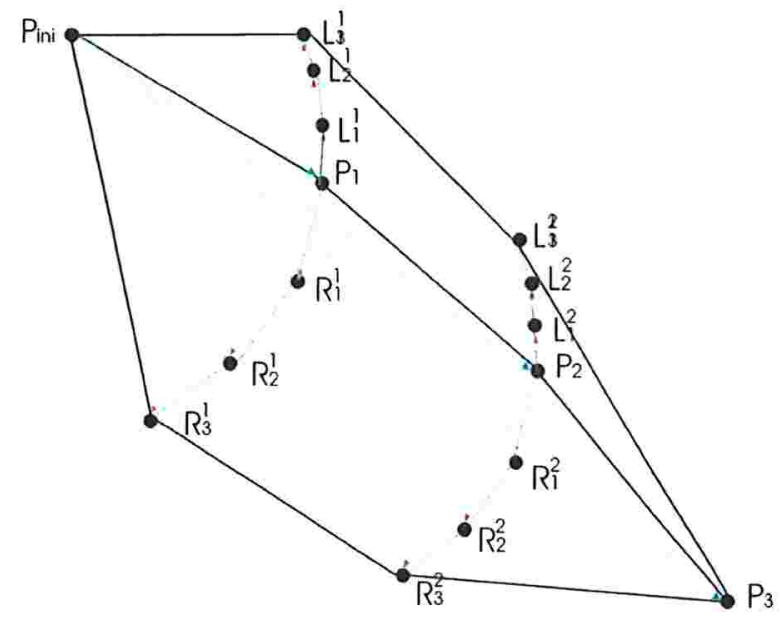

a.

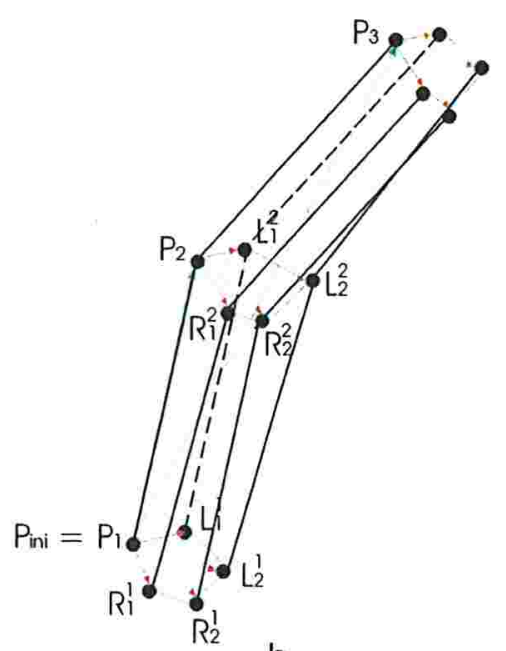

b.

Vetores do eixo principal

vetores dos eixos laterais

Figura 3.2: (a) Uma folha modelada utilizando a representação por vetores. Os pontos $\left\{P_{1}, P_{2}, P_{3}\right\}$ definem o eixo principal, os pontos $L_{j}^{i}$ e $R_{k}^{i}$ também são ilustrados. Os vetores em verde pertencem a $C_{1}$ e definem o eixo principal dos componentes. Os vetores em vermelho à esquerda do eixo pertencem a $C_{2}$ e os vetores em vermelho à direita pertencem a $C_{3}$.

Os conjuntos de vetores são pré-computados para diferentes ângulos do mesmo com a normal do solo. A diferença dos ângulos deve ser especificada pelo usuário, de forma que quanto maior o número de ângulos definidos, mais posições do mesmo componente são armazenados na pré-computação. $\mathrm{O}$ aumento da quantidade de ângulos pré-computados implica na utilização maior de memória, porém 
torna a animação mais suave, pois o algoritmo de animação utiliza essas posições para movimentar os componentes como é descrito na seção 3.5 .

A Figura 3.3 mostra o resultado da pré-computação de uma folha de grama em diversos ângulos. A Figura 3.3.b mostra a estrutura pré-computada com parâmetros físicos, que descrevemos na próxima seção.

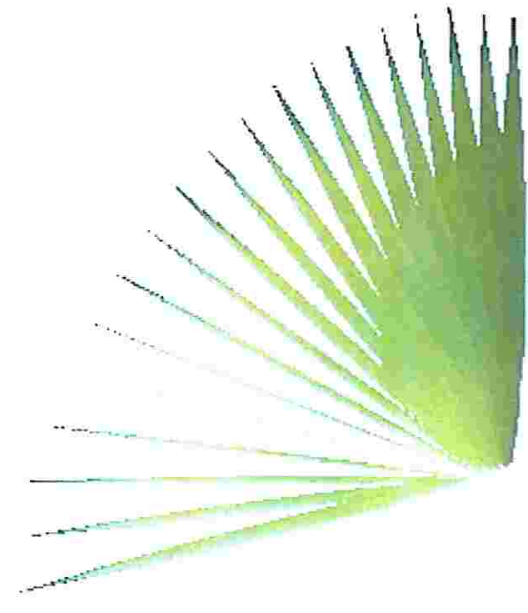

a.

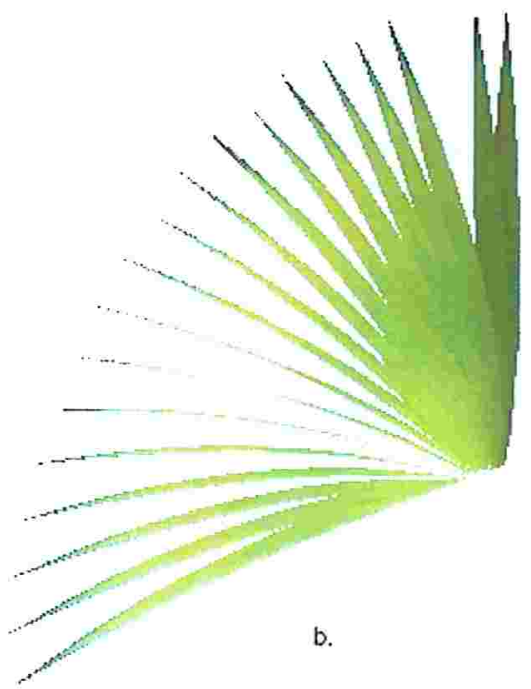

Figura 3.3: (a) Pré-computação de folhas de grama em diversos ângulos, sem ação da força da gravidade. (b) Estrutura de pré-computação com ação da força da gravidade.

\subsubsection{Modelo físico para componentes das plantas}

Na natureza folhas e galhos são ligeiramente curvados devido a ação da força de gravidade. Desenvolvemos uma técnica simples baseada em Física para modelar os componentes das plantas de forma mais realista, utilizando parâmetros físicos que determinam a posição dos vetores pertencentes a $C_{1}, C_{2}$ e $C_{3}$.

O modelo físico para os componentes das plantas considera apenas duas forças agindo sobre o corpo: a força de gravidade (Peso), que atrai o componente em direção ao solo, e uma força de natureza elástica criada para impedir a ação do Peso. Enquanto a força Peso depende apenas da massa da planta, a força elástica é proporcional à alteração da posição do componente de seu estado inicial devido à ação da gravidade. 


\section{Algoritmo para modelagem sobre ação da força de gravidade}

O algoritmo que curva os componentes, devido à ação do peso, utiliza a divisão de seções definidas pelos conjuntos de vetores na modelagem. Cada seção será curvada pela ação de diferentes forças resultantes. A primeira seção a ser curvada é a mais próxima ao galho ou ao solo, pois se trata de uma seção já fixada. As seções são representadas pelos intervalos $\overline{P_{i} P_{i+1}}$ para o eixo principal, e $\overline{L_{j}^{i} L_{j+1}^{i}} \mathrm{e}$ $\overline{R_{k}^{i} R_{k+1}^{i}}$ para os eixos laterais, seguindo a notação definida na seção anterior.

A força de gravidade, $\vec{F}_{g}$, curva o componente na seção fixada. Conforme o componente vai sendo curvado, a força elástica, $\vec{F}_{e l}$, aumenta. A força elástica é linearmente dependente à distância dos pontos $\vec{X}_{0}$ e $\vec{X}$, centro de massa das seções sobre a seção que está sendo dobrada antes e depois do curvamento, respectivamente. Esta força também depende de uma constante elástica $k$, definida para cada seção do componente como função de algumas propriedades como grossura do talo e largura do componente na seção.

Estas duas forças podem ser decompostas em componentes normal e tangencial às seções que estão sendo dobradas. A Figura $3.4^{1}$ ilustra a decomposição das duas forças.

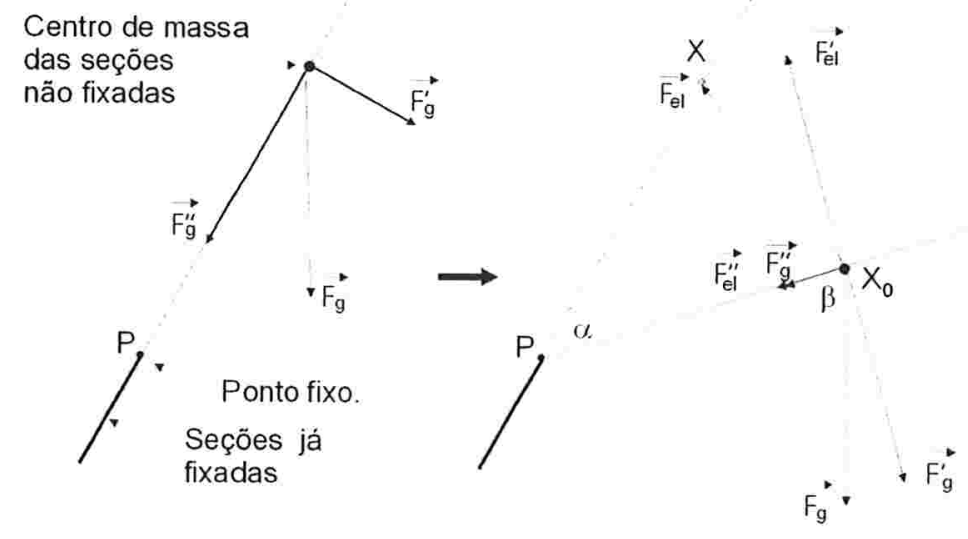

Figura 3.4: A seção fixada e as componentes das forças de gravidade $\left(\vec{F}_{g}\right)$ e elástica $\left(\vec{F}_{e l}\right)$ quando a normal destes são iguais.

Como consideramos que as seções abaixo da que está sendo dobrada estão fixadas, a reação da componente tangencial é aplicada pelo terreno, portanto não é necessário seu tratamento. Quando as componentes normais de $\vec{F}_{g}$ e $\vec{F}_{e l}$ são iguais, um equilíbrio é atingido e o componente deixa de ser curvado.

\footnotetext{
${ }^{1}$ Nesta figura, a força elástica é igual a $\vec{X}_{0}-\vec{X}$ apenas para facilitar a visualização, na verdade esta força é definida por $\vec{F}_{e l}=k \cdot\left(\vec{X}_{0}-\vec{X}\right)$.
} 
Definida a posição de equilíbrio, a seção atual é fixada e a próxima seção é curvada utilizando o mesmo algoritmo. Aplicando este algoritmo a cada seção curvamos o componente pela ação da força da gravidade. Para curvar os componentes é necessário o cálculo do centro de massa e do ângulo de curvatura para cada seção, em cada passo do algoritmo. Descrevemos estes processos nos parágrafos abaixo. Uma simulação do algoritmo é exibida na Figura 3.5.

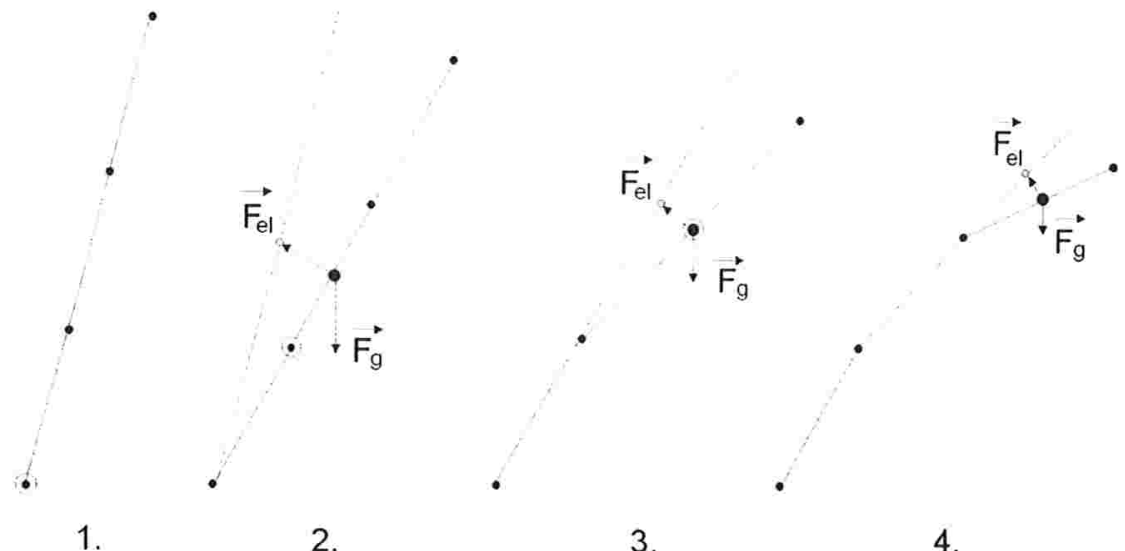

Figura 3.5: $\mathrm{O}$ processo de curvamento devido à força de gravidade: (1) $\mathrm{O}$ componente antes do cálculo de curvamento. (2) $\mathrm{O}$ componente curvado pela influência das forças de gravidade $\vec{F}_{g}$ e elástica $\vec{F}_{e l}$ no primeiro ponto fixado. $(3,4) \mathrm{O}$ mesmo processo para outros pontos fixados.

\section{Cálculo dos centros de massa}

O algoritmo de cálculo da posição do centro de massa de cada seção da folha recebe as massas das seções e vetores contendo informações físicas e geométricas das planta, como as bordas e comprimento da folha. Considerando que a densidade das seções não varia por toda extensão da folha, o algoritmo calcula os centros de massa para cada subseção considerando a parte da folha acima da seção que está sendo curvada.

Para cada seção que está sendo curvada pelo algoritmo, descrito na subseção anterior, o centro de massa da seção é retornado pelo algoritmo calcCenterOfMass, descrito abaixo.

Algoritmo "calcCenterOfMass" (COM) - Calcula o centro de massa para seção que está sendo curvada. Seja i o índice da seção que está sendo curvada, $\mathrm{n}$ o número total de seções e $\mathrm{M}$ a soma das massas de todas as seções ainda não curvadas. Seja MDOWN um contador para massa das seções mais próximas à inicial.

COM1. [Início] MDOWN $\leftarrow 0$. 
COM2. [Encontre a seção onde está o centro de massa] Enquanto MDOWN $+\mathrm{m}(j)<\mathrm{M} / 2$, faça MDOWN $\leftarrow$ MDOWN $+m(j)$. Onde $m(j)$ é uma função que retorna a massa da seção “ $j$ ”. Considere que $j=i$ no início e é incrementado de um a cada iteração.

COM3. [Encontre ponto do centro de massa] O passo anterior retorna um valor de MDOWN menor que M/2. Considerando que a densidade da folha é igual em todas seções, basta fazer o cálculo da área do trapézio, que determina as dimensões da seção, e verificar a porcentagem necessária para se obter a massa igual a $\mathrm{M} / 2-\mathrm{MDOWN}$.

\section{Cálculo do ângulo de curvatura}

Para determinarmos a posição dos pontos dos componentes da planta devemos determinar o ângulo que as seções são curvadas. Sejam $\alpha$ o ângulo de curvatura da seção atual e $\beta$ o ângulo entre a posição de equilíbrio das subseções que estão sendo dobradas com a normal do solo e $\overrightarrow{X P}$, conforme ilustrado na Figura 3.4. Seja ainda, $g$ a constante de gravidade. A equação que descreve o valor de $\alpha$ pode ser obtida calculando a igualdade abaixo.

$$
\begin{aligned}
& \vec{F}_{e l}^{\prime}=\vec{F}_{g}^{\prime} \\
& k \cdot\left(\overline{X_{0} X}\right) \cdot \sin \frac{180^{\circ}-\alpha}{2}=m \cdot g \cdot \sin \beta
\end{aligned}
$$

Seja $\gamma$ o ângulo de curvatura da seção anterior em relação à normal do solo, temos que

$$
\beta=\alpha+\gamma
$$

Pela lei do seno temos também que:

$$
\begin{aligned}
& \sin \frac{\alpha}{2}=\frac{\overline{X_{0} X} / 2}{\overline{X P}} \\
& \overline{X_{0} X}=2 \cdot \overline{X P} \cdot \sin \frac{\alpha}{2}
\end{aligned}
$$

Substituindo 3.2 e 3.3 em 3.1, temos que:

$$
k .2 \cdot \overline{X P} \cdot \sin \frac{\alpha}{2} \cdot \sin \frac{180^{\circ}-\alpha}{2}=m \cdot g \cdot \sin (\alpha+\gamma)
$$




$$
\frac{k \cdot \overline{X P}}{m \cdot g} \cdot 2 \cdot \sin \frac{\alpha}{2} \cdot \sin \left(90^{\circ}-\frac{\alpha}{2}\right)=\sin (\alpha+\gamma)
$$

Seja $c_{1}=\frac{k \cdot \overline{X P}}{m \cdot g}$, temos:

$$
\begin{aligned}
& c_{1} \cdot 2 \cdot \sin \frac{\alpha}{2} \cdot\left(\sin 90^{\circ} \cdot \cos \frac{\alpha}{2}-\sin \frac{\alpha}{2} \cdot \cos 90^{\circ}\right)=\sin \alpha \cdot \cos \gamma+\sin \gamma \cdot \cos \alpha \\
& c_{1} \cdot 2 \cdot \sin \frac{\alpha}{2} \cdot \cos \frac{\alpha}{2}=\sin \alpha \cdot \cos \gamma+\sin \gamma \cdot \cos \alpha \\
& c_{1} \cdot \sin \alpha=\sin \alpha \cdot \cos \gamma+\sin \gamma \cdot \cos \alpha \\
& \sin \alpha \cdot\left(c_{1}-\cos \gamma\right)=\sin \gamma \cdot \sqrt{1-(\sin \alpha)^{2}} \\
& (\sin \alpha)^{2} \cdot\left(c_{1}-\cos \gamma\right)^{2}=(\sin \gamma)^{2} \cdot\left(1-(\sin \alpha)^{2}\right) \\
& (\sin \alpha)^{2}=\frac{(\sin \gamma)^{2}}{\left(\left(c_{1}-\cos \gamma\right)^{2}+(\sin \gamma)^{2}\right)} \\
& \alpha=\arcsin \sqrt{\frac{(\sin \gamma)^{2}}{\left(\frac{k \cdot \overline{X P}}{m \cdot g}-\cos \gamma\right)^{2}+(\sin \gamma)^{2}}}
\end{aligned}
$$

\section{Resultados}

Podemos gerar componentes com diferentes aparências alterando os valores da massa, grossura e largura das seções do componente. A Figura 3.6 mostra imagens de diferentes tufos de grama gerados a partir de parâmetros diferentes. Se a força elástica não é capaz de se opor à força de gravidade em alguma de suas seções, o componente se quebra, como é ilustrado na Figura 3.6.c.

\subsubsection{Nível de detalhes para modelagem}

Apresentamos um algoritmo simples para obtenção de uma modelagem baseada em Física dos componentes da planta. A estrutura de dados utilizada para armazenar os conjuntos de vetores foi definida na seção 3.3.1. Nesta seção, descrevemos como utilizar os vetores que definem a modelagem das plantas para gerar componentes em diferentes níveis de detalhes.

Para modelagem escolhemos uma técnica que pode ser utilizada sem que haja muita diferença nas representações, o que torna a transição de níveis bastante suave. Utilizando a estrutura de vetores já 


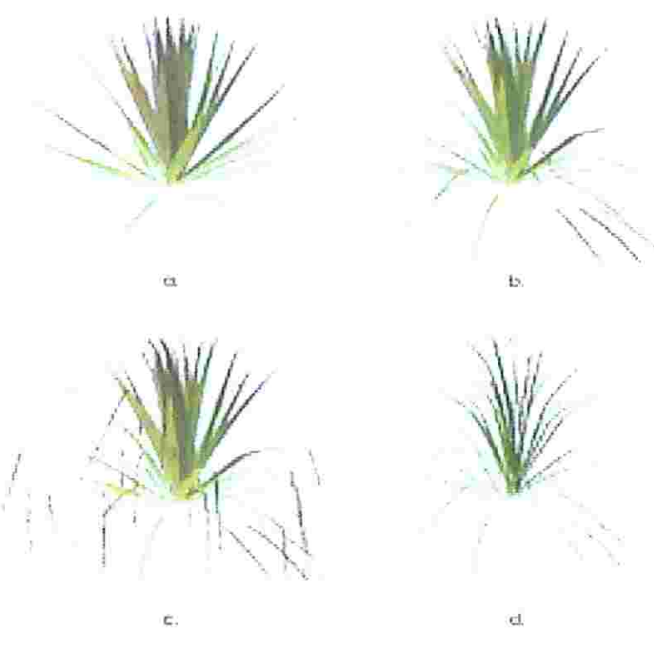

Figura 3.6: (a) Um tufo de grama sem propriedades físicas. (b) Um tufo de grama com propriedades físicas. (c) Um tufo com folhas quebradas. (d) Um tufo com diferentes propriedades físicas de a, b e c.

alterada pelo algoritmo de ação da força de gravidade, os componentes podem ser representados em diversos níveis de detalhes, utilizando modelagem por polígonos ou linhas.

A técnica consiste em se definir intervalos de distância em que cada representação será utilizada. Em cada nível, deve ser escolhido o modo de representação (utilizar polígonos ou linhas) e os vetores que são utilizados para representar o objeto. Por exemplo, podemos definir um nível de detalhe intermediário que utilize metade dos vetores da estrutura definida e que seja modelado utilizando linhas, isto torna o modelo mais rápido de ser modelado, e inclusive animado, do que um nível que defina representação por polígonos e utiliza todos os vetores para gerar o componente.

O sistema permite que o usuário defina quais vetores devem ser utilizados em cada nível, portanto podem ser criados quantos níveis o usuário determinar. Outra vantagem evidente é que a partir de uma estrutura de vetores os componentes podem ser modelados de várias formas alterando-se os vetores que o representam ou a primitiva (polígonos ou linhas). Além disso, o usuário pode escolher se quer utilizar ou não uma certa representação, isto é, ele não está preso a um número fixo de níveis com técnicas estabelecidas para cada um deles, o que geralmente é encontrado na literatura.

O desempenho do sistema pode ser melhorado bastante sem comprometer o realismo caso os níveis de detalhes na modelagem sejam bem descritos pelo usuário. A animação de um modelo baseado em linha que contém poucos pontos de controle é bem mais rápida que a de um modelo que utiliza diversos polígonos. O resultado do algoritmo de níveis de detalhes para modelagem é ilustrado na Figura 3.7, a 
complexidade de cada objeto é descrita na tabela 3.1.

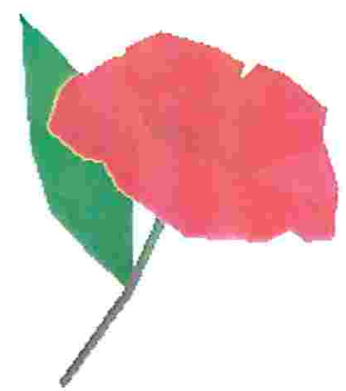

a.

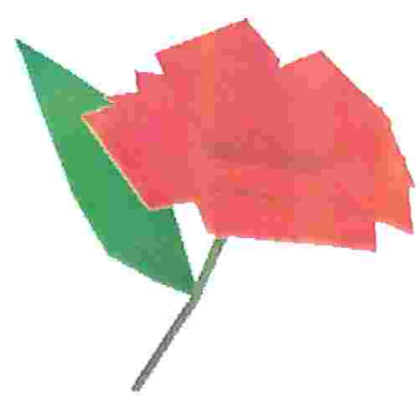

b.

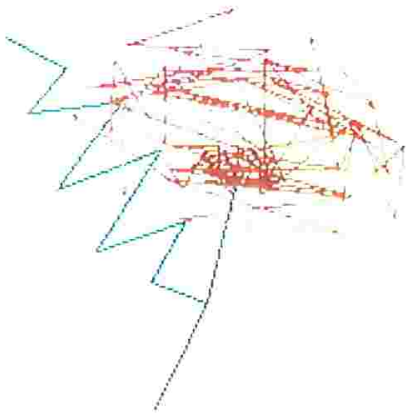

c.

Figura 3.7: Três diferentes representações de um modelo de uma rosa. O modelo b difere de a por utilizar menos triângulos nas pétalas da flor.

\begin{tabular}{|l|l|c|}
\hline \hline Modelo & Primitivas & Número de primitivas \\
\hline $\mathrm{a}$ & triângulo & 177 \\
$\mathrm{~b}$ & triângulo & 105 \\
$\mathrm{c}$ & linhas & 118 \\
\hline \hline
\end{tabular}

Tabela 3.1: Tabela de complexidade dos diferentes modelos de uma rosa em diferentes níveis de detalhes.

\subsubsection{Resultados obtidos e discussão}

Já foram apresentados resultados para seções da modelagem com a ação da gravidade sobre os componentes e a representação por Nível de detalhes. A Figura 3.8 mostra uma cena contendo vegetação modelada com as técnicas descritas nesta seção.

Alguns modelos foram criados para ilustrar o funcionamento do sistema, porém para um maior realismo poderíamos determinar os dados para geração dos modelos utilizando dados biológicos reais. A técnica de Nível de detalhes utiliza representação por linhas como mecanismo para melhorar o desempenho do sistema, porém em cenas contendo muitos vegetais de geometria complexa, como árvores e arbustos, é muito difícil renderizar modelos realistas e animá-los em tempo real, mesmo utilizando aproximações. Esta limitação é decorrente principalmente da incapacidade da renderização e animação das próprias primitivas utilizadas quando em grande número. Atualmente apenas técnicas baseadas em imagem são capazes de renderizar uma grande quantidade de plantas em tempo real. Porém estas técnicas têm o grau de realismo bastante comprometido. 


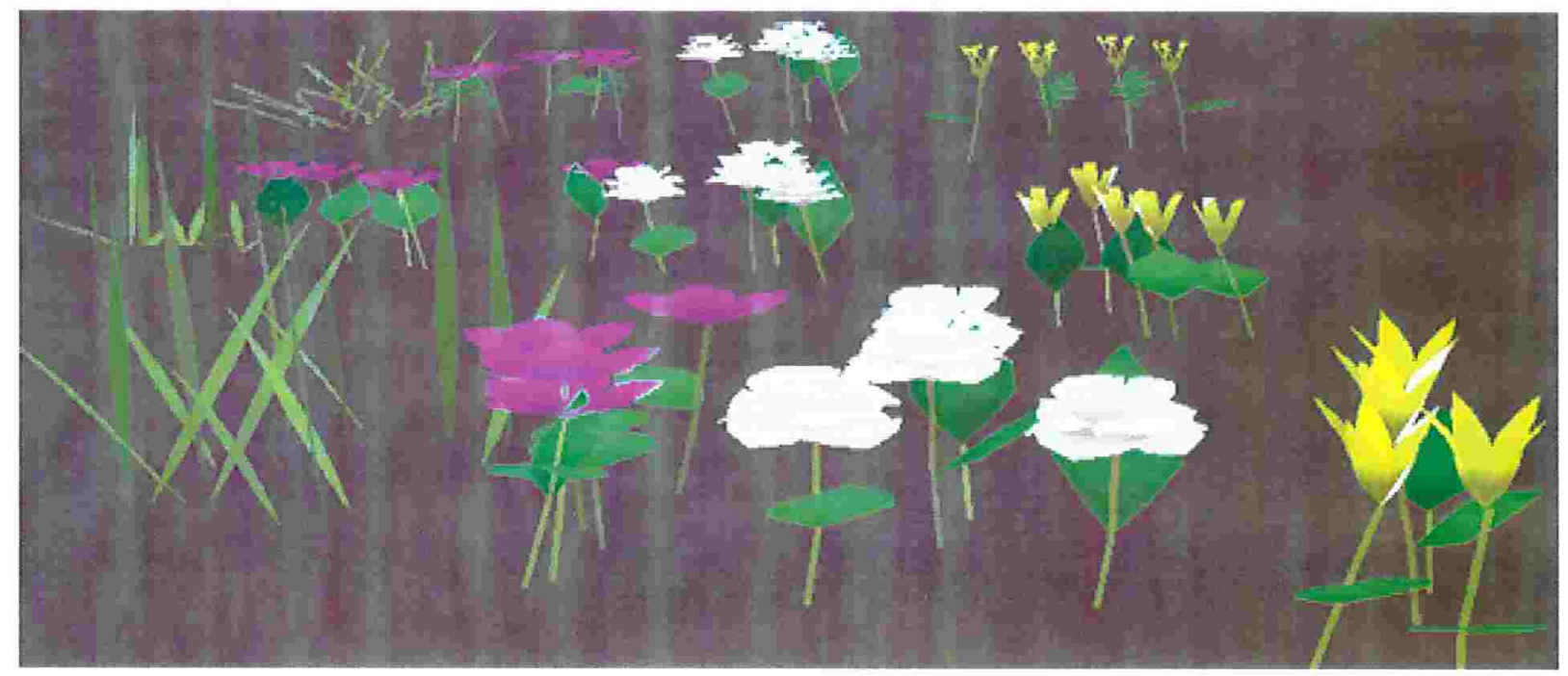

Figura 3.8: Quatro diferentes espécies de plantas modeladas pelo sistema. Três níveis de detalhes são utilizados para representação das plantas.

\subsection{Campo de forças}

Nesta seção descrevemos o conceito de Campo de forças, técnica implementada para tratar e concentrar toda forma de interação sobre as plantas definidas pelo sistema.

Na subseção 3.4.1 descrevemos o conceito e a idéia do campo de forças. Na subseção 3.4.2 explicamos a estrutura de dados utilizada para manutenção das informações do campo de modo eficiente. A subseção 3.4.3 descreve o algoritmo para atualizar o campo de forças, considerando todos elementos que agem sobre ele.

\subsubsection{Introdução}

O método baseado em aerodinâmica para animação pela ação do vento, apresentado em [WH91], define algumas primitivas de fluxo que representam campos de velocidade. Estes campos determinam a intensidade e direção do fluido. Objetos ou obstáculos dentro deste campo de velocidade recebem a ação de uma força calculada considerando-se a área, a posição e a orientação do objeto em relação ao fluxo.

Neste trabalho, definimos o conceito de campo de forças, estendendo a idéia de campos de velocidade. Os campos de velocidade imprimem uma força nos obstáculos que estão dentro dele. Se definirmos um campo de forças diretamente evitamos alguns cálculos relacionados ao fluido. Esta 
simplificação torna a técnica mais genérica, pois ela pode ser utilizada não apenas para representar a ação de fluidos para animação da cena, mas também para representar a interação de qualquer agente capaz de aplicar uma força sobre os objetos no campo.

O campo de forças é uma malha volumétrica definida sobre o terreno, composta por diversas regiões de ação de forças. Os elementos dentro desta malha recebem a ação de uma força, determinada pelo campo, de acordo com a região em que se encontram. Todos os objetos dentro de uma mesma região recebem a ação da mesma força. A Figura 3.9 mostra um esquema simples de um campo de forças.

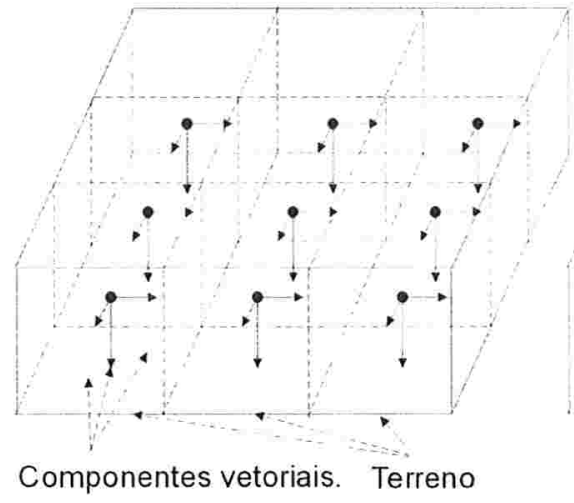

A.

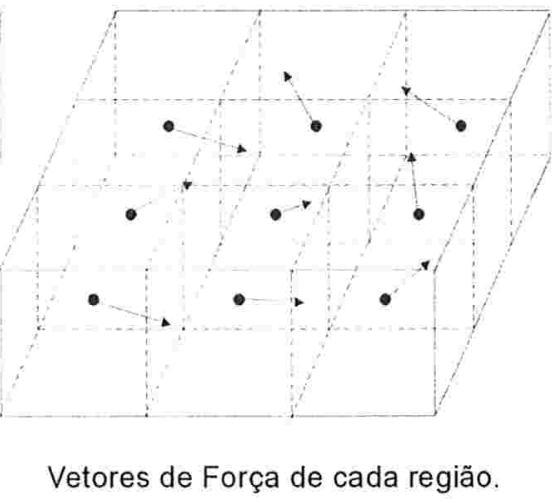

B.

Figura 3.9: (a) O campo de forças uniforme (com regiões de volumes idênticos) sobre o terreno. (b) Um exemplo dos vetores de forças para uma determinada configuração do campo.

Fluidos como vento podem ser modelados alterando a intensidade e a direção da força. Todas primitivas descritas em [WH91] podem ser modeladas alterando os vetores do campo de força de acordo com o movimento do fluxo descrito. As forças devem se propagar entre os vetores do campo, considerando perdas de intensidade ou mudança de direção caso haja interação com algum objeto no campo. Na seção 3.7.1, descrevemos a ação do vento sobre o campo de forças.

A princípio, acreditava-se que apenas com a criação de um campo uniforme, como o descrito na Figura 3.9, era possível reduzir os cálculos de modo a gerar uma animação em tempo real. Os resultados gerados mostraram uma animação rápida, no entanto, objetos distantes do observador eram animados utilizando uma área da malha igual a de objetos próximos, resultando em uma animação pobre para plantas próximas ao observador e ineficiente para plantas distantes.

Poderíamos apenas diminuir a área dos elementos da malha para resolver o problema de resultados não realistas para objetos próximos, porém o cálculo de muitas forças utilizadas para animar objetos distantes comprometia o desempenho do sistema. Percebemos então a necessidade de uma otimização 
desta idéia para torná-la válida. Utilizando o conceito de Nível de detalhes, o algoritmo foi otimizado como descrevemos nas próximas subseções.

\subsubsection{Técnica de Quadtree}

O objetivo da otimização é animar os objetos mais próximos ao observador utilizando um maior número de vetores de força, e poupar recursos computacionais ao se utilizar menos vetores para representar uma área maior composta por objetos distantes do observador ou com pouca variação e atividade de forças.

A idéia de níveis de detalhes é bastante aplicável neste problema, pois o movimento de plantas próximas deve ser simulado com mais detalhes, enquanto o de plantas distantes pode ser aproximado e simulado com menor exatidão. Isto porque apesar das plantas também estarem se movimentando, a percepção deste movimento é menor devido à distância.

Para criar uma malha de forças não uniforme e que seja de fácil alteração, escolhemos utilizar uma estrutura de dados bastante popular e conhecida na Computação Gráfica, a técnica de Quadtrees. As quadtrees são basicamente árvores onde as células que não são folhas têm sempre quatro filhos. As células podem definir regiões, de modo que os filhos de uma célula devem, juntos, definir a mesma região definida pela célula pai.

A figura 3.10 mostra uma parte da quadtree que define o campo de forças onde planos são utilizados para separar os volumes. Regiões com maior quantidade de células (volumes) representam locais com maior concentração de objetos, onde é necessária maior precisão.

Os objetos que inicialmente recebem a ação das forças devem ser definidos. O campo de forças inicial deve ser pré-calculado, pois sua criação em tempo de execução afetaria o desempenho do sistema, por ser um processo relativamente caro computacionalmente. No entanto, novos objetos podem ser adicionados ao campo em tempo de execução, para isto, basta utilizar o algoritmo addObj $2 Q T$, descrito logo abaixo.

Algoritmo "createQT" (CQT) - Cria a Quadtree que define o Campo de forças. A árvore começa com apenas uma célula. Células filhas são criadas quando objetos são inseridos. Dado um volume mínimo, MINVOL que define o tamanho da menor célula que a quadtree pode ter.

CQT1. [Volume mínimo] Defina o valor de MINVOL.

CQT2. [Adicione todos os nós] Adicione todos objetos iniciais a árvore. Chame addObj2QT para cada objeto. 
Algoritmo "addObj2QT" (QT) - Adiciona um objeto à Quadtree, cria novas regiões caso seja necessário e possível. Localiza a célula que o novo objeto deve pertencer na quadtree. Caso a célula já tenha um objeto associado e não seja do tamanho MINVOL, o algoritmo cria as quatro células filhas desta e adiciona os objetos nas células que definem o local onde cada objeto se encontra. Seja SIZE (N) a função que determina o tamanho de uma célula $\mathrm{N}$ da quadtree. Seja OBJ um novo objeto a ser adicionado a quadtree. Faça:

QT1. [Localize o nó onde o objeto deveria estar.] Localize a célula, folha da árvore atual, em que o objeto deveria estar, dada a posição do objeto. Seja NODE um ponteiro que define a célula que o objeto OBJ se encontra em cada passo do algoritmo. Faça NODE apontar para célula localizada e vá para $Q T 2$.

QT2. [Verifique se já existe um objeto associado] Caso a célula NODE tenha um objeto associado, digamos OBJ2, defina um novo ponteiro NODE2 para a célula que OBJ2 pertence e vá para QT3. Caso contrário o algoritmo termina.

QT3. [Verifique os nós em que os objetos OBJ e OBJ2 estão] Se NODE $\neq$ NODE2 ou SIZE (NODE) $=$ MINVOL, o algoritmo termina. Caso contrário, vá para QT4

QT4. [Crie os filhos de NODE] Crie quatro novas células, cada uma com 1/4 do volume de NODE e que juntas definem a célula NODE, conforme a definição de quadtree.

QT5. [Associe os objetos às novas células] Atribua à NODE e NODE2 os ponteiros para as novas células, dentre as quatro filhas, onde os objetos $\mathrm{OBJ}$ e $\mathrm{OBJ} 2$ deve estar, respectivamente. Volte ao passo QT3.

Aplicando este algoritmo pode haver mais que um objeto no menor nível da árvore, dependendo do menor volume definido. Estes objetos irão receber a ação da mesma força, definida no campo. $\mathrm{O}$ problema de se utilizar muitas regiões do campo em locais sem nenhum objeto também é reduzido por este algoritmo. Apenas locais com grande concentração de objetos recebem a ação de um maior número de forças.

Muitas propriedades do algoritmo podem ser alteradas para melhorar o desempenho. Por exemplo, aumentar o número de objetos que define quando o algoritmo deve repartir uma célula, ou definir um valor maior para MINVOL. Objetos podem ser adicionados em tempo de execução sem perdas utilizando o algoritmo addObj2QT. No entanto, caso muitos objetos sejam adicionados em um curto período, o desempenho do sistema pode ser afetado. 


\subsubsection{Nível de detalhes por distância e células visíveis.}

Utilizando quadtrees conseguimos separar regiões com maior número de objetos e utilizar um número maior de forças para animação dessas áreas. Porém, encontramos áreas com muitos vetores de forças sendo calculados, mesmo onde essas áreas estão fora do campo de visão do observador. Para melhorar o desempenho e reduzir o gasto de recursos computacionais, cálculos desnecessários para simulação devem ser poupados.

Para uma maior otimização do processo da geração do campo de forças foi desenvolvido um algoritmo que, além de eliminar o cálculo de forças fora do campo de visão, aproveita a estrutura de quadtrees para gerar uma representação menos detalhada em áreas distantes ao observador.

Objetos em regiões mais distantes do observador podem ser animados utilizando menos vetores de força. O processo de estimativa da força aplicada por uma ou várias fontes sobre uma região pode ser bastante caro. Isto afetaria a atualização das forças, caso muitas regiões de atualização sejam necessárias, comprometendo a eficiência do sistema.

Aproveitando a estrutura de quadtree já criada, podemos aproximar a ação sobre uma região utilizando o pai das células onde os objetos estão definidos. A célula pai representa a mesma região das quatro células filhas, logo estimando uma força para esta área evita três estimativas semelhantes para sub regiões menores. A economia de cálculos utilizando esta idéia é da ordem de $4^{h}$, onde $h$ é a diferença de altura da célula pai para suas filhas. Descrevemos o algoritmo abaixo.

Algoritmo "visibleDistanceLOD" (LD) - Determina o Nível de detalhe por distância e células visíveis. Define as células da quadtree que representam o nível de detalhe da árvore para uma certa posição do usuário. Os vetores de força devem ser calculados apenas para as células definidas neste algoritmo. Seja LODBOUNDARY um vetor definindo o intervalo de distâncias que deve ser considerado para os detalhes de representação. Por exemplo, as células com distância em relação ao observador dentro do primeiro intervalo definido por LODBOUNDARY devem ser representados pelas folhas da quadtree. Células com distâncias definidas pelo segundo intervalo podem ser representadas pelas células pais das folhas, e assim por diante. Definimos também um ponteiro, UPNODE, para cada nó para células que representam o nível de detalhe atual.

LD1. [Atualize a posição do usuário] Armazene a posição e a direção do campo de visão do usuário.

LD2. [Inicio] Inicie o algoritmo da célula raiz da quadtree.

LD3. [Selecione as células visíveis] Utilizando as informações do usuário verifique quais células estão dentro do campo de visão. Se a célula não é visível atribua UPNODE $\leftarrow \emptyset$. Caso a célula esteja no 
campo de visão vá para $L D 4$.

LD4. [Verifique a distância da célula ao observador] Calcule a distância do centro da célula ao observador. Defina o nível de detalhes para esta distância, verificando o intervalo de distância em LODBOUNDARY que a célula se encontra. Caso o número de níveis na árvore até as folhas seja menor ou igual ao definido pelo índice no vetor vá para $L D 6$. Caso contrário, vá para $L D 5$.

LD5. [Execute o algoritmo recursivamente nos filhos] Atribua UPNODE para a própria célula. Para cada um dos quatro filhos da célula execute o passo $L D 3$.

LD6. [Atribua o nível de detalhes a todas células filhas] Atribua UPNODE para a própria célula. Atribua UPNODE de todos os filhos para esta célula.

A figura 3.10 mostra o nível de detalhes pintado em diferentes níveis de cinza para células próximas ao observador. Cada nível de cinza definido na legenda representa um nível na árvore. Os tons mais claros representam volumes menores, enquanto os mais escuros representam volumes maiores. Podemos observar que algumas regiões com muitos objetos longe do observador são representados pelos pais. Regiões fora do campo de visão são representadas por células mais próximas à raiz, seus vetores podem não ser calculados.

O problema de definição de quais células são visíveis é o que define a eficiência do algoritmo. Caso um algoritmo ineficiente fosse utilizado, a comparação de uma grande quantidade de células da quadtree seria muito cara se comparada à melhoria em eficiência que a técnica de níveis de detalhes proporciona.

Para solucionar o problema de forma eficiente, é necessária a implementação de um algoritmo de verificação de células visíveis extremamente simples e rápido, pois o mesmo será executado várias vezes para diversas células da quadtree. A estrutura de quadtree, onde as células são definidas por retângulos, simplifica esta verificação.

Implementamos um algoritmo que faz a projeção do campo de visão sobre a quadtree. Esta projeção pode definir um polígono de até cinco lados, como é discutido no algoritmo viewProjBoundingBox. Utilizando os pontos definidos pela projeção definimos uma "bounding box" retangular que define o campo de visão projetado na quadtree.

Este algoritmo de projeção tem grande complexidade. Porém, uma vez definida esta projeção, é bastante simples e eficiente se determinar quais células da quadtree se encontram no campo de visão do observador, já que se trata apenas da verificação da intersecção de retângulos com lados paralelos aos eixos $\mathrm{X}$ e $\mathrm{Z}$, como foi definida a quadtree.

A "bounding box" contém regiões não visíveis, pois se trata de uma aproximação que contém toda a projeção. O cálculo das forças nessas regiões poderia ser considerado desnecessário. Porém, este pro- 

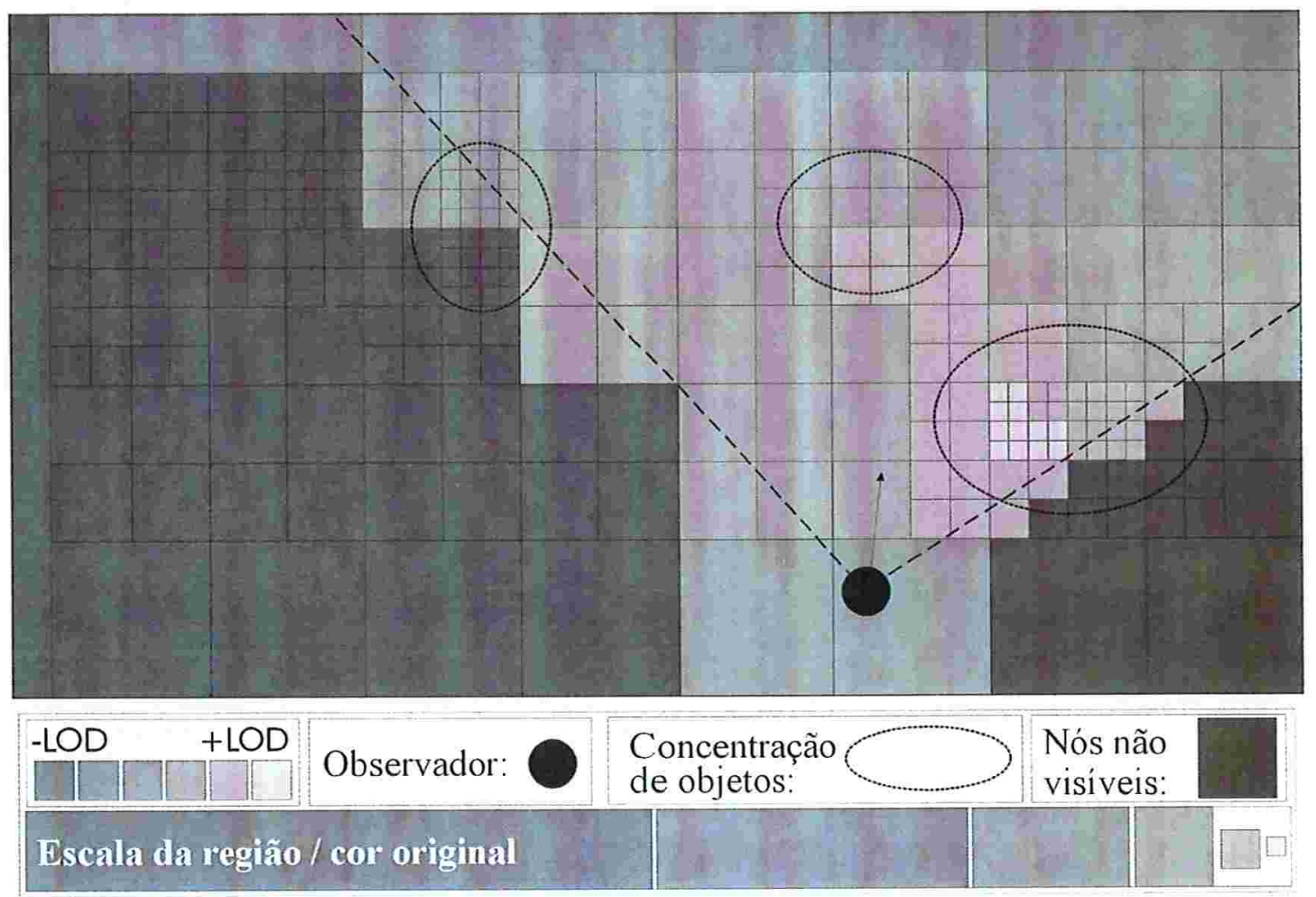

Figura 3.10: Os volumes em destaque definem o melhor nível de detalhe que pode ser utilizado para forças, sua definição depende do número de objetos na região representada. Os tons de cinza definem o nível de detalhe em que os vetores serão calculados. Obs: A legenda mais abaixo indica a cor original de cada volume. No caso em que volumes pequenos que deveriam estar com cores mais claras estarem representados por níveis mais escuros indica que o nível acima é utilizado (no caso a célula pai da quadtree) para economizar cálculos como foi descrito no algoritmo "visibleDistanceLOD".

cedimento evita que a animação seja comprometida em mudanças bruscas de direção da visualização do observador. Além disso, a animação fica mais fluente pois os objetos aparentam estar sendo movimentados anteriormente pela ação de uma força já calculada.

Algoritmo "viewProjBoundingBox" (BB) - Determina a "Bounding box" sobre a quadtree. Seja PROJSIZE o raio máximo da projeção do campo de visão sobre a quadtree no ponto onde há intersecção do vetor de direção de visualização do observador com a quadtree. Seja o vetor normal, $\vec{N}=$ $(0,1,0)$, lembrando-se que o eixo y determina o eixo vertical da cena neste sistema. Seja $\overrightarrow{V_{\text {view }}}$ o vetor de direção de visão do observador. Seja $O$ o ponto que determina a posição do olho do observador. Seja $P_{i}$ o ponto onde a direção de visão intersecta a quadtree. Assumindo ainda que o observador esteja acima da quadtree, o algoritmo abaixo determina a "bounding box" da projeção do campo de visão sobre a 
quadtree.

BB1. [Atualize a posição do usuário] Armazene $O$ e $\overrightarrow{V_{\text {view }}}$ atuais.

BB2. [Trate os dois casos possíveis de $\overrightarrow{V_{\text {view }}}$ ] Verifique se o vetor $\overrightarrow{V_{\text {view }}}$ intersecta a quadtree. Caso haja interseç̧ão prossiga para $B B 3$, caso contrário vá $B B 8$.

BB3. [Caso $\overrightarrow{V_{\text {view }}}$ intersectar a Quadtree] Seja $P_{i}$ o ponto de intersecção de $\overrightarrow{V_{\text {view }}}$ com a quadtree. Seja ainda PROJSIZE o valor do diâmetro máximo que a projeção pode ter em $P_{i}$, definido utilizando a ângulo de visão do observador e a distância de $P_{i}$ à janela que a imagem é projetada. Determine os pontos que definem a área de projeção do campo de visão seguindo ao passo $B B 4$.

BB4. [Determine os pontos laterais na quadtree] Calcule o vetor, $\overrightarrow{V_{L A T}}$, perpendicular ao vetor $\overrightarrow{V_{\text {view }}} \mathrm{e}$ ao vetor $\vec{N}$, atribuindo ao seu comprimento o valor PROJSIZE. Os pontos laterais, $P_{1}$ e $P_{2}$, são determinados somando este vetor e seu oposto a $P_{i}$.

BB5. [Determine o ponto de projeção mais próximo ao observador] Calcule o vetor $\overrightarrow{V_{v e r}}$ perpendicular ao vetor $\overrightarrow{V_{L A T}}$ e ao vetor $\overrightarrow{V_{\text {view }}} \cdot \overrightarrow{V_{\text {ver }}}$ é tal que este se encontra abaixo da quadtree. Atribua ao seu comprimento o valor PROJSIZE. Somando-se $P_{i}$ ao vetor $\overrightarrow{V_{v e r}}$ determinamos um ponto abaixo da quadtree que determina o ponto, $P_{b}$, mais abaixo do campo de visão. O vetor $\overrightarrow{O P}$ intersecta a quadtree no ponto $P_{3}$, que é a projeção na quadtree do ponto mais abaixo do campo de visão.

BB6. [Tente determinar o ponto mais distante do observador] O vetor oposto a $\overrightarrow{V_{v e r}}$ somado a $P_{i}$ determina o ponto, $P_{u}$, mais acima do campo de visão. O vetor $O \vec{P}_{u}$ intersecta o plano da quadtree em um ponto $P_{4}$. Porém se este ponto estiver atrás do observador considere $P_{4} \leftarrow \emptyset$.

BB7. [Chame o algoritmo que define a "Bounding box"] Passe os pontos $P_{1}, P_{2}, P_{3}$ e $P_{4}$, se este último existir, para $B B 12$

BB8. [Caso $\overrightarrow{V_{\text {view }}}$ não intersectar a quadtree] Determine o ponto de intersecção, $P_{i}{ }^{\prime}$, com um dos planos perpendiculares às bordas da quadtree. De modo semelhante ao que foi descrito no item $B B 3$ determine PROJSIZE.

BB9. [Determine o ponto de projeção mais próximo ao observador] Calcule o vetor $\overrightarrow{V_{L A T}}$ ' perpendicular ao vetor $\overrightarrow{V_{\text {view }}}$ e à normal em relação ao plano de intersecção. Determine então o vetor $\overrightarrow{V_{\text {ver }}}$ ' perpendicular a $\overrightarrow{V_{\text {view }}}$ e $\overrightarrow{V_{L A T}}$ '. O vetor $\overrightarrow{V_{\text {ver }}}$ ' em direção a quadtree somado ao ponto $P_{i}{ }^{\prime}$ determina um ponto, $P_{b}^{\prime}$, mais abaixo do campo de visão. Caso o vetor $\overrightarrow{O P}_{b}^{\prime}$ intersecte a quadtree, determinamos o ponto de interseç̧ão e o atribuímos a $P_{1}$, caso contrário o observador não vê a quadtree e o algoritmo termina. 
BB10. [Determine os pontos laterais na quadtree] O vetor $\overrightarrow{V_{L A T}}$ ' e seu oposto somados a $P_{i}{ }^{\prime}$ determinam dois pontos laterais de campo de visão máximo sobre o plano perpendicular. Para facilitar os cálculos basta simplesmente projetar estes na quadtree determinando $P_{2}$ e $P_{3}$.

BB11. [Chamada do algoritmo de definição da "Bounding box"] Passe os pontos $P_{1}, P_{2}, P_{3}$ para $B B 12$.

BB12. [Definição da "Bounding box" dados os pontos de controle] Dados os pontos basta verificar os maiores e menores valores de $\mathrm{x}$ e $\mathrm{z}$ dentro das fronteiras definidas pela quadtree. Lembrando aqui que a quadtree foi definida com células com bordas paralelas aos eixos $\mathrm{X} \mathrm{e} \mathrm{Z}$.

\subsubsection{Resultados obtidos e discussão}

A técnica apresentada nesta seção permite a interação eficiente de diversos objetos por ação de diferentes agentes, baseada em um modelo de regiões de ação. Esta técnica é utilizada com sucesso, nesta dissertação, para simulação de fenômenos naturais como por exemplo plantas e o vento.

O algoritmo que aproxima a projeção do campo de visão por uma "bounding box" pode selecionar uma célula grande como visível, mesmo que haja apenas uma mínima intersecção entre as "bounding boxes". Entretanto, isto não é um problema grave visto que caso a célula seja grande poucos objetos são animados dentro desta região, conforme a definição da geração da quadtree.

Calculadas as regiões de ação das forças os elementos que interagem com o sistema, as forças que agem em cada região do campo de forças devem ser definidas. Diversos agentes podem ser implementados, um exemplo implementado é o componente que simula o vento e age sobre o campo de forças, descrito na seção 3.7.1.

Se uma região sofre o efeito de mais de uma força, é aplicado o princípio de superposição de Euler. Este princípio permite a combinação das forças aplicadas no centro de massa de um corpo em uma força resultante equivalente.

$$
\vec{F}=\sum_{\text {forces } i} \vec{F}_{i}
$$

\subsection{Animação de plantas}

A animação das plantas será gerada utilizando modelos físicos de modo a se obter resultados realistas. Na técnica desenvolvida, as plantas se movem devido à ação de uma força externa, definida pelo campo de forças. 
De tempos em tempos, as forças externas aplicadas sobre as plantas são verificadas para se determinar a alteração da posição dos componentes das plantas. O movimento entre dois estados dos componentes determina a animação.

Para animação suave das plantas iremos utilizar a técnica de Controles Dinâmicos, descrita na seção 2.3.2. Forças de controles (restrição) podem animar modelos, movendo seus componentes para uma configuração desejada. Utilizamos esta característica para definirmos uma técnica de animação baseada em Física que é capaz de movimentar componentes com diferentes acelerações, o que gera resultados realistas.

Como as plantas estão fixadas no solo, e portanto não podem girar livremente sobre sua própria base, não precisamos nos preocupar com velocidades e acelerações angulares, nem com Torque e Momento Angular neste estudo. Esta simplificação faz com que diversos cálculos sejam poupados.

O algoritmo responsável pela geração de uma animação realista para as plantas será descrito na subseção 3.5.2, na próxima subseção descrevemos como calcular a posição inicial e final para os componentes, dado um certo intervalo de tempo e a força que está sendo aplicada.

\subsubsection{Utilização dos modelos físicos pré-computados}

A cada passo de animação os componentes, que se encontram em células visíveis do campo de forças, devem verificar a força externa que está sendo aplicada pelo campo na região em que eles se encontram. Esta força pode alterar a posição do componente.

Uma nova força elástica é definida na animação. Enquanto na modelagem das plantas uma força elástica foi definida para criar uma resistência à curvatura dos componentes pela ação da força da gravidade, a força elástica da animação se opõe a mudança da posição de repouso (posição em que foi definido inicialmente) dos componentes. Outra diferença importante, entre estas forças, é que esta força move o componente todo de uma só vez, isto é, consideramos o componente um corpo rígido para simplificação dos cálculos envolvidos na animação.

A força elástica da animação existe apenas quando uma força externa altera a posição inicial do componente. A intensidade desta força aumenta à medida que a distância entre o centro de massa do componente na posição de repouso e atual cresce. A Figura 3.11 ilustra o comportamento da força de animação.

Quando a força elástica se torna maior que a força externa, o componente tende a voltar à sua posição original, de repouso. Todas as posições que os componentes podem assumir já foram pré-computadas na fase de modelagem, isto torna a animação eficiente, mesmo em cenas com muitas instâncias de plantas. 


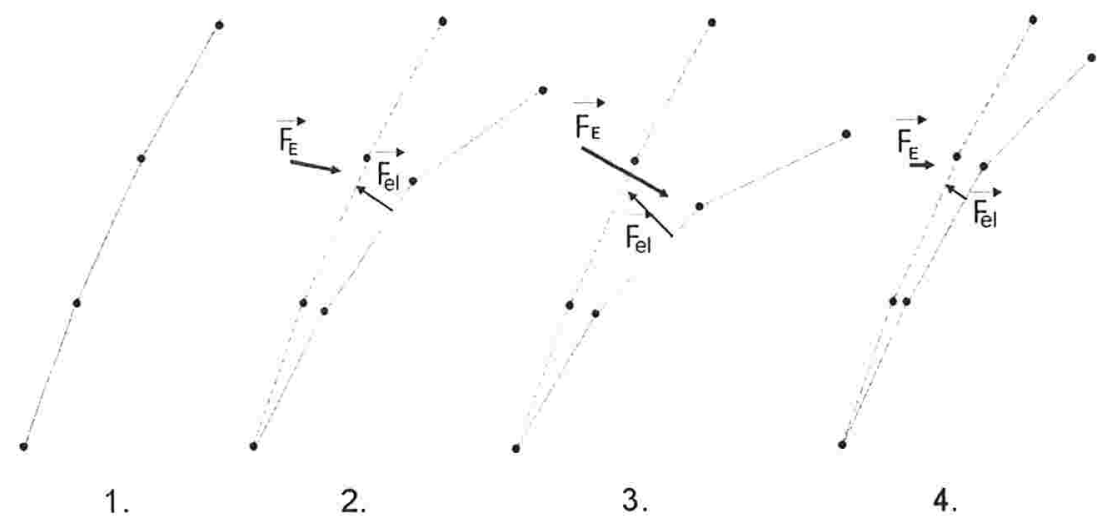

Figura 3.11: (a) O componente em sua posição de repouso. (b) $\mathrm{O}$ componente recebe ação de uma força externa $F_{E}$, a força elástica $F_{e l}$ tenta restaurar a posição inicial do componente. (c) A intensidade de $F_{E}$ aumenta e um novo ponto de equilíbrio é estabelecido. (d) A intensidade de $F_{E}$ diminui e a força elástica tenta fazer com que o componente retorne ao seu estado inicial.

\subsubsection{Animação realista utilizando controles dinâmicos}

Nesta seção descrevemos uma aproximação do modelo de Controles Dinâmicos, desenvolvido por Barzel e Barr [BB88], para animação realista de plantas. Para utilizar este modelo em tempo real, algumas simplificações foram consideradas, como veremos a seguir.

No modelo de Controles Dinâmicos, o cálculo de uma força de controle ("constraint force") simples é definida pela equação 3.5 .

$$
\sum_{\text {constraints } j}\left(\sum_{\text {bodies } i}\left(\Gamma^{i} G_{j}^{i}+\Lambda^{i} H_{j}^{i}\right) \vec{F}_{e_{j}}\right)+\sum_{\text {bodies } i}\left(\Gamma^{i} \vec{F}_{E}^{i}+\Lambda^{i} \vec{T}_{E}^{i}\right)+\vec{\beta}+\frac{2}{\tau} \vec{D}^{(1)}+\frac{1}{\tau^{2}} \vec{D}=0
$$

Como pode ser visto, trata-se de uma equação bastante complexa. A primeira somatória refere-se a todas as forças de controles atuantes, e a segunda somatória às forças externas. Os atributos $T, H$ e $\Lambda$ estão relacionadas ao Torque no corpo e como, na animação das plantas, consideramos que os componentes não podem girar sobre seus próprios eixos, estas variáveis são nulas em nosso sistema.

Como utilizamos o centro de massa dos componentes na animação, o modelo utilizado neste trabalho é bastante similar ao exemplo "Point - to - Nail" do artigo de Barzel e Barr. Este exemplo ilustra um corpo sobre efeito da gravidade sem rotação sobre seu eixo. $\tau$ é uma constante relacionada ao tempo necessário para a restrição ser satisfeita.

As outras variáveis da equação 3.5 são definidas por Barzel e Barr como:

$\vec{D}$ - a distância do corpo ao ponto de controle ("constraint point") que deve ser alcançado; 
$\vec{D}^{(1)}$ - a taxa de mudança de $\vec{D}$;

$\vec{D}^{(2)}$ - a aceleração de $\vec{D}$, é definida pela equação 3.6 .

$$
\vec{D}^{(2)}=\sum_{\text {bodies } i}\left(\Gamma^{i}(y) \vec{F}^{i}+\Lambda^{i}(y) \vec{T}^{i}\right)+\vec{\beta}(y)
$$

Seja $\vec{X}$ a posição do centro de massa após a restrição ser satisfeita, $\vec{X}_{0}$ a posição inicial do centro de massa, $\vec{v}$ a velocidade que o objeto se movimenta, $\vec{F}$ a força necessária para que o movimento seja realizado e $m$ a massa do objeto. O desvio $\vec{D}$, a velocidade $\vec{D}^{(1)}$ e a aceleração $\vec{D}^{(2)}$ são dadas pelas equações abaixo:

$$
\begin{aligned}
& \vec{D}=\vec{X}-\vec{X}_{0} \\
& \vec{D}^{(1)}=\vec{v} \\
& \vec{D}^{(2)}=\vec{F} / m
\end{aligned}
$$

Ainda definimos que existe apenas uma força de controle, $\vec{F}_{c}$, e uma força externa, $\vec{F}_{E}$, definida pelo campo de forças, agindo no sistema. Utilizando estas informações reescrevemos a equação 3.5 de modo mais simplificado:

$$
\Gamma \vec{F}_{c}+\Gamma \vec{F}_{E}+\vec{\beta}+\frac{2}{\tau} \vec{v}+\frac{1}{\tau^{2}}\left(\vec{X}-\vec{X}_{0}\right)=0
$$

De 3.6 e 3.7 temos que $\beta=0$ e $\Gamma=1 / \mathrm{m}$. Isto nos dá a força de controle necessária para levar o corpo da posição $\vec{X}$ para $\vec{X}_{0}$.

$$
\vec{F}_{c}=-\vec{F}_{E}-\frac{2}{\tau} m \vec{v}-\frac{1}{\tau^{2}} m\left(\vec{X}-\vec{X}_{0}\right)
$$

Como o modelo de controles calcula a força necessária para levar o corpo a um ponto de controle definido. A força de controle pode ser decomposta em três componentes: um que se opõe à força externa, um que se opõe à velocidade do corpo e outro que atrai o corpo para o ponto de controle.

Em nossa aproximação utilizamos o mesmo modelo descrito. No entanto, ao invés de calcular a força de controle, definimos uma força de controle para obter a posição do objeto quando as forças atingirem o equilíbrio. A força de controle é função de uma propriedade do componente, PC, definida 
pelo usuário do sistema. Definimos a força de controle pela fórmula simples, de natureza elástica, dada pela equação 3.9 .

$$
\vec{F}_{c}=\operatorname{PC}\left(\vec{X}-\vec{X}_{0}\right)
$$

O problema da animação é simplificado em apenas determinar a posição $\vec{X}$ do centro de massa do componente da planta. Para isso, são dadas a posição inicial do centro de massa $\left(\vec{X}_{0}\right)$, a força de externa agindo sobre o componente $\left(\vec{F}_{E}\right)$, a força de controle $\left(\vec{F}_{c}\right)$, a velocidade anterior de movimento do componente $(\vec{v})$ e um intervalo de tempo decorrido desde a última mudança de posição $(\tau)$.

De 3.8 e 3.9 temos que:

$$
\begin{aligned}
& \mathrm{PC}\left(\vec{X}-\vec{X}_{0}\right)=-\vec{F}_{E}-\frac{2}{\tau} m \vec{v}-\frac{1}{\tau^{2}} m\left(\vec{X}-\vec{X}_{0}\right) \\
& \left(\mathrm{PC}+\frac{1}{\tau^{2}} m\right)\left(\vec{X}-\vec{X}_{0}\right)=-\vec{F}_{E}-\frac{2}{\tau} m \vec{v}
\end{aligned}
$$

Seja: $\mu=\mathrm{PC}+\frac{1}{\tau^{2}} m$

$$
\vec{X}-\vec{X}_{0}=-\frac{1}{\mu} \vec{F}_{E}-\frac{2 m}{\tau \mu} \vec{v}
$$

A equação 3.10 descreve a variação da posição do centro de massa do componente em função do tempo, da força externa aplicada e da velocidade de movimentação atual. Esta equação pode ser utilizada para determinar a posição do componente dadas as configurações anteriores de velocidade e a força externa agindo sobre o corpo. Cálculos envolvendo constantes relacionadas ao componente podem ser feitos uma única vez, de modo a otimizar o tempo de animação.

Em um dado intervalo de simulação podemos entender a equação 3.10 da seguinte forma: "Se o componente não está em sua posição inicial, isto é devido à ação de uma força externa e/ou a um movimento anterior cuja velocidade causou o deslocamento de sua posição de repouso".

A força externa definida pelo campo de forças pode se alterar durante a animação. A força de controle também se altera, visto que o centro de massa do componente está se movendo. $\mathrm{O}$ algoritmo descrito na próxima seção descreve como se obter a posição do centro de massa do componente dada equação 3.10 e as pré-computações definidas na fase de modelagem.

Calculamos desta forma os efeitos da força de controle para subintervalos de $\tau$, e a posição que o componente estará em cada intervalo de tempo. Isto gera uma animação mais realista pois o componente irá se mover com diferentes velocidades e acelerações como em cenas reais. 


\subsubsection{Algoritmo de animação por aproximação baseado na técnica de controles dinâmicos}

A equação 3.10 permite a atualização da posição de um componente de planta, com animação realista. No entanto, mesmo sendo uma equação relativamente simples, por se tratar de uma equação baseada em Física, se a aplicarmos para um grande número de componentes, comprometemos o desempenho do sistema. Devemos lembrar que só para a renderização e alteração de posição dos inúmeros polígonos que representam os componentes há uma grande utilização de memória e tempo de processamento.

Conforme definido na seção anterior, o campo de forças é responsável pela definição das forças externas que são aplicadas nos componentes do sistema. Para atingirmos o objetivo de animação em tempo real, devemos fazer uma aproximação na técnica de animação utilizando controles dinâmicos.

O algoritmo abaixo descreve como atualizar a posição de um componente de planta utilizando a técnica de controles dinâmicos, as definições de campo de forças e pré-computações.

\section{Passo 1: Simulação por tipo de planta e célula do campo de forças}

A animação no sistema é realizada em dois processos concorrentes. Um dos processos obtém as informações do campo de forças e determina a posição atual de cada componente que teve sua posição alterada, em cada célula visível do campo. O outro processo se encarrega de animar os modelos, isto é alterar a geometria dos objetos na cena, dados as posições determinadas pelo processo anterior.

Em cada célula da quadtree podem estar definidos diversos componentes de plantas diferentes, cada um com propriedades que alteram os valores retornados pela equação 3.10. Para cada componente devemos calcular a variação determinada pela equação 3.10 , de acordo com a sua posição em relação à força externa.

Para evitarmos cálculos repetidos implementamos um sistema de "cache". A equação 3.10 utiliza dois valores que dependem única e exclusivamente de dados do componente e não se alteram durante o intervalo de tempo de simulação. Os valores $\mu \mathrm{e} \frac{2 m}{\tau \mu}$, associados à força externa e à velocidade de movimentação na simulação anterior, podem ser calculados apenas uma vez por passo de simulação para componentes semelhantes. Por exemplo, ao se considerar um campo de gramas, composto por 4000 folhas de propriedades físicas semelhantes, este cálculo pode ser poupado 3999 vezes com o "cache". Portanto o ganho em desempenho é evidente.

A força externa e a velocidade anterior de movimento não podem ser adicionadas aos valores em "cache" pois dependem de cada componente. Para facilitar os cálculos em tempo de execução projetamos o vetor da força externa no eixo perpendicular à superfície do componente e que passa sobre o 
centro de massa do mesmo. Consideramos que a velocidade é sempre aplicada sobre este eixo. Deste modo para determinar a variação de posição sobre este eixo basta fazer três operações: multiplicar a norma da força externa pelo valor $\frac{1}{\mu}$ e somar com o produto da norma da velocidade com o valor $\frac{2 m}{\tau \mu}$ em cache.

O algoritmo abaixo descreve este processo de simulação de cada tipo de componente das plantas. Na próxima subseção, descrevemos o processo de alteração da geometria.

Algoritmo "simulatePlants" (SP) - Executa a simulação dos componentes de planta com informações do campo de forças. Seja LANIM a lista dos componentes que serão animados. Para todos componentes faça:

SP1. [Verifique se os componentes estão visíveis] Caso o componente esteja numa célula visível do campo de forças, vá para SP2. Caso contrário, selecione o próximo componente.

SP2. [Calcule a ação da força externa nos elementos que dividem o intervalo] Para isto basta projetar a força externa sobre o eixo perpendicular à superfície do componente e que passa sobre o centro de massa do mesmo. Siga para o passo SP3.

SP3. [Calcule a variação de posição do componente] Calcule o deslocamento D do componente no intervalo de tempo definido utilizando a equação 3.10 e os valores em "cache" de $\mu$ e $2 m / \tau \mu$. Siga para o passo SP4.

SP4. [Defina o ângulo de deslocamento em relação à posição de repouso] Para determinar o novo ângulo que o componente se encontra de modo eficiente, estimamos a distância (DCOM) dos centros de massa para dois modelos pré-computados adjacentes do componente. A diferença do índice do modelo pré-computado que será utilizado para representar o componente após a iteração é definida pela equação: D / DCOM. Siga para o passo SP5.

SP5. [Estime a velocidade atual nos intervalos] Basta dividir D pelo intervalo de tempo definido. Siga para o passo SP6.

SP6. [Adicione o objeto à lista LANIM] Se houve alteração no ângulo de deslocamento adicione o objeto a LANIM. Selecione o próximo componente e volte ao passo SP1.

\section{Passo 2: Animação dos componentes que foram alterados}

Dada a lista LANIM definida pelo algoritmo anterior e a variação de ângulo de curvatura para cada componente que será animado. A animação é executada, de modo eficiente e realista para cada componente, utilizando os vetores definidos na fase de pré-computação. 
Algoritmo "animPlants" (AP) - Executa a animação dos componentes de planta com informações do campo de forças. Para cada componente em LANIM faça:

AP1. [Utilize a pré-computação] Dado o índice pré-computado que o componente deve utilizar, obtenha os vetores que definem o modelo.

AP2. [Utilize o nível de detalhe da modelagem] Como foi descrito na seção 3.3.3, o modelo pode utilizar apenas algumas coordenadas. Apenas estas devem ser animadas, isto é, terem suas posições atualizadas.

\subsubsection{Resultados obtidos e discussão}

As Figuras 3.12 e 3.13, apresentadas em [EMF03], mostram sequências de animações geradas pelo sistema para diferentes tipos de vegetação.

A animação apresenta um bom desempenho dado o grau de realismo obtido. Um dos problemas é que a animação é realizada por componente de planta, o que pode ser custoso, apesar das précomputações, dependendo da planta modelada e do número de componentes visíveis.

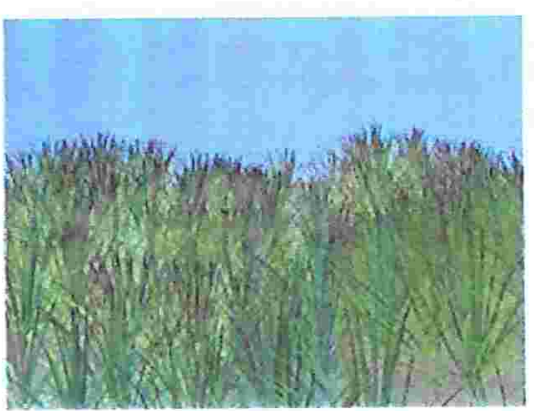

a.

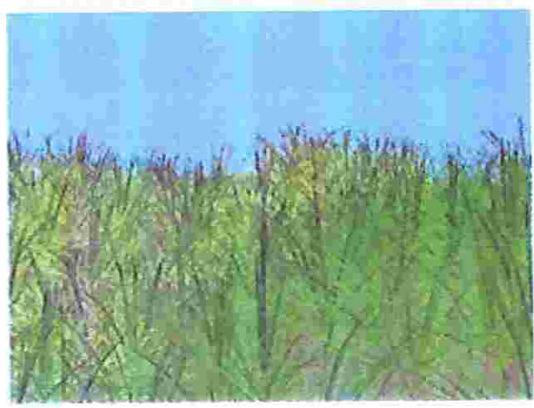

b.

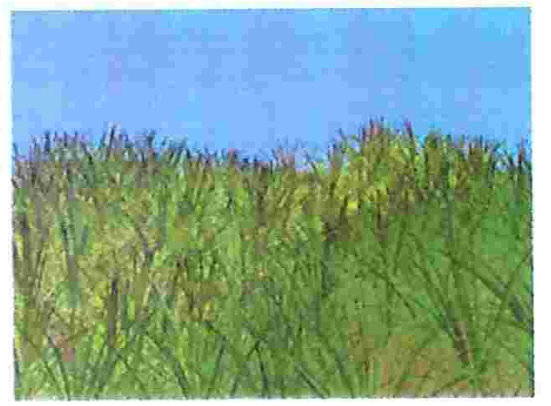

c.

Figura 3.12: Animação de um campo de grama. As folhas se curvam quando o vento passa sobre o terreno.

\subsection{Distribuição de plantas}

Foi criado um algoritmo simples para geração da distribuição das plantas sobre o terreno. Este algoritmo utiliza a irrigação e a fertilidade do solo (quantidade de nutrientes) como atributos para determinar a posição das plantas na cena. 


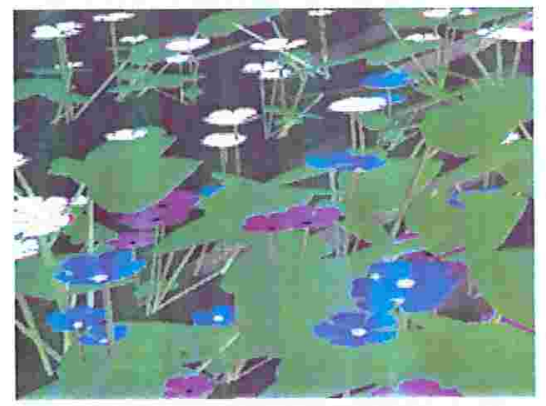

a.

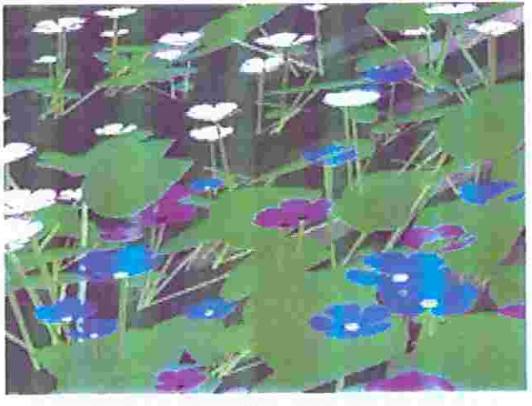

b.

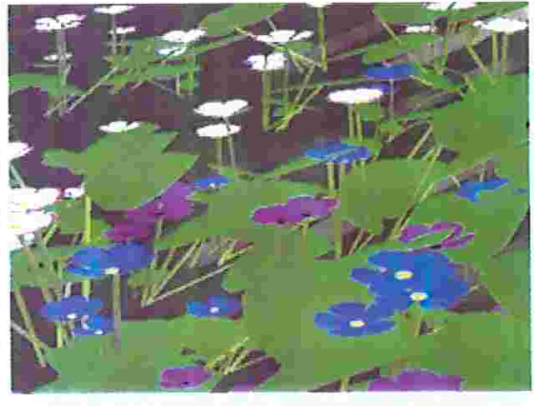

c.

Figura 3.13: Campo de flores animadas em tempo real pela ação do vento.

Esses atributos devem ser definidos no terreno, como foi citado na seção 3.2. As espécies de plantas também devem ter informações sobre suas necessidades de água e nutrientes. Na próxima subseção, descrevemos o algoritmo desenvolvido. Na subseção 3.6.2, mostramos alguns resultados obtidos utilizando diferentes parâmetros definidos, além de uma discussão sobre o algoritmo.

\subsubsection{Descrição da solução}

O algoritmo depende diretamente das informações definidas para os nutrientes e irrigação. Todas as espécies de planta do sistema devem ter configurados valores mínimos e o máximos de irrigação e nutrientes necessários para sua sobrevivência. A disposição desses parâmetros no terreno também deve ser configurada.

A idéia do algoritmo é verificar se é possível expandir a distribuição, dados uma posição inicial de propagação e os atributos do terreno. Também deve ser definida uma distância máxima em que novas plantas podem ser criadas a partir de outra planta da mesma distribuição. Caso as condições sejam favoráveis, a distribuição pode criar o número de plantas definido, caso contrário, pode ser criada uma quantidade de plantas menor que a esperada.

$\mathrm{O}$ algoritmo adiciona plantas para diferentes distribuições de modo concorrente. Isto pode gerar a seguinte situação: uma distribuição $A$ começa a ocupar a região que uma outra distribuição $B$ poderia estar ocupando, retirando nutrientes ou água necessária para o desenvolvimento de $B$, o que inibe a propagação de $B$ sobre a porção de terreno que $A$ está ocupando. Por outro lado, é possível que aconteça o contrário, ou seja, que uma certa distribuição retire o excesso de nutrientes ou água de uma porção de terreno, permitindo assim, que outra distribuição ocupe a mesma região.

Os parâmetros do terreno, das plantas e da distribuição são essenciais para a determinação da disposição das plantas na cena. O algoritmo é descrito abaixo. 
Algoritmo "plantDistrib" (PD) - Determina a distribuição das plantas pela cena. Sejam N o número de distribuições de plantas diferentes e DISTRIB uma lista de distribuições, onde DISTRIB $(i)$ é a i-ésima distribuição. Seja TOTAL o número de instâncias já criadas para cada distribuição, MAX$\operatorname{PLANT}(i)$ o máximo número de plantas a ser criadas para a i-ésima distribuição e MAXEXPAND a distância máxima de propagação, isto é, a distância máxima que uma nova planta pode ser criada em relação às plantas já criadas em uma mesma distribuição.

PD1. [Até que sejam criadas todas plantas definidas] Enquanto DISTRIB $\neq \emptyset$, vá para $P D 2$.

PD2. [Incremente o contador de plantas já criadas] Faça TOTAL $\leftarrow$ TOTAL +1 e vá para PD3.

PD3. [Inicialize o contador de distribuições ativas] $i \leftarrow 0$.

PD4. [Para cada distribuição ativa] Se $\mathrm{i}<\mathrm{N}$, vá para $P D 5$, caso contrário volte à $P D 1$

PD5. [Se a distribuição ainda deve criar plantas] Caso MAXPLANT $(i)>$ TOTAL, vá para PD6. Caso contrário, vá para $P D 9$.

PD6. [Localize uma região com concentrações de nutrientes e água favoráveis] Crie uma "bounding box" que represente a área ocupada pelas plantas já criadas, para a distribuição que está sendo considerada, incrementando seu tamanho em MAXEXPAND. Dentro desta região, defina um local para criação da nova planta, isto é feito utilizando um algoritmo aleatório simples. Caso não seja possível criar a planta, por falta ou excesso de nutrientes ou irrigação na região definida, vá para $P D 9$. Caso contrário siga para $P D 7$.

PD7. [Crie a planta e atualize os dados do terreno] Crie a planta e retire os nutrientes e irrigação que estão sendo utilizados pela planta do terreno. Vá para $P D 8$.

PD8. [Incremente contador de distribuições] $i \leftarrow i+1$. Volte para PD4.

PD9. [Remova a distribuição] Retire a distribuição da lista DISTRIB. Faça $\mathrm{N} \leftarrow \mathrm{N}-1$ e volte a PD4.

\subsubsection{Resultados obtidos e discussão}

O algoritmo gerado é bastante parametrizado, dependendo das definições de nutrientes e irrigação definidas pelo usuário. A técnica permite a competição de diversas distribuições de plantas para obtenção de espaço no terreno. Os resultados são ilustrados na Figura 3.14. 


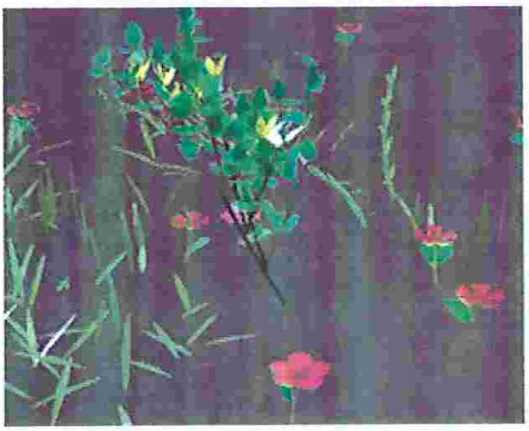

a.

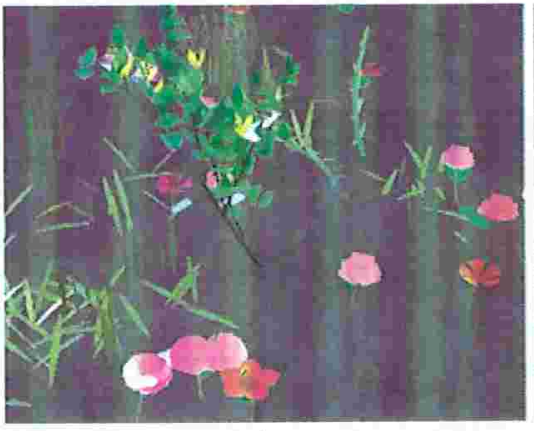

b.

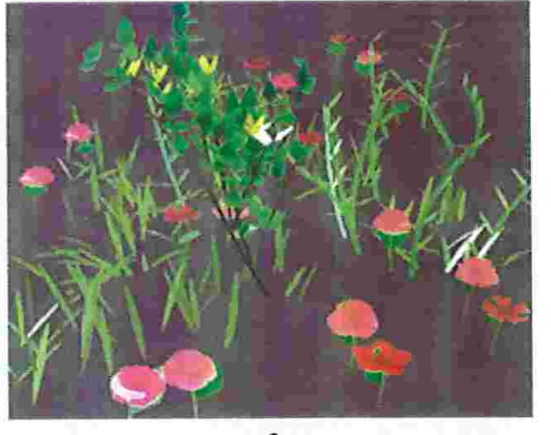

c.

Figura 3.14: (a) Utilização de poucos nutrientes e irrigação escassa, distribuição esparsa. (b) Aumento na irrigação, poucos nutrientes. (c) Grande quantidade de nutrientes e irrigação.

A distribuição explícita, feita por escolha do usuário, não foi implementada. Além da competição por espaço e nutrientes poderia ter sido implementado a competição pela iluminação. Caso fossem modelados vegetais que criam grandes regiões de sombra, deveria ser verificado se há luz suficiente para que vegetais menores se desenvolvam perto deste. Por exemplo, uma árvore faria sombra abaixo dela, o que inibiria o crescimento de grama ou flores perto dela. Porém, a modelagem e animação de árvores de forma realista em tempo real é muito difícil.

\subsection{Modelagem de fenômenos naturais}

A modelagem de fenômenos naturais é bastante importante para simulação de ecossistemas. Com informações de aspectos climáticos definimos os tipos de vegetação que melhor se adaptam às situações que podem ser simuladas. Modelamos apenas um fenômeno natural, o vento. A simulação do vento é de grande importância para animação das plantas, já que sua ação afeta diretamente o campo de forças. Nesta seção descrevemos a modelagem do vento e as técnicas desenvolvidas para a interação deste com a vegetação.

\subsubsection{Modelagem do Vento}

Adotamos um modelo baseado em partículas para modelagem do vento. Diferentemente do modelo baseado em aerodinâmica de Wejchert e Haumann [WH91], nosso modelo assume que o ar é composto por várias micro-partículas que se movem por ação de forças. Também assumimos que estas partículas têm forma fixa, logo elas não quebram nem deformam em colisões. O fluxo de vento é definido pelo movimento destas partículas. 
O fluxo é gerado por uma fonte de forças que agem sobre partículas próximas que começam a se movimentar. Cada partícula $i$ se move com velocidade e direção definidas por um vetor $\overrightarrow{v_{i}}$. A figura 3.15 ilustra esta definição. Ao se moverem, as partículas exercem forças nas outras que estão na direção do movimento. Também pode haver colisões entre partículas em movimento ou das mesmas com um obstáculo. Um obstáculo é qualquer agente que interfere no caminho do fluxo e não é uma partícula.

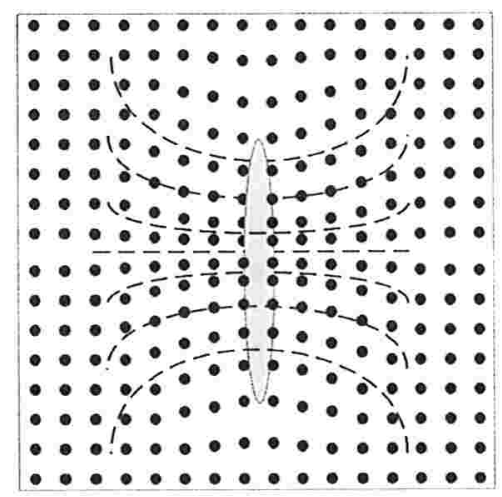

a.

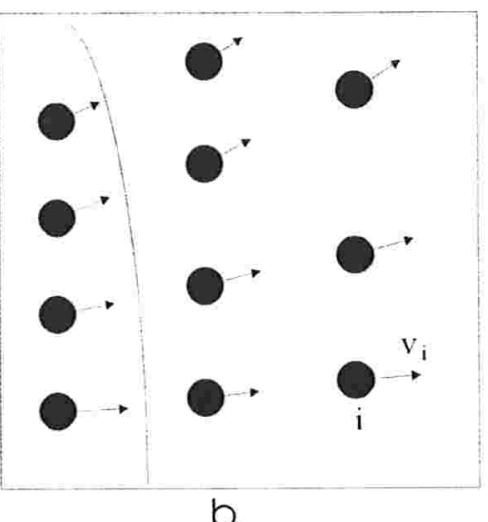

b.

Figura 3.15: (a) Partículas de vento se movendo sob ação de uma fonte de forças. As linhas representam a atração e repulsão da fonte. (b) Uma imagem ampliada das partículas próxima à fonte. Uma partícula $i$, com velocidade $\overrightarrow{v_{i}}$, é representada no canto inferior direito.

Assumimos que nas colisões há conservação de energia, de acordo com a Dinâmica, e que estas são perfeitamente elásticas. Quando duas partículas, $i$ e $j$, se colidem com velocidades $\overrightarrow{v_{i}}$ e $\overrightarrow{v_{j}}$, a colisão altera ambos vetores das velocidades para valores, digamos $\vec{v}_{i}^{\prime}$ e $\vec{v}_{j}^{\prime}$, geralmente diferentes dos iniciais.

O resultado de todas estas colisões define o fluxo. Quando uma partícula com uma velocidade definida colide com uma partícula em repouso, esta começa a se mover com uma velocidade menor que da partícula que inicialmente estava em movimento. A velocidade das partículas tende a diminuir nas colisões até que se tornem desprezíveis. Além disso, podem existir partículas se movendo na direção oposta das definidas por um fluxo, devido à ação de outros fluxos definidos. Logo temos uma ação do vento menor em áreas distantes da fonte, pois as partículas têm menor velocidade devido às colisões.

Se há obstáculos no caminho do fluxo as partículas têm seu movimento bloqueado, e aplicam força sobre o obstáculo. Um obstáculo pode receber a ação de várias partículas simultaneamente. O movimento do obstáculo dependerá de sua massa e da intensidade da força aplicada pelas partículas. Se esta força não for suficiente para movimentar o obstáculo o comportamento das partículas é similar ao das partículas agindo sobre um corpo rígido fixo.

Quando a fonte do fluxo aplica força nas partículas de ar próximas à fonte, estas são lançadas 
deixando um espaço não ocupado. Neste caso, outras partículas são atraídas para este espaço. Estas partículas recebem então a ação da fonte, sendo lançadas com velocidade definida pela fonte. Este movimento ao redor da fonte de fluxo depende do formato da fonte, e determina o movimento do fluxo gerado.

\subsubsection{Animação rápida pela ação do Vento}

Um modelo composto por partículas seria bastante ineficiente, pois a simulação de milhares de partículas seria necessária, comprometendo o desempenho do sistema. Seguindo a proposta de se construir um sistema para animação das plantas em tempo real, devemos propor uma técnica que que simule o vento de modo eficiente e realista.

$\mathrm{O}$ modelo de interação com as plantas pelo campo de forças foi descrito na seção anterior. O modelo de ação do vento deve ser adequado para uma fácil integração com o campo de forças, ou seja, sua ação deve se refletir diretamente no mesmo. O campo de forças está baseado em uma estrutura de quadtree, que contém regiões representadas por células desta árvore.

A representação do vento deve ser capaz de indicar a força aplicada em cada célula da quadtree que pertence ao conjunto definido pelo campo de forças e que são consideradas para geração da interação. $O$ algoritmo de simulação do vento pode aproveitar o fato de apenas algumas células do campo de forças estarem no campo de visão do observador para evitar cálculos desnecessários.

Nesta seção descrevemos a técnica que calcula a ação do vento em cada célula visível no nível de detalhe definido pela quadtree do campo de forças. A idéia por trás da técnica desenvolvida é acreditar na representação do campo de forças, visto que este já define um algoritmo de níveis de detalhes apropriado, de acordo com a posição relativa ao observador.

Descrevemos inicialmente as ações e tipos de fluxos considerados para animação, descrevendo posteriormente como simular o vento de modo eficiente e integrado ao campo de forças.

\section{Fluxos}

Um fluxo é um elemento capaz de movimentar as partículas de vento seguindo uma certa regra. O sistema permite que sejam criados fluxos de diversas formas. Três tipos de fluxo são criados como exemplo, descrevemos estes exemplos a seguir.

Os fluxos podem ser combinados gerando ações diferentes das padrões. Também é possível se movimentar o centro de geração de um fluxo pela ação de outros fluxos agindo sobre este ponto. Além disso, os fluxos podem ser iniciados a qualquer momento durante a simulação das plantas.

Deve-se definir os fluxos cuja ação é visível pelo usuário, pois caso um fluxo não seja visível não é 
necessário simulá-lo. Veremos isto no algoritmo simulateActiveFlows.

Definimos três tipos básicos de fluxos: uniforme, de atração e de repulsão. O fluxo uniforme age sobre as partículas atribuindo a elas uma força direcionada. $\mathrm{O}$ fluxo de atração atribui às partículas uma força em direção a um ponto de atração. Já o fluxo de repulsão, por sua vez, é o oposto do de atração, ou seja, atribui uma força na direção oposta a de um ponto de repulsão. Um esquema com estes fluxos é ilustrado na Figura 3.18.

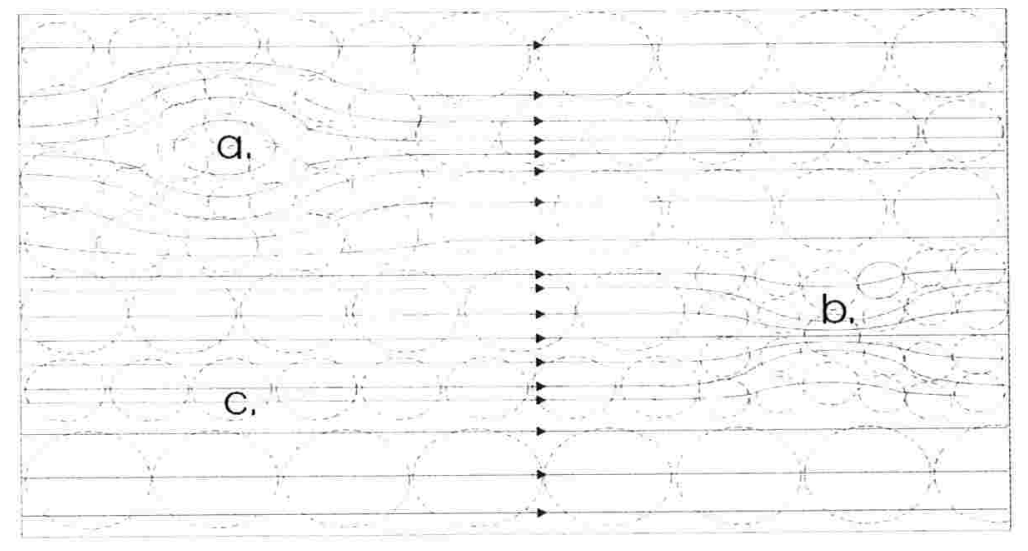

Figura 3.16: Diferentes tipos de fluxo. (a) fluxo de repulsão de partículas, (b) fluxo de atração de partículas e (c) fluxo uniforme direcionado.

\section{Tratamento do conjunto de fluxos}

Deve ser feito o isolamento de fluxos que estão no campo de visão do observador (fluxos ativos), dos que não estão (não ativos). Os fluxos não ativos não precisam ser simulados pois sua ação não é exibida. Porém, devemos simular a posição de todos os fluxos que podem se mover, pois estes podem se tornar visíveis a qualquer momento, dependendo da posição do observador.

É definido um tempo de início e de término da ação dos fluxos durante a execução da animação. Devemos checar o estado do fluxo para ver se ele já foi iniciado ou extinto. O algoritmo simulateActiveFlows é responsável pelo tratamento dos fluxos, alternando seu estado para ativo, não ativo ou extinguindo fluxos que tiveram o tempo de vida encerrado.

Algoritmo "simulateActiveFlows" (SAF) - Simula os fluxos ativos. Seja LACTIVE a lista de fluxos ativos. Seja LNONACTIVE a lista de fluxos não ativos. Consideramos três possíveis estados para um fluxo: ACTIVE, para fluxos ativos, NONACTIVE, para fluxos não ativos e NOTBORN para fluxos não iniciados. Os fluxos com estado ACTIVE são armazenados na lista LACTIVE, os fluxos NONACTIVE e NOTBORN na lista LNONACTIVE. 
SAF1. [Atualize a posição e velocidade dos fluxos cuja fonte pode se mover] Utilizando a velocidade da célula da quadtree que estava na configuração de nível de detalhe anterior, atualize a velocidade de locomoção do fluxo. Com esta velocidade calcule a nova posição dado o tempo de simulação decorrido.

SAF2. [Verifique se houve criação ou extinção de fluxos] Caso um fluxo tenha seu tempo de vida esgotado retire-o da lista LACTIVE ou LNONACTIVE. Caso o tempo de simulação seja maior que o tempo de nascimento determinado para um fluxo altere seu estado de NOTBORN para NONACTIVE.

SAF3. [Atualize as listas LACTIVE e NONACTIVE] Percorra a lista LNONACTIVE e verifique se os fluxos são visíveis na configuração de nível de detalhe atual. Caso sejam visíveis altere seu estado para ACTIVE e transfira o fluxo para lista LACTIVE. Percorra também a lista LACTIVE e verifique se algum fluxo não é mais visível. Neste caso, transfira-o para a lista LNONACTIVE alterando seu estado para NONACTIVE.

SAF4. [Atualize o "cache" de células de fluxos cuja fonte não se move] O "cache" armazena as células em que um fluxo age. Quando o nível de detalhe muda este cache deve ser atualizado para apontar para novas células. Este cache será bastante útil para simulação eficiente do vento, o algoritmo updateFlowCellCache descreve como é gerado o cache de células dos fluxos.

SAF5. [Execute a simulação da ação dos fluxos sobre as células visíveis] A simulação dos fluxos é complexa e será detalhada no algoritmo simulateFlowsAction.

\section{Integração com o campo de forças}

Após o tratamento dos fluxos, devemos verificar como eles agem sobre o campo de forças. Cada fluxo tem uma área de ação definida, para isto utilizamos uma "bounding box". O fluxo é representado por um único vetor em cada célula do campo de forças que sua "bounding box" intersecta. Logo temos uma estrutura de dados bastante simples para representação dos fluxos, adequada para sistemas interativos.

O fluxo é definido pelo conjunto de vetores definidos nas células visíveis do campo de forças. Diversos fluxos podem agir sobre uma célula. O campo de forças é responsável pelo cálculo da força resultante aplicada em cada célula visível. Logo não é necessário o tratamento ou a criação de um algoritmo de níveis de detalhes para simulação do vento, já que o campo de forças já trata esta otimização automaticamente. A Figura 3.17 descreve um esquema simples para esta técnica.

Para atualizar a ação do vento sobre o campo de forças, devemos calcular a ação exercida sobre cada célula que se encontra na área de ação de cada fluxo. Para isto, criamos um algoritmo, updateFlowVisi- 


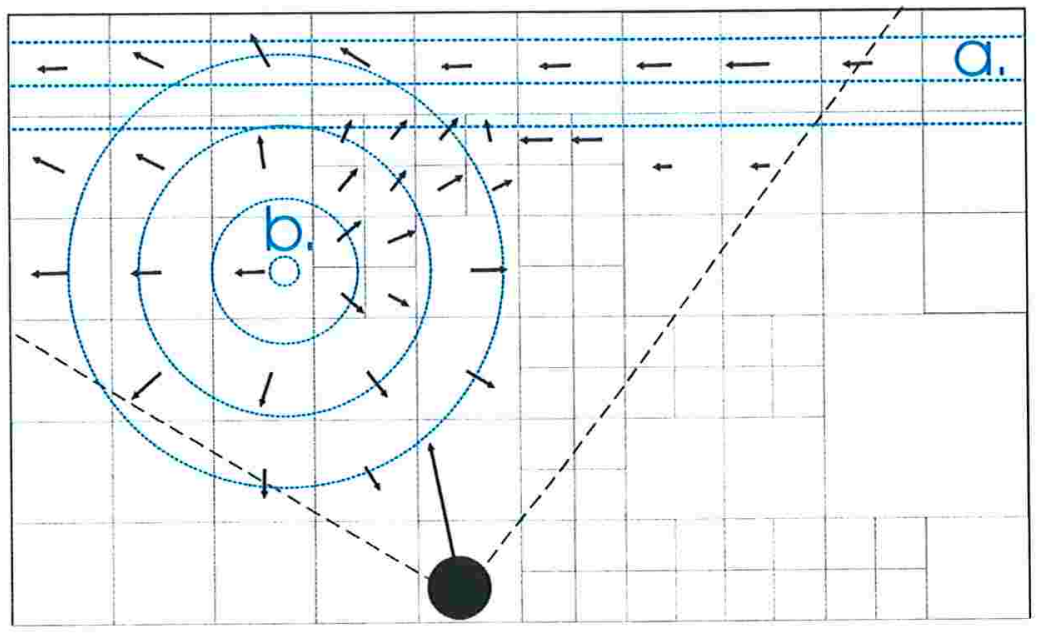

Figura 3.17: A simulação dos fluxos sobre o campo de forças. As células da árvore que recebem ação do vento possuem um vetor que descreve a força resultante sobre a região definida por elas. (a) Descreve um fluxo uniforme. (b) Um fluxo de repulsão.

bleCells, que cria e atualiza uma lista de células, que estão no nível de detalhe atual do campo de forças, e também se encontram na área de ação dos fluxos que estão ativos.

Algoritmo "updateFlowVisibleCells" (UVC) - Atualiza a lista de células em que um fluxo age. Sejam FLOWAUX um fluxo e LAUX a lista de célula sobre as quais o fluxo age. No início do algoritmo LAUX contém apenas a célula raiz da quadtree. Seja UPNODE o ponteiro para as células que representam o nível de detalhe atual, conforme descrito no algoritmo visibleDistanceLOD. Seja LINDEX o índice da célula que está sendo verificada na lista LAUX. Seja NEWUPPERLIST a lista de novas células que pertencem ao nível de detalhe atual e são ancestrais de células que estavam em LAUX mas não pertencem ao nível de detalhe atual. Observação: a definição dos valores atribuídos a UPNODE são importantes para o entendimento deste algoritmo.

UVC1. [Início] LINDEX $\leftarrow 0$.

UVC2. [Percorra LAUX] Para cada célula em LAUX dado o índice LINDEX execute:

UVC3. [Verifique o estado da célula] Caso a célula CEL, tal que CEL $\leftarrow$ LAUX[LINDEX], represente o nível de detalhe ou não seja visível atribua LINDEX $\leftarrow$ LINDEX +1 e volte para $U V C 3$. Caso contrário vá para $U V C 4$.

UVC4. [O nível de detalhe mudou para esta célula] remova a célula da lista. Caso UPNODE(CEL) seja igual a CEL, por definição, o nível de detalhe está em algum filho desta célula, vá para UVC5. 
Caso contrário, o nível de detalhe está em um célula acima de CEL, vá para UVC6.

UVC5. [Nível de detalhe mudou para célula descendente] chame o algoritmo addChildrenCells2List passando a célula CEL, a lista LAUX e o índice LINDEX. O algoritmo retorna o novo valor de LINDEX, após adicionar as células filhas que estão no nível de detalhe atual em LAUX. Volte para UVC3.

UVC6. [Nível de detalhe mudou para célula ancestral] Caso UPNODE(CEL) não esteja em NEWUPPERLIST, adicione CEL a NEWUPPERLIST e a LAUX, atribuindo LINDEX $\leftarrow$ LINDEX+1. Caso contrário não é necessário nenhuma ação, pois a célula já foi inserida em LAUX anteriormente. Volte para UVC3.

Algoritmo "addChildrenCells2List" ACL) - Adiciona as células filhas que estão no nível de detalhe atual. Dados a célula CEL, a lista LAUX e o índice LINDEX definidos no algoritmo acima.

ACL1. [Verifique se o fluxo realmente age sobre a célula] Verifique se o raio de ação do fluxo que está sendo analisado intersecta a região descrita pela célula CEL. Caso o fluxo não afete a célula retorne LINDEX. Caso contrário, vá para $A C L 2$

ACL2. [Verifique o estado da célula] Caso CEL represente o nível de detalhe ou não seja visível, adicione CEL a LAUX e retorne LINDEX+1. Caso contrário, vá para ACL3.

ACL3. [Chame recursivamente para os filhos] Para os quatro filhos da célula chame o algoritmo addChildrenCells 2 List recursivamente, retornando a soma dos valores retornados pelas quatro chamadas recursivas.

\section{Simulação da ação do vento nas células do campo de forças}

Tomadas as medidas que previnem que simulemos a ação do vento em regiões que não são visíveis. Definimos a ação de cada fluxo nas células que se encontram dentro de sua área de ação.

Algoritmo "simulateFlows" SF) - Calcula a ação exercida por cada fluxo ativo nas células em que estes agem Dados os fluxos ativos FLOWS. Seja CELLS [i] o conjunto de células que o i-ésimo fluxo age. Seja THRESHOLD o limiar que define o tipo de simulação que será utilizada.

SF1. [Para todos fluxos executa a simulação das células ativas] Para cada fluxo em FLOWS, execute o passo $S F 2$.

SF2. [Para as células no nível de detalhe atual que o fluxo age] Para cada célula em CELLS [i] caso a distância desta com o observador seja maior que o limiar THRESHOLD vá para $S F 3$, caso contrário vá para $S F 4$. 
SF3. [Simulação por aproximação] Defina a ação do vento sobre a célula por aproximação. A máscara define a direção do fluxo no ponto central da célula e é estimada a velocidade do fluxo a esta distância do centro do fluxo, considerando que o fluxo não tem sua direção alterada.

SF4. [Simulação por partículas] Defina a ação do vento sobre a célula utilizando a simulação por partículas. Neste caso é feita uma simulação das partículas que teriam sido criadas pelo fluxo e suas ações sobre a célula. $\mathrm{O}$ resultado é semelhante à aplicação da simulação por aproximação várias vezes e se determinando um valor médio considerando algumas partículas criadas com diferentes direções iniciais.

\subsubsection{Resultados obtidos e discussão}

Os resultados da animação das plantas pela ação do vento podem ser observados na Figura 3.18.

Dois fenômenos naturais não implementados poderiam contribuir para o realismo do sistema. A chuva e a neve estão mais ligadas às condições climáticas como temperatura e umidade que implicam na distribuição das plantas. Porém, como o trabalho discute apenas a simulação de plantas a implementação destes fenômenos não foi essencial. 


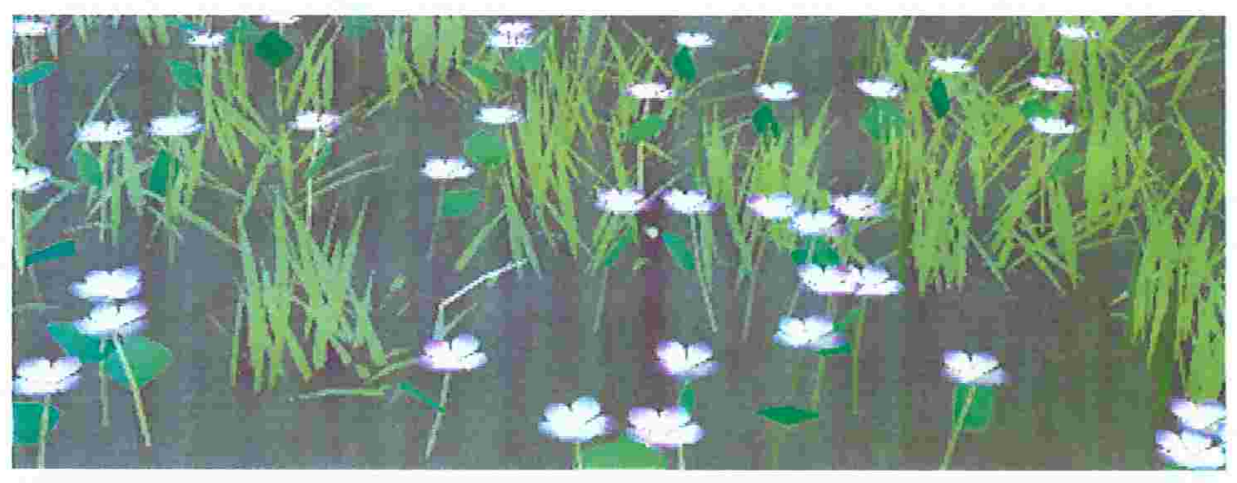

a.

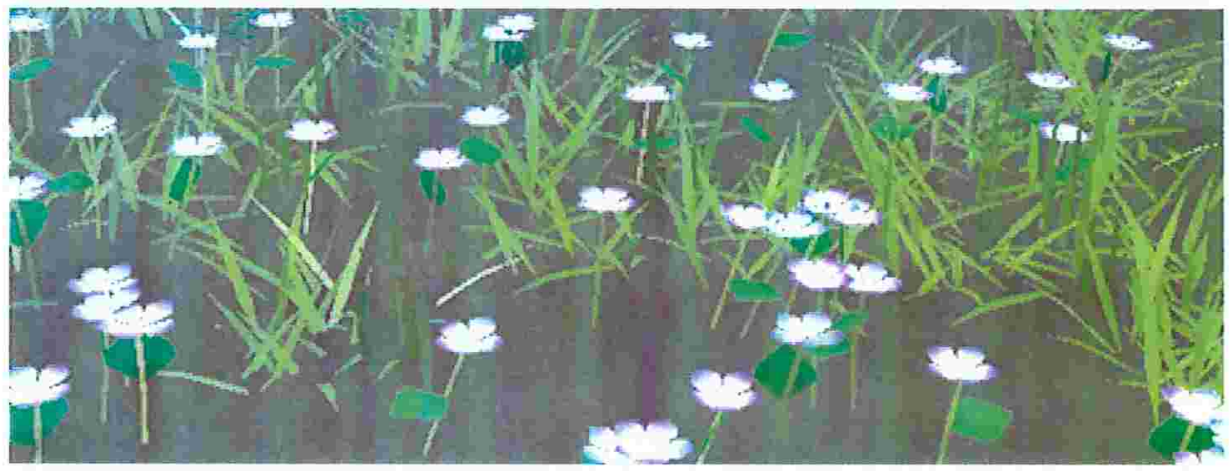

b

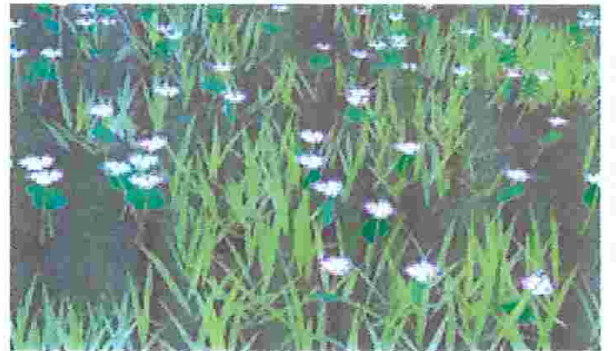

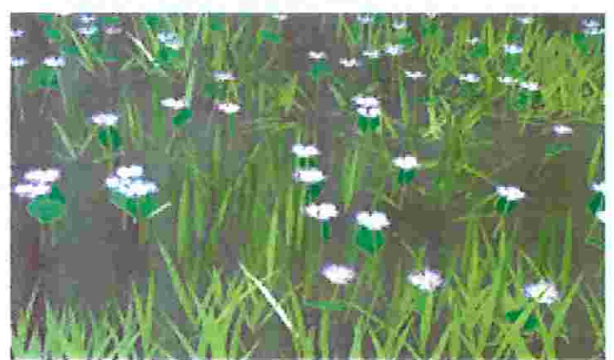

Figura 3.18: Ação do vento sobre a vegetação. (a) Vegetação em repouso, (b) Ação de um fluxo uniforme, (c) Vegetação em repouso, (d) Ação de um fluxo de repulsão (agindo no centro da imagem). 


\section{Capítulo 4}

\section{O Arcabouço}

\subsection{Introdução}

A proposta do trabalho inclui a implementação de um arcabouço reutilizável para simulação de vegetação. Neste capítulo apresentamos o arcabouço desenvolvido, discutindo sua arquitetura e fazendo uma análise de seu desempenho.

Primeiramente, faremos uma breve discussão sobre a plataforma de desenvolvimento escolhida para a implementação do arcabouço, analisando as suas vantagens e desvantagens em relação às demais. Também descrevemos brevemente algumas características relevantes da plataforma escolhida, necessárias para um melhor entendimento da arquitetura do arcabouço.

A arquitetura do arcabouço é apresentada na seção 4.3. Nela apresentamos as principais idéias e organização do arcabouço. Uma descrição em maiores detalhes foi feita no apêndice A, onde detalhamos todas as classes fundamentais para extensão do projeto, ou seja, como substituir ou implementar novas funcionalidades do sistema sem ter que alterar toda arquitetura. Exemplos para extensão de diversos módulos do sistema são apresentados.

A seção 4.4 apresenta tabelas com comparações de tempo de execução para diversas situações e diferentes parâmetros utilizados para geração de cenas, com o objetivo de analisar o desempenho do arcabouço. Após a apresentação dos valores medidos é feita uma análise e discussão dos mesmos.

A linguagem para descrição de cenas definida, ESL, é apresentada e detalhada no apêndice B. 
A linguagem utiliza XML ("Extensible Markup Language") ${ }^{1}$ McL00] para descrever as informações necessárias para geração de uma cena. Todas "tags" e atributos definidos para descrição de uma cena que representa um mini-ecossistema vegetal são descritos. O exemplo visa ilustrar os parâmetros utilizados no sistema, além de provar a facilidade para sua utilização.

\subsection{Java 3D}

A linguagem de programação $\mathrm{Java}^{2}$ [AC96] foi escolhida para o desenvolvimento deste projeto, tendo em vista sua portabilidade e escalabilidade. Um programa em Java é executado por uma máquina virtual (JVM - Java Virtual Machine), que pode ser instalada em diversos sistemas operacionais, logo o mesmo programa pode ser executado em muitas plataformas.

Java é uma linguagem orientada a objetos, logo satisfaz os requisitos para criação de um arcabouço reutilizável por outras aplicações. Java permite a utilização de conceitos de orientação a objetos como abstração, encapsulamento, herança, agregação, associação, generalização. Desta forma evita redundância de código e permite esconder informações que só dizem respeito às classes.

A plataforma Java disponibiliza uma API (Application Programming Interface) para renderização de gráficos tridimensionais sofisticados, a Java $3 D^{T M}$ API ${ }^{3}$ [jav]. Esta API permite a manipulação e criação de objetos geométricos $3 \mathrm{D}$ em um modelo de programação de alto nível. O usuário pode ainda optar por dois tipos de implementações do Java 3D, uma baseada em OpenGL ${ }^{4}$ e outra em DirectX ${ }^{5}$.

O Java 3D vem sendo cada vez mais utilizado por disponibilizar muitas ferramentas que facilitam a implementação de sistemas gráficos tridimensionais. Dentre as funcionalidades disponibilizadas podemos citar:

- Facilidade na modelagem geométrica e geração da aparência dos objetos.

- Diversas opções para interação e animação, implementando inclusive alguns métodos de interpolação, e níveis de detalhe.

- Algoritmos para iluminação, textura e shading.

- Métodos para implementação rápida de comportamentos para objetos.

\footnotetext{
${ }^{1}$ http://www.w3.org/XML/

${ }^{2}$ http://java.sun.com

${ }^{3}$ http://java.sun.com/products/java-media/3D/

${ }^{4} \mathrm{http}: / / \mathrm{www}$.opengl.org/

${ }^{5} \mathrm{http} / / / \mathrm{www}$.microsoft.com/windows/directx/
} 
Em uma breve comparação com a arquitetura geralmente utilizada em aplicações gráficas, baseada em $\mathrm{C}$ e OpenGL, podemos citar diversas vantagens e desvantagens. Dentre as desvantagens a mais importante é o desempenho, o código executável gerado em C + OpenGL é mais rápido que o código pseudo compilado do Java, que depende da interpretação do código pela máquina virtual do Java, segredo de sua portabilidade. O próprio Java 3D é implementado sobre o OpenGL, logo está dependente desta que é a API mais amplamente utilizada e adotada com padrão em aplicações gráficas.

Porém, muitos citam o Java 3D como o próximo avanço na área de API's gráficas. A própria SUN cita o Java 3D como a quarta geração de APIs gráficas 3D, "One can think of OpenGL Scene GraphTM as machine language programming for graphics and Java 3D API as a higher level programming language" ${ }^{6}$. Desta forma, esta API tende a ser cada vez mais utilizada e adotada para aplicações gráficas, o número de usuários vem crescendo bastante, como pode ser acompanhado pelo número de mensagens diárias enviadas à lista de discussão da SUN. O site J3D.ORG ${ }^{7}$ contém diversas informações sobre esta tecnologia, inclusive alguns códigos fontes.

Muitas vantagens da linguagem Java podem ser estendidas para a Java 3D API, a fácil adaptação de uma aplicação à Internet, utilizando Applets ${ }^{8}$ ou a tecnologia Java Web Start ${ }^{9}$, o tratamento de erros utilizando exceções, a utilização do "garbage collector" automático que evita o uso de memória desnecessária desalocando objetos não mais utilizados, entre outras. Pode-se também aproveitar muitas das outras API's disponibilizadas na plataforma Java. Podemos implementar facilmente interfaces com o usuário utilizando Swing e todas outras ferramentas disponibilizadas pela Java Foundation Classes $(\mathrm{JFC})^{10}$, que é um conjunto de bibliotecas auxiliares para gráficos e GUI (Graphics User Interface). O Java 3D também se beneficia das Java Threads, permitindo a renderização em paralelo.

Utilizamos o sistema de prioridade das threads para otimizar a animação das plantas. Três threads são iniciadas pelo sistema, a primeira cuida da atualização do campo de forças, a segunda que trata a simulação das plantas por ação do campo enquanto a terceira trata exclusivamente da animação das mesmas (neste caso, apenas alteração da posição das plantas). Conforme a quantidade de objetos na tela, a thread que trata a animação deve ter uma prioridade maior sob as demais, para que a animação não comprometa o desempenho do sistema. O sistema de threads torna possível a animação em tempo real, pois enquanto a animação não for terminada podemos fazer a thread de simulação e atualização do campo de forças esperarem e utilizar um maior processamento para animação.

\footnotetext{
${ }^{6}$ http://java.sun.com/products/java-media/3D/collateral/wp_mktg/wp_mktg.html

${ }^{7} \mathrm{http}: / / w w w . j 3 d . o r g$

${ }^{8} \mathrm{http} / / /$ java.sun.com/applets/

${ }^{9} \mathrm{http} / / /$ java.sun.com/products/javawebstart/

${ }^{10} \mathrm{http}: / /$ java.sun.com/products/jfc/
} 


\subsubsection{Detalhes relevantes da API}

Nesta seção faremos uma breve apresentação de algumas funcionalidades da API do Java 3D. Por se tratar de uma API grande iremos tratar apenas funcionalidades relevantes que facilitarão o entendimento da implementação.

\section{Grafo de uma cena Java 3D}

A hierarquia de um programa em Java 3D é definida por um grafo da cena, composta basicamente por objetos do tipo: VirtualUniverse, Locale, Canvas3D, Group e Leaf. Um objeto VirtualUniverse tem uma lista de objetos Locale, estes por sua vez, são utilizados pelo universo virtual para determinar a localização de objetos visuais dentro do universo definido.

O objeto Locale ainda serve de raiz de subgrafos para o grafo da cena. Há duas categorias diferentes de subgrafos: um que trata o conteúdo do universo virtual, como geometria, comportamentos, iluminação, entre outros; e outro que especifica parâmetros de visualização, como localização e direção de visualização.

Para qualquer cena que venha a ser elaborada, deve-se criar um subgrafo de visualização, para isto basta implementar os objetos: View, ViewPlatform, PhysicalBody e PhysicalEnvironment. Estes três últimos, junto ao objeto Canvas3D, devem ser associados ao objeto View. O subgrafo de conteúdo deverá conter os objetos visuais, no nosso caso as plantas, o terreno e outros atributos da cena. Ambos os subgrafos devem ser associados ao objeto Locale. A figura 4.1 ilustra um grafo de cena contendo os objetos básicos de um programa em Java 3D.

Os objetos visuais do sistema deverão ser adicionados ao universo virtual para fazer parte da cena. O pacote de visualização do arcabouço encapsula os métodos para adição de objetos no subgrafo de conteúdo do sistema.

\section{Hierarquia básica de classes}

O grafo da cena é composto de vários nós, representados pela classe Node. Esta classe é uma superclasse abstrata das classes Group e Leaf, que são os dois tipos possíveis de nós do grafo.

Objetos que estendem a classe Group são utilizados na especificação da localização, transformação, e agrupamento de objetos visuais. Por exemplo. a classe BranchGroup é geralmente utilizada como raízes dos subgrafos da cena, sendo composto por outros nós. A classe TransformGroup pode alterar a posição, orientação e escala de uma série de objetos associados.

Já os objetos que estendem a classe Leaf são nós terminais, ou seja, não contém filhos. Estes 


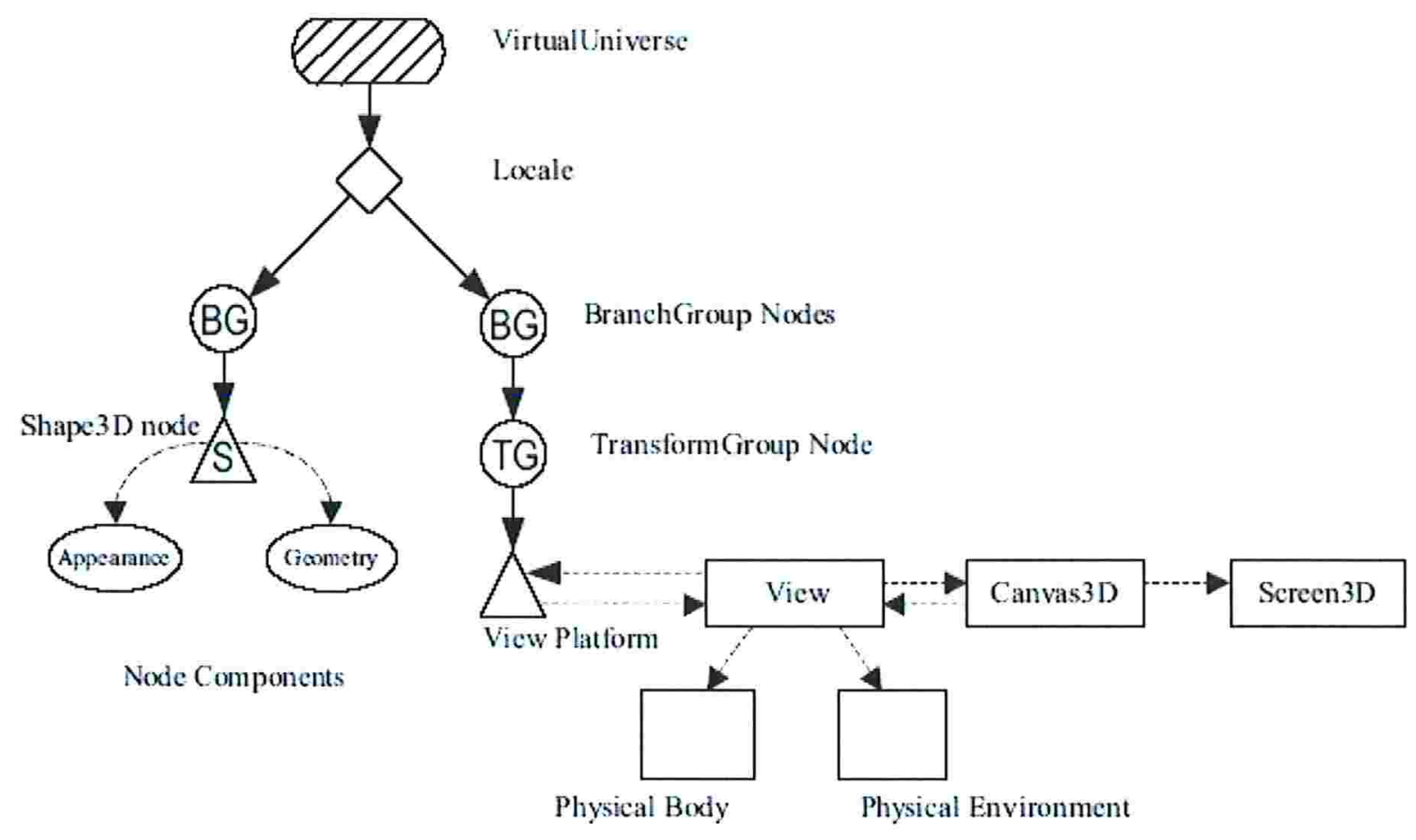

Figura 4.1: Grafo da cena de uma aplicação em Java 3D. Fonte: [AC96]

objetos são utilizados para especificação da forma, aparência, comportamento, textura e iluminação de objetos visuais. Um exemplo de um objeto Leaf é a classe Shape3D que será bastante utilizada na definição dos objetos visuais do sistema. Esta classe referencia objetos do tipo Appearance e Geometry, que definem a aparência e geometria do objeto visual, respectivamente.

\section{Geometria - Formas}

$\mathrm{Na}$ biblioteca podem ser encontradas diversas primitivas, que podem ser utilizadas para criação de objetos. Podemos identificar estas classes facilmente já que todas estendem a classe Geometry. Essas classes podem ser utilizadas para modelagem dos objetos do sistema.

Classes como: LineArray, PointArray, TriangleArray e GeometrystripArray são exemplos destas. Utilizando as duas primeiras podemos modelar facilmente um sistema baseado em pontos e linhas, como descrito na seção 2.5. Neste trabalho, utilizamos objetos TriangleStripArray e LineStripArray, que estendem a classe GeometrystripArray, para modelagem dos objetos.

A classe TrianglestripArray desenha conjuntos de uma sequência de triângulos conectados. 
A vantagem de se utilizar tal estrutura é que os triângulos compartilham vértices, o que resulta em economia de memória. Para poder utilizar esta estrutura basta ter em mente que na faixa, cada vértice, começando do terceiro define um triângulo a ser desenhado, utilizando-se o vértice atual e os dois anteriores. Além da geometria a classe TrianglestripArray também armazena dados como as normais (importante para iluminação e "shading") e as cores de cada triângulo.

As mesmas vantagens nos levaram a utilizar a classe LineStripArray para modelagem por linhas, no algoritmo de nível de detalhes para modelagem.

\section{Comportamentos}

Tanto a interação quanto a animação são especificadas por objetos do tipo Behavior. O propósito de objetos deste tipo é a alteração do grafo da cena, em resposta a algum estímulo.

São diversos os objetos do tipo Behavior fornecidos pela API do Java 3D. Dentre eles podemos destacar os que implementam técnicas descritas na seção 2.5, como por exemplo o objeto Billboard, que implementa a técnica de billboard.

O comportamento Dist anceLOD, que implementa um algoritmo de nível de detalhes por distância, define diferentes modelos para representar um objeto. Cada um destes modelos é utilizado para um certo intervalo de distância em relação ao observador. Um objeto do tipo Switch deve ser criado, para adicionar os diferentes modelos, e associado ao objeto DistanceLOD para que os modelos sejam alterados corretamente. Neste sistema, utilizamos este comportamento para alterar a modelagem das plantas, diminuindo o número de polígonos utilizados na animação ou utilizando linhas para aproximar os modelos, como foi descrito na seção 3.3.3.

Outro comportamento muito importante utilizado neste sistema é o KeyNavigatorBehavior, para movimentação da posição do observador pela cena utilizando o teclado. Implementamos também um comportamento que utiliza uma condição de quadros que foram renderizados em um certo período de tempo para medir o desempenho do sistema.

Inúmeras condições são disponibilizadas pela API como WakeuponCollisionEntry, WakeuponTransformChange ou WakeuponElapsedTime e podem ser utilizadas como estímulo a um certo comportamento.

\section{Animação}

A API do Java 3D disponibiliza diversas classes que podem gerar animação utilizando interpolação. Um exemplo disto é a classe Morph, que implementa a técnica de "morphing". Esta técnica utiliza interpolação para transformar um objeto em outro. 
Na versão 1.2 da API foi introduzida a interface GeometryUpdater, que permite alterar a geometria de um objeto em tempo de execução, o que não era possível nas técnicas anteriores de animação. Por utilizarmos modelos pré-computados esta forma de animação é mais adequada ao nosso problema, visto que, podemos alterar um modelo pré-computado por outro, gerando animações mais rápidas.

A utilização desta técnica associada à de níveis de detalhes por distância é muito proveitosa, pois podemos alterar uma quantidade menor de coordenadas, ao invés de alterar toda geometria. No caso de um modelo, que será utilizado para representar um objeto a uma certa distância em relação ao observador, utilizar menos polígonos que um modelo utilizado para representar o objeto mais próximo ao observador podemos animar apenas as coordenadas que serão utilizadas por este modelo mais simples.

\subsection{Arquitetura}

A arquitetura do arcabouço deve satisfazer uma série de pré-requisitos propostos. Ela deve ser orientada a objetos, reutilizável, facilmente adaptável a outras aplicações e ser capaz de gerar cenas com diferentes tipos de vegetação dados alguns parâmetros de entrada.

Para melhor organização do código, o arcabouço foi dividido em vários módulos (pacotes). Além da organização, os pacotes colaboram com o encapsulamento do sistema. Conceitos de abstração e herança foram amplamente utilizados a fim de tornar as implementações facilmente extensíveis. Nesta seção discutiremos detalhes da arquitetura dos pacotes, e os conceitos utilizados. O apêndice A descreve a modelagem e arquitetura do sistema em maiores detalhes.

As classes relacionadas ao campo de forças foram implementadas no pacote ecosys . interaction. Este pacote é totalmente independente dos demais, isto propicia que esta técnica de interação possa ser utilizada por outras aplicações, mesmo fora do arcabouço. Além disso, outros meios de interação com as plantas do sistema podem ser facilmente adaptados ao sistema, desde que se siga a implementação definida pelas classes de integração.

O pacote ecosys . naturalphenomena . wind encapsula toda implementação do algoritmo de simulação do vento. O pacote foi adaptado para que a ação do vento refletisse sobre o campo de forças. Foram criadas classes que definem a ação das primitivas do vento. Portanto, podem ser criadas diferentes primitivas para uma ação do vento diferente das implementadas. A implementação deste pacote mostrou a facilidade de se adaptar uma solução para que esta defina uma ação sobre o campo de forças.

O pacote ecosys.plants encapsula grande parte das técnicas desenvolvidas neste trabalho, sobre a modelagem, animação e distribuição das plantas. Os conceitos de componentes de planta foram implementados nos subpacotes: ecosys.plants.branch, ecosys.plants. leaf e ecosys. plants.flower definem os componentes galho, folha e flor, respectivamente. Novos componentes 
com modelagem diferente da proposta podem ser adicionados os projeto, bastando para isto implementar a definição de componente de plantas. O pacote ecosys .plants . distribution e ecosys . plants. animation encapsulam as classes responsáveis por implementar as técnicas de distribuição e animação de plantas. Já os pacotes ecosys.plants.underbrush e ecosys.plants.bush implementam plantas do tipo: vegetação rasteira e arbustos. $\mathrm{O}$ arcabouço proporciona a atualização da ação do campo de forças em cada planta. A implementação das plantas deve definir a ação deste sobre seus componentes.

Nesta seção explicamos apenas uma visão geral da ligação entre os pacotes principais. O apêndice $\mathrm{A}$ contém informações de como os mecanismos de adaptação e integração foram implementados em cada pacote. Para maiores informações sobre as classes pode ser consultado ainda o JavaDoc (documentação das classes do java), que será disponibilizado com o arcabouço.

O apêndice A pode tratar de assuntos bastante técnicos, porém todos eles são relevantes para o desempenho do sistema, visto que mesmo uma boa técnica mal implementada pode ser bastante ineficiente. Além disso, detalhamos as classes que tornam possível a extensão do sistema para que este possa ser utilizado por outros sistemas ou aperfeiçoado.

\subsection{Análise do desempenho do arcabouço}

Nesta seção descrevemos alguns testes elaborados para medir o desempenho do sistema. Foram criadas tabelas que ilustram os resultados obtidos, e permitem a comparação, análise e discussão da eficiência dos componentes do arcabouço.

Os testes foram realizados em um computador Pentiun III $900 \mathrm{Mhz}$, com $256 \mathrm{Mb}$ de memória e placa de vídeo de $64 \mathrm{Mb}$. O sistema operacional utilizado foi o Windows XP.

Foram utilizados três diferentes tipos de distribuição de plantas para os testes. A tabela 4.1 descreve a complexidade geométrica de cada planta. Foram criados três níveis de detalhes para modelagem, os dois mais realistas utilizam triângulos, enquanto o menos realista utiliza linhas para representar as plantas.

\begin{tabular}{|c|c|c|c|c|}
\hline \hline Planta & Informação & LOD1 & LOD2 & LOD3 \\
\hline A & grama & 250 triângulos & 150 triângulos & 175 linhas \\
B & flor amarela & 72 triângulos & 52 triângulos & 37 linhas \\
C & flor lilás & 78 triângulos & 58 triângulos & 39 linhas \\
\hline \hline
\end{tabular}

Tabela 4.1: Dados da complexidade das plantas utilizadas para os testes de desempenho. 
Podemos observar que as flores $\mathrm{B}$ e $\mathrm{C}$ são praticamente idênticas em termos de complexidade, porém suas aparências são bastante diferentes, os dados descritos são relativos a apenas uma flor. $\mathrm{O}$ tufo de grama A é composto por 25 folhas. Informações sobre os níveis de detalhes (LOD1, LOD2 e LOD3) são exibidas na tabela 4.2 .

\begin{tabular}{|c|c|c|}
\hline \hline Nivel de detalhe & Distância para o observador & Primitiva utilizada \\
\hline LOD1 & 0 a 10 metros & triângulo \\
LOD2 & 10 a 15 metros & triângulo \\
LOD3 & mais de 15 metros & linha \\
\hline \hline
\end{tabular}

Tabela 4.2: Tabela de informação dos níveis de detalhes utilizados nos testes.

\begin{tabular}{|c|c|c|c|}
\hline \hline Cena & Quantidade de A & Quantidade de B & Quantidade de C \\
\hline C1 & 100 & 30 & 30 \\
C2 & 50 & 15 & 15 \\
C3 & 150 & 0 & 0 \\
C4 & 75 & 0 & 0 \\
C5 & 0 & 200 & 200 \\
C6 & 0 & 100 & 100 \\
\hline \hline
\end{tabular}

Tabela 4.3: Tabela que descreve as cenas utilizadas para os testes.

Para realização dos testes foram criadas seis cenas utilizando as plantas definidas. As cenas são descritas na tabela 4.3 e ilustradas na Figura 4.2. Nas próximas subseções analisamos o desempenho do sistema. Diversas tabelas foram criadas e a variação da taxa de quadros gerados por segundo ("frame rate"), medidas em fps ("frames per second"), são apresentadas.

Consideramos um índice de incerteza para os testes, visto que estes dependem das condições do computador. A notação "valor tincerteza" é utilizada. Por exemplo, $10 \pm 4$ indica que o resultado teve um valor médio igual a 10 e uma variação de 4, portanto os valores podem estar na faixa de 6 a 14.

\subsubsection{Análise de desempenho dada a complexidade geométrica dos ob- jetos}

Nesta tabela ilustramos o desempenho do sistema dada a complexidade geométrica da cena. Neste teste, o campo de forças e o algoritmo de animação das plantas estão ativos. A variação da taxa de quadros gerados por segundo, é descrita na tabela 4.4 


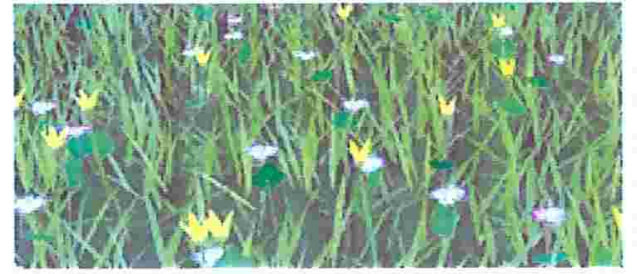

c1

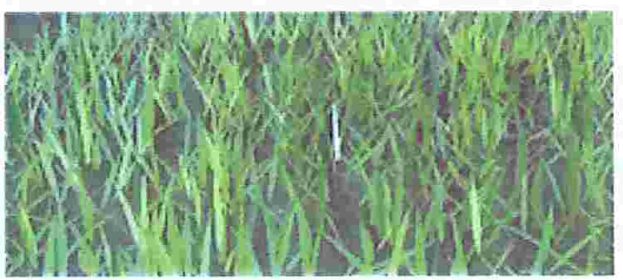

63

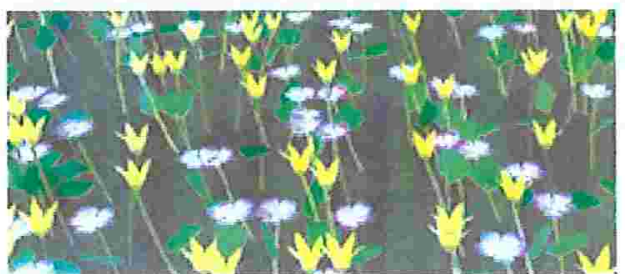

65

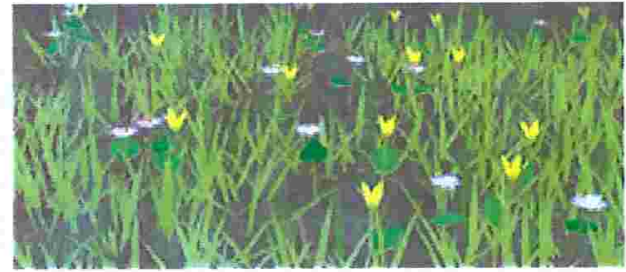

$\mathrm{C} 2$

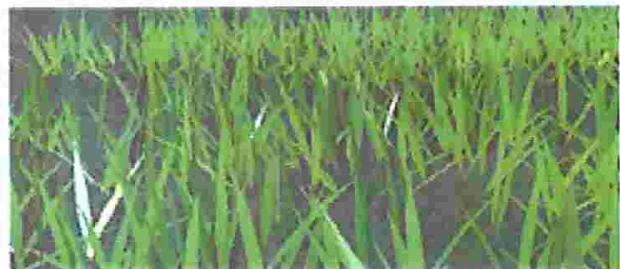

C. 4

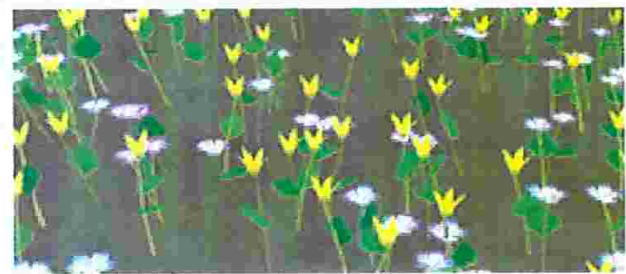

$\mathrm{C6}$

Figura 4.2: Cenas geradas para os testes.

\begin{tabular}{|c|c|c|c|}
\hline \hline Cena & Núm. aprox. de Triângulos & Núm. aprox. de Linhas & Frame rate \\
\hline C1 & 14600 & 7950 & $17 \pm 10 \mathrm{fps}$ \\
C2 & 7300 & 4000 & $29 \pm 11 \mathrm{fps}$ \\
C3 & 20000 & 8750 & $15 \pm 10 \mathrm{fps}$ \\
C4 & 10000 & 4400 & $26 \pm 09 \mathrm{fps}$ \\
C5 & 16000 & 7500 & $19 \pm 04 \mathrm{fps}$ \\
C6 & 8000 & 3750 & $33 \pm 06 \mathrm{fps}$ \\
\hline \hline
\end{tabular}

Tabela 4.4: Tabela de análise de desempenho x complexidade geométrica da cena. 
A análise de desempenho dada a complexidade geométrica depende de diversos fatores importantes, dentre eles os principais são:

- O número de primitivas que estão sendo animadas - A movimentação simples de muitas primitivas tem um custo computacional considerável. Isto é comprovado na tabela 4.7 a seguir.

- A quantidade de componentes da planta - Cada componente é animado separadamente pelo algoritmo de animação. O custo de animar, por exemplo, A, composta por 25 componentes (folhas), é bem maior que animar $B$ ou $C$, compostas por apenas 7 componentes ( 5 pétalas, 1 folha e 1 galho).

Analisando estes fatores entendemos porque o desempenho das cenas C5 e C6 é superior ao de C1 e C2, mesmo tendo maior complexidade geométrica. Os resultados demonstram que é possível simular cenas contendo cerca de 4000 folhas de grama ou 400 flores simples em tempo real utilizando o sistema.

\subsubsection{Análise de desempenho dados os modelos geométricos dos ob- jetos}

As plantas podem ser modeladas com diferentes primitivas ou mesmo com um diferente número delas. A simplificação dos modelos é base do algoritmo de nível de detalhes para modelagem deste trabalho. Nesta seção analisamos o desempenho da animação das cenas onde o algoritmo de nível de detalhes para modelagem foi desativado.

Realizamos testes onde os objetos das cenas foram todos criados utilizando os modelos descritos em LOD1 e LOD3. Os resultados são apresentados na tabela 4.5. Novamente consideramos ativos o campo de forças e o algoritmo de animação dos componentes das plantas.

\begin{tabular}{|c|r|r|}
\hline \hline Cena & Frame rate (Apenas LOD1) & Frame rate (Apenas LOD3) \\
\hline C1 & $13 \pm 5 \mathrm{fss}$ & $19 \pm 5 \mathrm{fps}$ \\
C2 & $20 \pm 6 \mathrm{fps}$ & $31 \pm 7 \mathrm{fps}$ \\
C3 & $10 \pm 3 \mathrm{fps}$ & $18 \pm 4 \mathrm{fps}$ \\
C4 & $20 \pm 5 \mathrm{fps}$ & $28 \pm 3 \mathrm{fps}$ \\
C5 & $16 \pm 3 \mathrm{fps}$ & $29 \pm 5 \mathrm{fps}$ \\
C6 & $29 \pm 3 \mathrm{fps}$ & $36 \pm 5 \mathrm{fps}$ \\
\hline \hline
\end{tabular}

Tabela 4.5: Tabela de análise de desempenho x modelos geométricos.

Pelos resultados obtidos comprovamos que a animação de linhas é um pouco mais eficiente que a animação de triângulos. Além disso, o LOD3 utiliza menos primitivas (linhas) que o LOD1, portanto a animação é mais rápida. A complexidade de um modelo no LOD3 para flores é bem menor que 
utilizando triângulos, como podemos ver na tabela 4.1, no caso da grama a diferença não é tão grande. Por este motivo o desempenho de C5 e C6 no LOD3 é bastante superior em relação aos demais.

\subsubsection{Análise de desempenho pela quantidade de modelos pré-computados}

A pré-computação de modelos geométricos faz com que seja possível a animação de folhas modeladas com propriedades físicas. Porém, o número de modelos pré-computado consome memória e poderia afetar o desempenho do sistema. Alguns testes foram realizados, porém, não houve alteração significativa considerando a alteração da quantidade de modelos pré-computados, considerando-se a incerteza envolvida.

\subsubsection{Análise do desempenho do campo de forças}

O campo de forças é responsável pela interação eficiente de elementos externos nas plantas. A atualização do campo de forças de acordo com a posição do observador pode influenciar no desempenho do sistema. Os benefícios do campo de forças devem ser maiores que sua influência no desempenho, medida na tabela 4.6.

Para este teste consideramos um algoritmo que cria movimentação aleatória das plantas, pois com o campo de força inativo não haveria movimento. Quando o campo de forças está ativo consideramos que o algoritmo que calcula a ação do vento também está ativo. Portanto, o tempo ilustrado na tabela indica o tempo total para a atualização dos níveis de detalhes do campo de forças e da geração das forças pela ação do vento.

\begin{tabular}{|c|c|c|c|}
\hline \hline Cena & Campo de forças ativo & Tempo de atualização do campo & Frame rate \\
\hline C2 & Sim & $40 \pm 30$ milisegundos & $44 \pm 10 \mathrm{fps}$ \\
C2 & Não & - & $47 \pm 05 \mathrm{fps}$ \\
C4 & Sim & $30 \pm 20$ milisegundos & $42 \pm 07 \mathrm{fps}$ \\
C4 & Não & - & $44 \pm 06 \mathrm{fps}$ \\
C6 & Sim & $45 \pm 35$ milisegundos & $36 \pm 15 \mathrm{fps}$ \\
C6 & Não & - & $38 \pm 05 \mathrm{fps}$ \\
\hline \hline
\end{tabular}

Tabela 4.6: Taxa de quadros por segundo gerada pelo sistema, considerando o campo de forças agindo.

Para os testes realizados o observador permaneceu em movimento contínuo, para que o campo de forças fosse atualizado. A variação da incerteza do "framerate" foi bastante alta, para os testes envolvendo o campo de forças, devido à variação da região do campo que está sendo observada a cada momento. 
Verificamos que a atualização do campo de forças e das forças dentro do mesmo é bastante eficiente. Dado que o campo de forças é atualizado cerca de uma vez por segundo, concluímos que este não compromete no desempenho do sistema. Os resultados mostram que a diferença média de desempenho, considerando o campo ativo, é de cerca de 2 fps. Portanto, se considerarmos a incerteza, os resultados obtidos são praticamente idênticos.

\subsubsection{Análise de desempenho do algoritmo de animação}

O algoritmo de animação baseado em Física é responsável pelo realismo na animação das plantas. A tabela 4.7 ilustra o desempenho do sistema em três situações: cenas estáticas (sem animação), com animação baseada em um movimento aleatório e com animação utilizando o algoritmo baseado em controles dinâmicos. O campo de forças está ativo em todas as situações estabelecidas.

\begin{tabular}{|c|r|r|}
\hline \hline Cena & Técnica de animação & Taxa de quadros por segundo \\
\hline C2 & Objetos estáticos. & $50 \pm 10 \mathrm{fps}$ \\
C2 & Animação com movimento aleatório & $44 \pm 10 \mathrm{fps}$ \\
C2 & Animação por controles dinâmicos. & $29 \pm 11 \mathrm{fps}$ \\
C4 & Objetos estáticos. & $52 \pm 08 \mathrm{fps}$ \\
C4 & Animação com movimento aleatório & $42 \pm 07 \mathrm{fps}$ \\
C4 & Animação por controles dinâmicos. & $26 \pm 09 \mathrm{fps}$ \\
C6 & Objetos estáticos. & $49 \pm 11 \mathrm{fps}$ \\
C6 & Animação com movimento aleatório & $36 \pm 15 \mathrm{fps}$ \\
C6 & Animação por controles dinâmicos. & $33 \pm 06 \mathrm{fps}$ \\
\hline \hline
\end{tabular}

Tabela 4.7: Tabela de análise de desempenho do algoritmo de animação baseado em controles dinâmicos.

Ao se analisar o número máximo de instâncias de plantas que podem ser modeladas de modo que o usuário possa se mover sobre a cena em tempo real, podemos concluir que os resultados obtidos para as técnicas de animação e interação são bons. Isto por que mesmo considerando os objetos estáticos não seria possível criar uma quantidade de plantas muito superior à gerada nos exemplos.

Ainda se considerarmos o tempo de animação aleatória (o tempo gasto para apenas movimentar as plantas), verificamos que para geração de uma animação realista, por componente de planta e considerando dados físicos, a variação no desempenho é pequena. Podemos verificar isto na cena C6 que contém um menor número de componentes de planta que a diferença entre os resultados de uma movimentação aleatória para o algoritmo desenvolvido é mínima. 


\subsubsection{Análise do desempenho do algoritmo de nível de detalhes}

A tabela 4.8 descreve o desempenho do sistema ao se utilizar o algoritmo de níveis de detalhes nas cenas $\mathrm{C} 2, \mathrm{C} 4$ e C6. O desempenho do sistema é descrito para cada técnica de modelagem e em seguida o desempenho do sistema utilizando o algoritmo de níveis de detalhes. O intervalo de distância que define a região que é utilizada cada nível é definida entre parênteses.

\begin{tabular}{|c|l|r|}
\hline \hline Cena & Técnica de modelagem & Taxa de quadros por segundo \\
\hline C2 & Apenas LOD1 & $20 \pm 06 \mathrm{fps}$ \\
C2 & Apenas LOD2 & $24 \pm 05 \mathrm{fps}$ \\
C2 & Apenas LOD3 & $31 \pm 07 \mathrm{fps}$ \\
C2 & 3 Níveis de detalhes $(0|10| 15)$ & $29 \pm 11 \mathrm{fps}$ \\
C2 & 3 Níveis de detalhes $(0|15| 20)$ & $28 \pm 08 \mathrm{fps}$ \\
C2 & 3 Níveis de detalhes $(0|20| 30)$ & $26 \pm 10 \mathrm{fps}$ \\
\hline C4 & Apenas LOD1 & $20 \pm 05 \mathrm{fps}$ \\
C4 & Apenas LOD2 & $23 \pm 05 \mathrm{fps}$ \\
C4 & Apenas LOD3 & $28 \pm 03 \mathrm{fps}$ \\
C4 & 3 Níveis de detalhes $(0|10| 15)$ & $26 \pm 09 \mathrm{fps}$ \\
C4 & 3 Níveis de detalhes $(0|15| 20)$ & $23 \pm 07 \mathrm{fps}$ \\
C4 & 3 Níveis de detalhes $(0|20| 30)$ & $20 \pm 09 \mathrm{fps}$ \\
\hline C6 & Apenas LOD1 & $29 \pm 03 \mathrm{fps}$ \\
C6 & Apenas LOD2 & $34 \pm 04 \mathrm{fps}$ \\
C6 & Apenas LOD3 & $36 \pm 05 \mathrm{fps}$ \\
C6 & 3 Níveis de detalhes $(0|10| 15)$ & $33 \pm 06 \mathrm{fps}$ \\
C6 & 3 Níveis de detalhes $(0|15| 20)$ & $30 \pm 08 \mathrm{fps}$ \\
C6 & 3 Níveis de detalhes $(0|20| 30)$ & $29 \pm 05 \mathrm{fps}$ \\
\hline \hline
\end{tabular}

Tabela 4.8: Tabela de análise de desempenho dado o algoritmo de nível de detalhes de modelagem.

Os resultados obtidos justificam a utilização dos níveis de detalhes. A qualidade da animação é melhorada sem comprometer muito o desempenho do sistema. Os dados mostram que ao se utilizar diferentes níveis de detalhes o desempenho se encontra entre o nível de detalhe mais eficiente e o menos eficiente. Além disso, isto mostra que o algoritmo de transição entre níveis não compromete o desempenho do sistema, além de gerar transições razoavelmente suaves. 


\section{Capítulo 5}

\section{Conclusão}

Esta dissertação apresentou novas técnicas para resolver problemas relacionados à simulação de um mini-ecossistema vegetal em tempo real. Diversos assuntos relacionados ao tema foram abordados e diversas aproximações foram desenvolvidas para solução de cada problema específico. Muitas destas podem ser aproveitadas para resolver outros problemas semelhantes.

Dentre as técnicas desenvolvidas, duas se destacam pelas idéias que certamente são importantes contribuições para o estado da arte em pesquisa de simulação em tempo real: o campo de forças e a técnica de animação baseada em controles. Estas técnicas serão apresentadas no artigo [EMF], a ser submetido. Algumas técnicas, ainda que incompletas, podem ser encontradas no artigo [EMF03] que trata do problema específico de vegetação rasteira.

Foi criado um arcabouço que satisfaz a todos os requisitos propostos no início deste trabalho. Além disso, este arcabouço foi projetado para ser expansível e reutilizável, pois um sistema que simula ecossistemas pode ser tão complexo quanto imaginarmos.

Um estudo profundo de diversas técnicas já desenvolvidas possibilitou que fossem criadas técnicas mais adequadas ao nosso problema, além de facilitar a identificação das que mais satisfazem o mesmo. Muitas dessas técnicas foram estendidas ou utilizadas em conjunto com outras para obtenção de melhores resultados com sucesso.

A comparação dos resultados obtidos com outras técnicas que se propõem a simular a animação realista e interativa de objetos complexos, é outro ponto que nos faz afirmar que o objetivo do trabalho foi atingido. A eficiência do sistema faz com que seja possível de executá-lo em computadores comuns, com qualidade que pode ser comparada inclusive com técnicas que não exigem eficiência de algoritmo 
e execução em tempo real.

Apresentamos os resultados obtidos na seção 5.1. São exibidas cenas com sequências de animação geradas pelo sistema. Na seção 5.2 sugerimos trabalhos que podem ser válidos para melhoria e extensão do arcabouço desenvolvido. Considerações finais sobre o trabalho e o tema da tese, após a implementação do arcabouço, são discutidas na seção 5.3.

\subsection{Resultados}

Como o trabalho foi composto de diversos tópicos, os resultados obtidos para cada técnica desenvolvida já foram apresentados em suas devidas seções no capítulo 3. A análise dos resultados também já foi discutida no capítulo anterior. As figuras 5.1 e 5.2 apresentam uma sequência de animação que ilustra uma cena gerada pelo arcabouço e reproduz o resultado final gerado por todas técnicas desenvolvidas.

\subsection{Trabalhos futuros}

A complexidade da simulação de um mini-ecossistema de modo realista permite que citemos inúmeras melhorias ao sistema e trabalhos que o torne mais completo. Nesta seção citamos alguns itens que podem ser implementados como extensão do arcabouço.

Alguns problemas relacionados à Computação Gráfica podem ser resolvidos. A detecção de colisão entre componentes das planta foi um dos problemas não tratados. Este é um problema bastante difícil de ser implementado em tempo real, devido, novamente, ao grande número de instâncias em uma cena. A animação das plantas torna o desafio mais complexo, porém em caso de sucesso o realismo do sistema aumentaria bastante, pois o movimento de algumas plantas poderia ser impedido por outra.

O realismo do sistema também seria melhorado caso fossem utilizadas texturas de plantas reais sobre os modelos. A utilização de texturas já é possível neste sistema, de modo que alguns testes realizados mostraram que não houve perda no desempenho do sistema. Porém, a coleta de imagens de plantas reais para texturas é uma tarefa bastante trabalhosa. Uma implementação mais realista para iluminação poderia simular melhor a luz do sol em vários horários do dia, gerando assim cenas mais ricas em detalhes.

Um estudo do sistema em cooperação com pessoas relacionadas à área de Biologia pode ser feito de modo a se considerar propriedades importantes das plantas para que o sistema possa ser utilizado como uma aplicação para estudo de Ecologia ou Botânica pelo computador.

As técnicas de níveis de detalhes para modelagem ajudaram a melhorar o desempenho do sistema, porém ainda não são suficientes para modelar uma cena ampla, contendo muitos objetos. É provável 

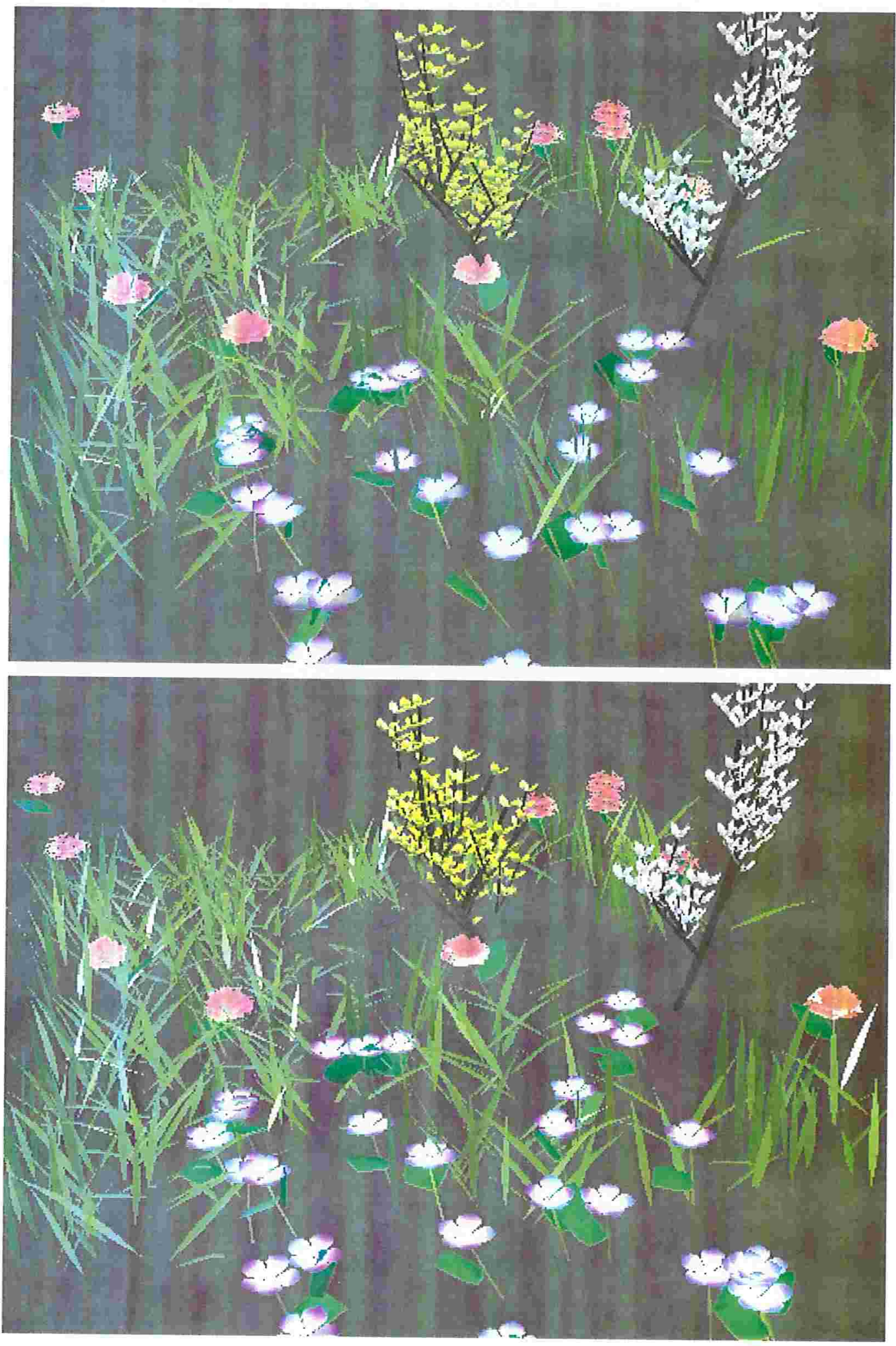

Figura 5.1: Mini-ecossistema animado em tempo real, pela ação do vento. 

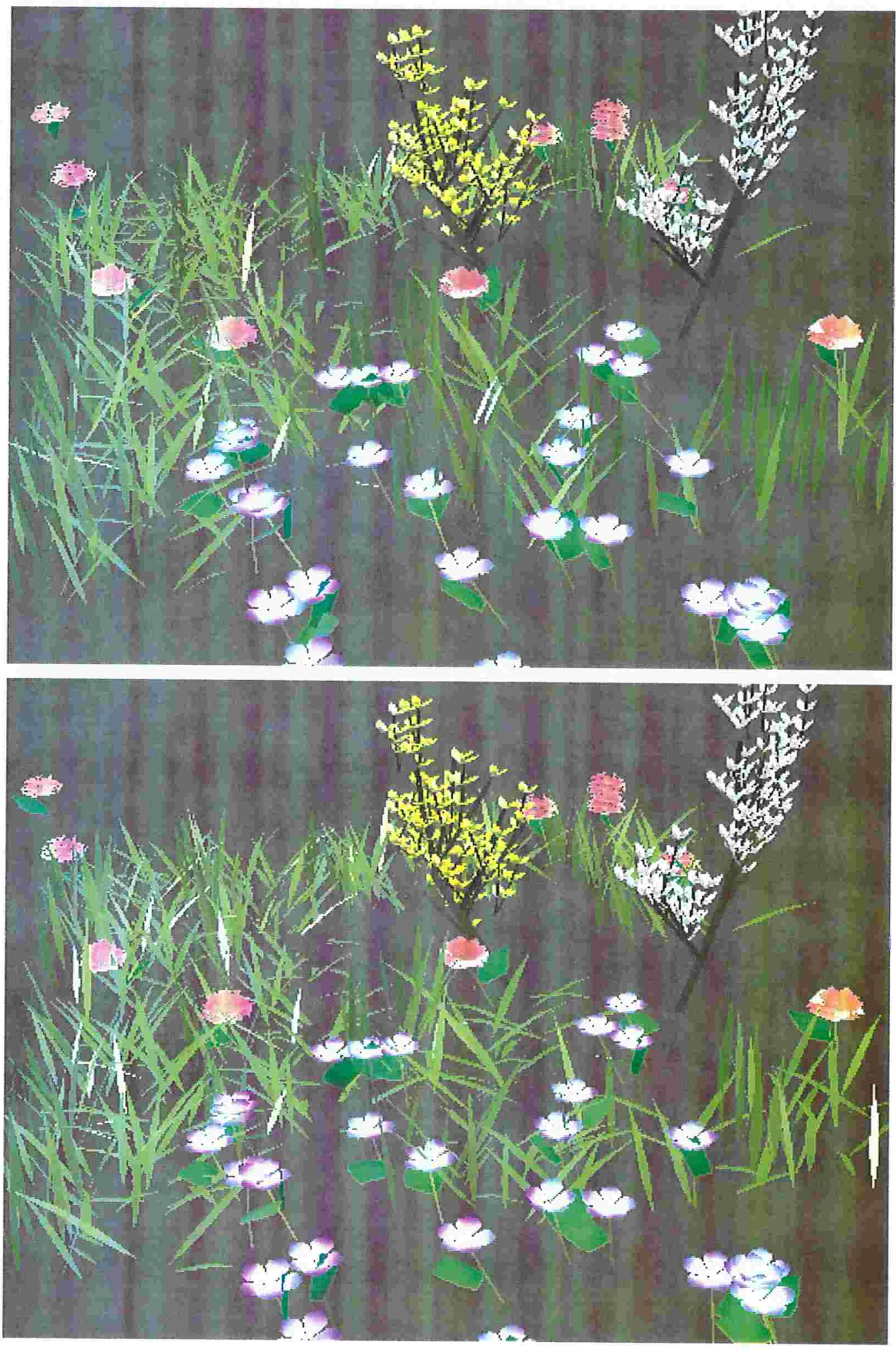

Figura 5.2: Continuação da animação... 
que nenhuma técnica baseada em polígonos ou mesmo pontos e linhas seja capaz de animar uma cena complexa em tempo real. Técnicas baseadas em imagem são capazes de resolver este problema, no entanto o realismo é seriamente comprometido. Um estudo de novas técnicas para este problema é certamente um trabalho futuro a ser implementado neste sistema.

A modelagem de árvores e arbustos de modo realista e em tempo real é o maior desafio para trabalhos futuros. Como se tratam de modelos bastante complexos, a animação realista destes é muito difícil. Modelos como L-Systems e Splines podem gerar imagens realistas mas devem ser simplificados e adaptados ao problema de animação interativa.

\subsection{Considerações finais}

A animação realista de cenários complexos contendo muitos objetos requer muitas aproximações e otimizações, considerando a cena que se quer modelar. A implementação deste sistema mostrou as limitações que ainda existem para este problema.

Com a capacidade dos computadores comuns atuais, ainda é difícil animar uma cena contendo muitos objetos de geometria complexa em tempo real. O realismo é bruscamente comprometido em técnicas capazes de animar objetos complexos em tempo real.

Apesar das dificuldades este projeto desenvolveu uma série de avanços que podem ser úteis para simulação de cenas complexas em tempo real. Com o avanço do "hardware", o número de polígonos por segundo que pode ser gerado de modo interativo irá aumentar, proporcionando melhores resultados. Sabemos que atualmente já existem computadores comuns muito mais poderosos, que o utilizado para os testes de desempenho, onde podemos obter melhores resultados utilizando o sistema desenvolvido.

Apesar de desenvolver técnicas eficientes, uma implementação correta e eficiente é necessária e pode representar ganhos maiores que as técnicas em si. Um bom planejamento do sistema faz com que o sistema seja mais eficiente. Isto foi comprovado neste projeto.

Este arcabouço foi o primeiro passo para a construção de um sistema complexo que se aproxime cada vez mais de um mini-ecossistema. Diversas sugestões para o aprimoramento do sistema foram citadas, e espera-se que este sistema seja utilizado para início de uma série de outras dissertações e artigos. 


\section{Apêndice A}

\section{Detalhes da Arquitetura do Arcabouço}

Neste apêndice a arquitetura do arcabouço é detalhada. O entendimento dos pacotes e de suas classes é de fundamental importância para extensão e utilização do arcabouço. Além disso, o arcabouço é o resultado da implementação das técnicas descritas nesta dissertação, e portanto deve refletir o funcionamento prático de todas as idéias introduzidas.

O arcabouço é composto por mais de 170 classes. Descrevemos a funcionalidade básica das classes mais importantes, assim como o modo de estender outras para que seja possível a modificação e agregação de novas funcionalidades ao sistema posteriormente. Explicamos como é possível a extensão do projeto, dada a arquitetura implementada em cada pacote.

Todos os pacotes criados são introduzidos e discutidos, as classes mais relevantes são representadas por diagramas de classes UML (Unified Modeling Language) ${ }^{1}$ [Alh98], padrão para modelagem de sistemas orientados a objetos. Esses diagramas foram gerados utilizando a ferramenta gratuita ArgoUML 2

Utilizamos diversos padrões de modelagem e arquitetura de sistemas orientados a objetos ("Design Patterns") no arcabouço. Alguns dos que foram utilizados serão citados nesta seção. A definição destes pode ser encontrado em detalhes em [GHJV95, Met02].

O pacote ecosys é a base do sistema, todas as classes e subpacotes estão abaixo deste. Nas próximas subseções, discutimos os detalhes relevantes de cada pacote abaixo de ecosys, que são os seguintes:

\footnotetext{
${ }^{1}$ http://www.omg.org/uml/

${ }^{2} \mathrm{http}$ ///argouml.tigris.org
} 
- ecosys.interaction

- ecosys.j3d

- ecosys.lib

- ecosys.naturalphenomena

- ecosys.plants

- ecosys.terrain

- ecosys.ui

- ecosys.util

- ecosys.visualization

Apresentamos os pacotes na mesma ordem que utilizamos para explicar as técnicas necessárias para sua implementação, descrita no capítulo 3. Portanto, começamos descrevendo o pacote responsável pela criação do terreno, seguido do pacote ecosys. interaction, que por sua vez trata a criação e manutenção do campo de forças. Em seguida detalhamos o pacote responsável pela criação das plantas, que concentra classes responsáveis pela modelagem, animação e distribuição das plantas. Apresentaremos então o pacote responsável por modelar o vento. Por fim, descrevemos os demais pacotes auxiliares que compõem o arcabouço.

\section{A.1 Pacote ecosys . terrain}

O terreno foi modelado utilizando diversas faixas do objeto TrianglestripArray. Não serão usados splines para suavização do terreno, pois isto dificultaria a implementação e aumentaria o custo computacional do sistema, prejudicando a visualização em tempo real. Para suavizar os problemas da discretização utilizamos "shading".

O Diagrama A.1 ilustra as classes relativas ao pacote ecosys . terrain. Como podemos ver, trata-se de um pacote bastante simples. Descrevemos abaixo as informações necessárias para o entendimento e extensão deste módulo do sistema.

A classe TerrainData armazena todas informações relativas ao terreno, contendo inclusive dados sobre a irrigação e quantidade de nutrientes necessárias para geração da distribuição das plantas. A classe Terrain gera a malha de triângulos a partir dos dados do objeto TerrainData, trata-se da 


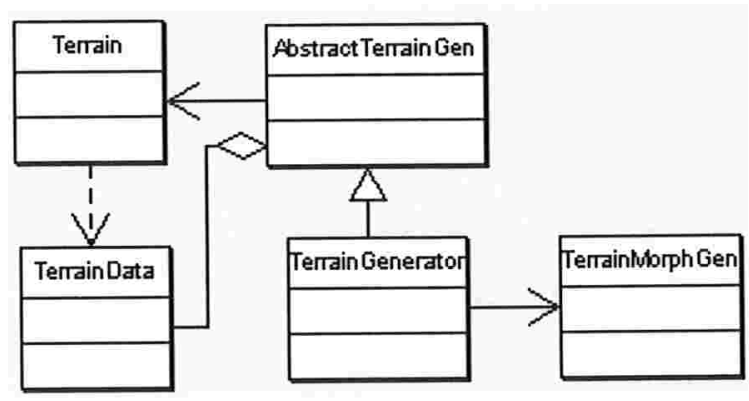

Figura A.1: Diagrama UML do pacote ecosys . terrain.

classe que estende Shape3D que será utilizada para renderização do terreno. A classe AbstractTerrainGen define métodos para que outros algoritmos de geração de terrenos possam ser implementados e integrados ao sistema.

O algoritmo de geração de terreno descrito na seção 3.2 foi implementado nas classes TerrainGenerator e TerrainMorphGen. Classes que estendem AbstractTerrainGen, como por exemplo TerrainGenerator, devem ser capazes de criar um objeto TerrainData, assim como retornar uma instância do objeto Terrain. Portanto, outros algoritmos de geração de terreno que forem futuramente integrados ao sistema devem seguir esta regra.

\section{A.2 Pacote ecosys.interaction}

Concentra as ações relacionadas com a interação externa sobre os objetos do sistema. Para poder se interagir com o sistema devem ser seguidas as regras definidas neste pacote. É um pacote de grande importância no sistema que implementa o campo de forças descrito na seção 3.4, e está diretamente relacionados aos pacotes ecosys.plants e ecosys. naturalphenomena. wind.

Um dos componentes mais importantes do sistema, o campo de forças, tem sua lógica implementada nas classes ForceField, ForceFieldActionManager e ForceFieldLODManager. A quadtree que compõe o campo de forças é implementada nas classes ForceFieldQuadTree e ForceFieldQTCell. Não entraremos em detalhes destas classes pois seu funcionamento já foi bem detalhado na seção 3.4. O Diagrama A.2 mostra como estas classes estão relacionadas. Maiores detalhes podem ser encontrados na documentação das classes.

Vamos detalhar o modo que um novo componente no sistema, capaz de interagir com os objetos do mesmo, deve ser adicionado. Também é importante descrever como adicionar novos objetos ao sistema de modo que estes sofram a ação do mesmo campo de forças. Estas duas funcionalidades são de grande 
importância para extensão do sistema.

Componentes, como o do pacote ecosys . naturalphenomena . wind, que agem sobre o campo de forças alterando a força aplicada nas regiões definidas pelo mesmo, devem implementar a interface ForceFieldActionHandlerInterface. Esta interface define métodos que serão utilizados pela classe ForceFieldActionManager, responsável pela atualização das forças nas células que estão no nível de detalhe atual do campo.

O componente que age sobre o campo de forças deve se registrar no objeto ForceFieldActionManager através do método addForceSource ( ) . Além disso, ele deve implementar de forma eficiente um mecanismo para adicionar uma ação nas células do nível de detalhe atual utilizando o método addForceAction() definido na classe ForceFieldQTCell. O objeto ForceFieldActionManager se encarrega de chamar todos os componentes que agem sobre o campo e atualizar a força resultante em cada célula após a ação de todos geradores de força.

Objetos que recebem a ação do campo de forças devem ser passados na inicialização do campo. Estes objetos devem estender a classe abstrata AbstractForceFieldobj, que contém ponteiros para a célula que o objeto irá pertencer no campo de forças e um método que retorna a força atual na célula que este se encontra. Esta classe também requer a implementação de métodos que retornam a posição e dimensão do objeto para que seja inserido na quadtree de modo correto.

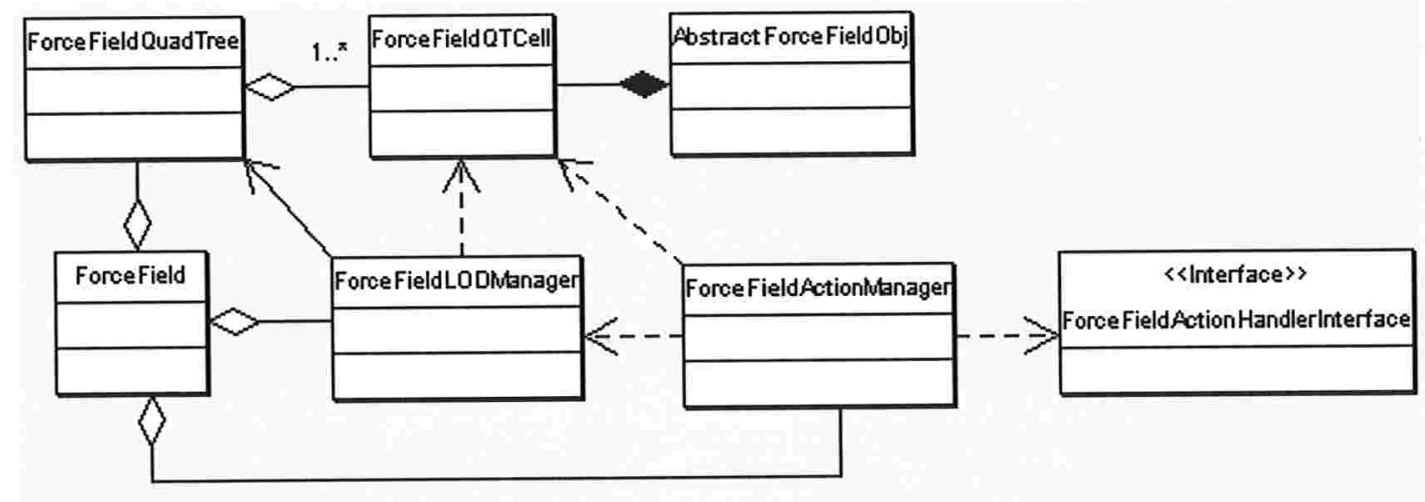

Figura A.2: Diagrama UML do pacote ecosys . interation.

\section{A.3 Pacote ecosys.plants}

O pacote ecosys . plant s concentra toda implementação relativa às plantas do sistema. Trata-se portanto de um pacote muito extenso, contendo diversos subpacotes. Cada um deles implementa uma 
funcionalidade do sistema descrita no capítulo 3 .

Além dos subpacotes, são definidas algumas classes básicas para as plantas neste pacote, como é mostrado no Diagrama A.3. A classe AbstractPlant deve ser implementada por todas as plantas que forem geradas pelo sistema, e define métodos que indicam dados relativos à distribuição e à ação do campo de forças sobre a planta. Esta classe estende AbstractForceFieldobj para que receba a ação do campo de forças e implementa a interface PlantDistribobj Interface relacionada à distribuição das plantas.

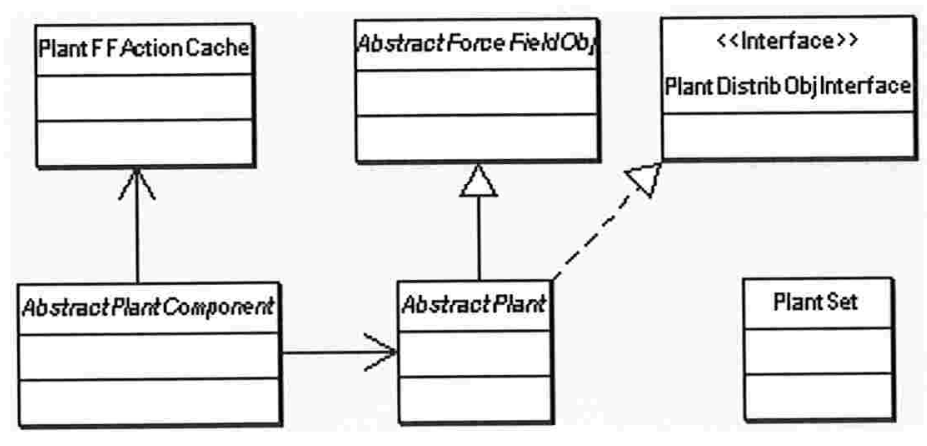

Figura A.3: Diagrama UML do pacote ecosys . plants.

A classe AbstractPlantComponent é uma classe abstrata que deve ser implementada por todos componentes de uma planta. A classe é estendida pelas classes Leaf, Branch e FlowerPetals, que representam uma folha, galho e flor, respectivamente. A classe PlantSet agrupa plantas em conjuntos e a classe $\mathrm{Pl}$ lantFFActionCache armazena dados relacionados à ação sobre as plantas que podem ser reaproveitados.

Nas próximas subseções descrevemos os pacotes relacionados às plantas. Começaremos estudando os pacotes ecosys.plants.leaf, ecosys.plants.branch e ecosys.plants.flower, que representam a modelagem dos componentes da planta descrita na seção 3.3. Em seguida, descrevemos os pacotes ecosys . plants . animation e ecosys . plants . distribution, que implementam a técnica de animação dos componentes baseada em controles, descrita na seção 3.5, e o algoritmo de distribuição das plantas, descrito na seção 3.6. O pacote ecosys .plants. underbrush cria alguns tipos de plantas que descrevem a vegetação rasteira. Já o pacote ecosys . plants . ds implementa algumas estruturas de dados auxiliares utilizadas nestes pacotes, porém, não relevantes para este texto. 


\section{A.3.1 Pacote ecosys.plants.leaf}

A classe Leaf Info contém as informações relativas a cada tipo diferente de folha que compõe a cena. Nela são armazenadas as informações: dimensões, massa e nível de maleabilidade das seções, cor, texturas, valor da variável de controle para o algoritmo de animação, níveis de nutrientes e irrigação que a folha suporta, além de informações sobre mudança de representação da folha (por polígonos ou linhas) utilizadas pelo algoritmo de nível de detalhe.

A classe AbstractLeaf define vários métodos para classes que a estenderem implementarem. Estes métodos definirão a forma da folha para cada posição pré-computada no objeto LeafLoad. O método generateGeometries () deve gerar a geometria básica da folha, enquanto o método initPhysicalProp(), por sua vez, deverá implementar a modificação da geometria utilizando atributos físicos. Após o cálculo da geometria final da folha, a classe AbstractLeaf cria a lista de centro de massa das folhas geradas. Esta informação será utilizada para animação das folhas.

A classe SectionBasedLeaf estende a classe AbstractLeaf. A sua implementação dos métodos generateGeometries() e initPhysicalProp() são baseadas na modelagem de componentes de plantas apresentados na seção 3.3.

A implementação da estrutura de dados de conjunto de vetores e armazenamento da pré-computação é realizado pela classe Leafobj Factory. Ela utiliza informações de geometria, alterada por física, da classe LeafLoad para criar o conjunto de vetores. Este conjunto de vetores é utilizado para calcular a forma das folhas que podem ser criadas em objetos do tipo GeometrystripArray ou LinestripArray, ambas da API do Java 3D, utilizando a quantidade de pontos desejada. A précomputação dos vetores é armazenada em um objeto do tipo GeomUpdaterDSCache, que também armazena informações das normais a cada face gerada pelos vetores.

A classe Leaf (estende AbstractPlantComponent) define a forma final da folha para cada nível de detalhe configurado pelo usuário. A classe LeafLOD determina os pontos que devem ser utilizados em cada nível de detalhe. Esta informação é passada para o objeto Leafobj Factory que retorna a geometria correta. O Diagrama A.4 ilustra as principais classes do pacote e as relações entre elas.

\section{A.3.2 Pacote ecosys.plants.branch}

As classes do pacote ecosys.plants.branch são responsáveis pela modelagem de galhos e troncos de plantas.

A classe Branch estende AbstractPlantComponent, ou seja, representa um componente de 


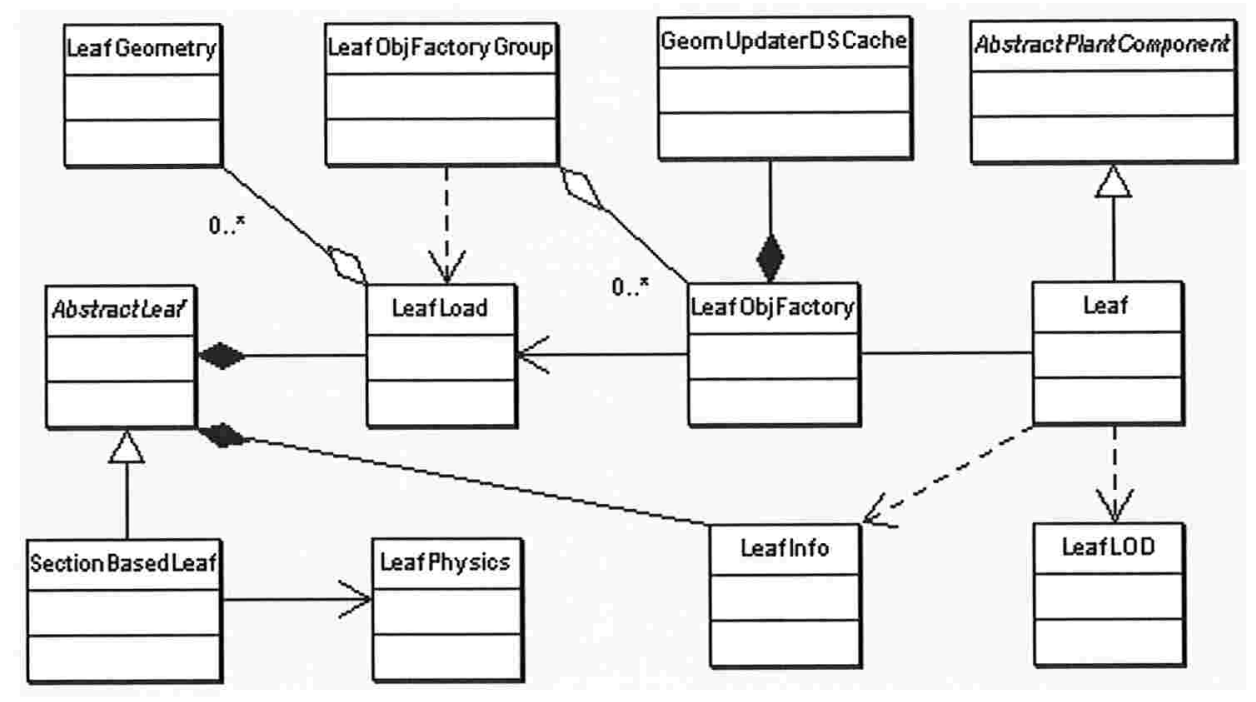

Figura A.4: Diagrama UML do pacote ecosys . plants . leaf.

planta. Ela depende da classe BranchLOD para retornar as geometrias de cada nível de detalhe do modelo do galho. Estas geometrias serão armazenadas em um objeto Switch, descrito na seção 4.2.1, que será adicionado ao grafo da cena para renderização do galho.

A classe BranchLOD, por sua vez depende das classes BranchInfo, Branchobj Factory e BranchData para gerar a geometria de cada nível de detalhe.

A classe BranchInfo contém informações relevantes ao tipo de galho que está sendo modelado. Com funcionalidade semelhante à classe Leaf Info, esta classe armazena as mesmas informações para o galho: dimensões, cor, texturas, níveis de nutrientes e irrigação, etc.

A classe BranchobjFactory é responsável por criar e alterar as coordenadas dos modelos. Para isto, utiliza a classe BranchData que contém as informações para se obter as geometrias précomputadas do eixo principal e das bases do galho em "cache". O galho é composto por vetores que representam o eixo principal e vetores que representam a forma do galho em cada parte do eixo principal como foi descrito na Figura 3.2. As classes responsáveis pelo "cache" destes vetores são BranchGeomCache e BranchBaseCache, respectivamente

A classe BranchModel utiliza informações da classe BranchInfo para criar objetos BranchGeometry que representam o eixo principal do galho. Dados sobre massa, espessura e até fototropismo são utilizados para geração dos modelos.

O Diagrama A.5 ilustra o relacionamento entre as classes deste pacote. A classe BranchAni- 
mationgeometry, do pacote ecosys.plants.animation, é responsável pela animação dos galhos. Ela depende de diversos objetos definidos neste pacote como podemos observar no diagrama.

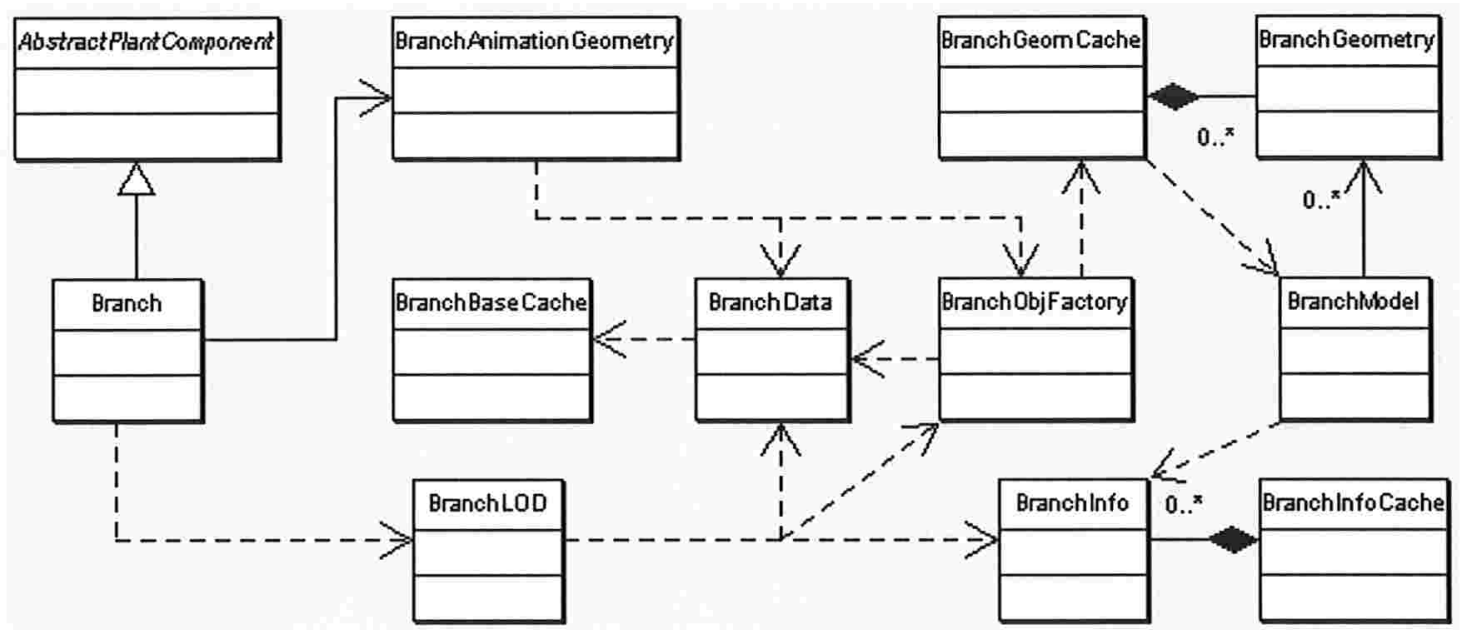

Figura A.5: Diagrama UML do pacote ecosys .plants . branch.

\section{A.3.3 Pacote ecosys.plants.flower}

O pacote ecosys.plants.flower é composto atualmente por apenas duas classes: FlowerInfo e FlowerPetals. A classe FlowerInfo é responsável por armazenar as informações necessárias para geração da flor. A classe FlowerPetals, que estende AbstractPlantComponent, cria um modelo de flor utilizando diversos objetos Leaf como pétalas das flores. Caso seja necessário estender este pacote para disponibilizar outros tipos de flores utilizando uma técnica de modelagem diferente basta criar o componente e estender a classe AbstractPlantComponent.

\section{A.3.4 Pacote ecosys.plants.animation}

As classes deste pacote tratam a animação dos componentes da planta. São definidas duas threads importantes para o sistema, que executam de forma concorrente com a thread do campo de forças. As threads PlantCompSimulationHandler e PlantCompAnimationHandler são responsáveis por simular a ação do campo sobre as plantas e animar as plantas dado o resultado da simulação, respectivamente.

É definida também uma classe abstrata chamada AbstractAnimationGeometry. As classes que a estendem são responsáveis por executar a simulação e a animação dos componentes. $\mathrm{O}$ arcabouço 
permite que esta funcionalidade seja implementada de diversas formas, desde que a classe implemente os métodos definidos por esta classe abstrata. As classes LeafAnimationGeometry e BranchAnimationGeometry implementam a simulação e animação dos componentes da planta (folhas e galhos), para isso utilizam a técnica descrita na seção 3.5.

Para simulação e animação das plantas, o seguinte processo é executado: A thread de simulação, que conhece todos objetos do tipo AbstractAnimationGeometry criados, pede para que os mesmos executem uma simulação dada a nova configuração do campo de forças, retornando a sua nova posição. Em seguida é gerada uma lista contendo os objetos cuja posição foi alterada e são visíveis. Esta lista é criada utilizando o objeto GeometryAngleDS, que se trata simplesmente de uma lista ligada contendo o objeto AbstractAnimationGeometry e o ângulo que este deve estar no próximo passo da animação.

A thread de animação continua executando a animação anterior, e quando termina de atualizar a posição de todos os componentes pede uma nova lista para a thread PlantCompSimulationHandler. Caso a lista esteja criada, a thread de animação utiliza a lista para animar os componentes que tiveram sua posição alterada. A criação de uma nova lista pela thread de simulação é iniciada apenas quando a thread de animação retira a lista mais recentemente gerada pela simulação. Enquanto a animação, que é mais lenta, é executada e há uma lista de simulação pronta, a thread de simulação passa a vez para a thread de animação ser executada. O Diagrama A.6 mostra o relacionamento das classes deste pacote.

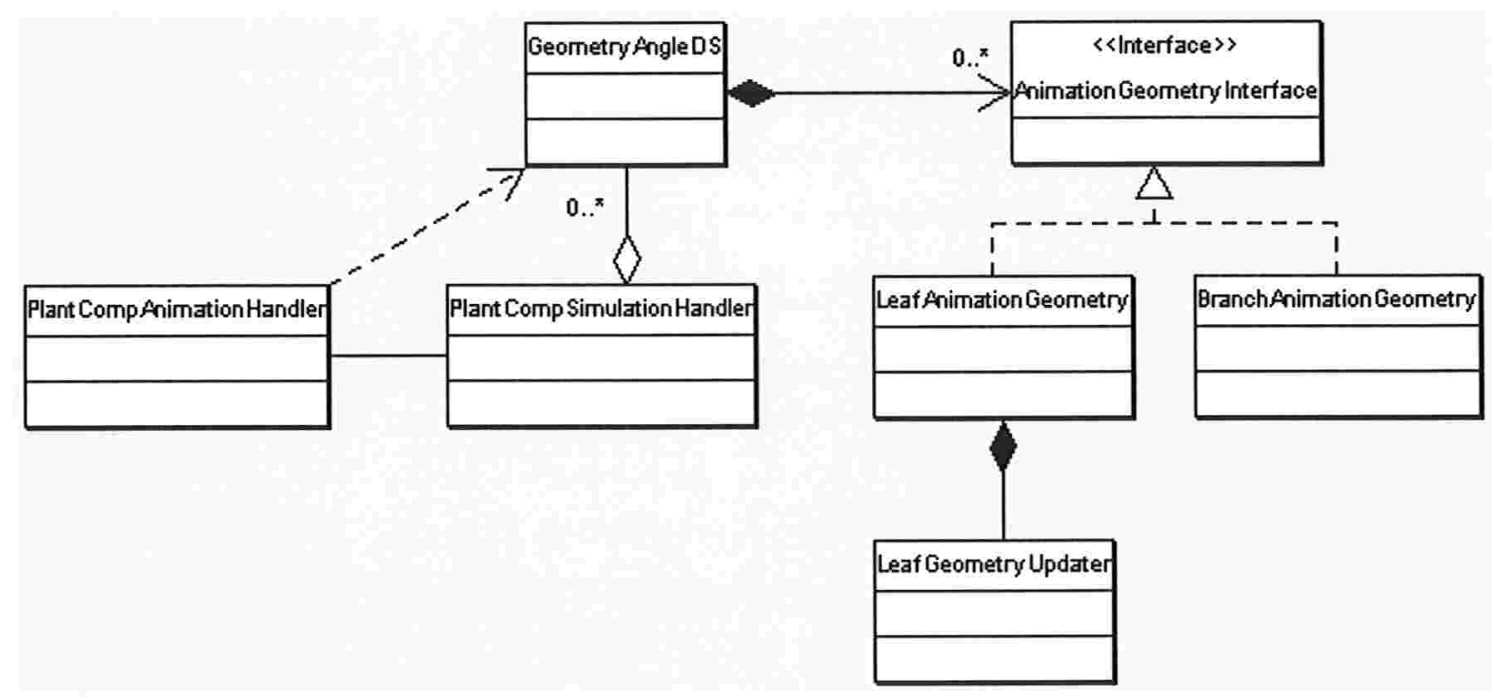

Figura A.6: Diagrama UML do pacote ecosys . plants . animation. 
Para animação utilizamos a interface GeometryUpdater, descrita na seção 4.2.1. Os componentes Leaf e Branch têm classes que implementam esta interface e atualizam as coordenadas utilizadas pelo modelo visível ao observador.

\section{A.3.5 Pacote ecosys.plants.distribution}

A distribuição das plantas é tratada pelo pacote ecosys .plants.distribution. É possível implementar outros algoritmos de distribuição, para isto basta que a nova classe que crie a distribuição estenda a classe AbstractPlantDistribution.

A classe PlantDistributionGenerator cria a distribuição concorrente das plantas como foi descrito na seção 3.6. A classe AbstractPlantDistribution implementa o padrão "Command", definindo um método expand, que é chamado pela classe PlantDistributiongenerator para criação de uma nova planta.

O algoritmo de distribuição baseado em nutrientes e irrigação do terreno é implementado na classe AbstractNutrientBasedDistribution. Esta classe estende AbstractPlantDistribution, e é estendida pelas classes que criam a distribuição dos tipos de vegetação do sistema. Exemplos de classes que estendem AbstractNutrientBasedDistribution são ilustrados no Diagrama A.7, que mostra o relacionamento das classes mais importantes deste pacote.

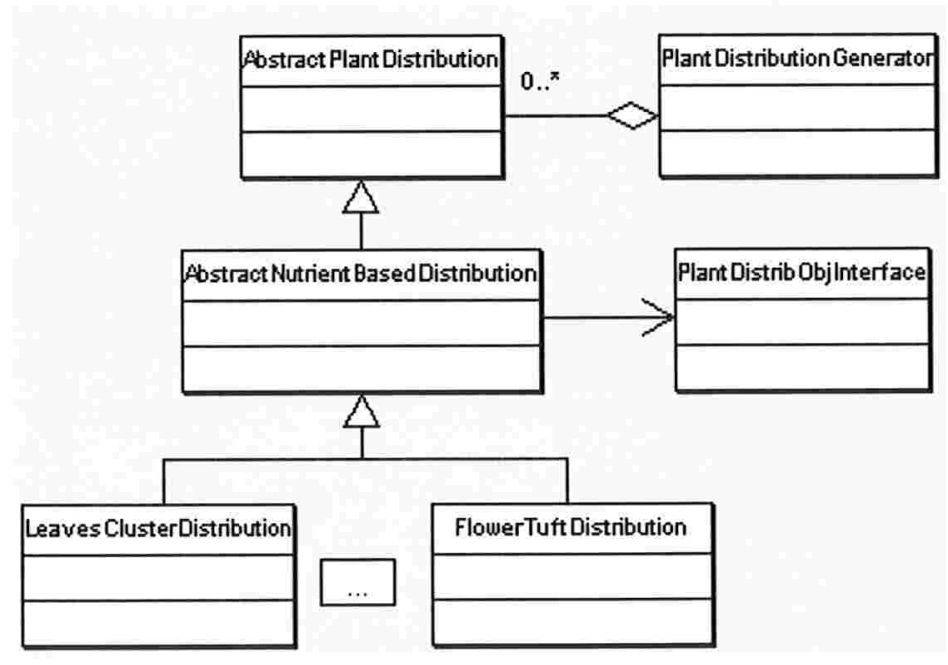

Figura A.7: Diagrama UML do pacote ecosys .plant.distribution. 


\section{A.3.6 Pacote ecosys.plants.underbrush}

Este pacote contém classes que são responsáveis por criar plantas que representam vegetação rasteira. Foram implementadas classes parametrizadas, que podem representar uma grande quantidade de tipos de vegetação. O Diagrama A.8 ilustra as principais classes deste pacote.

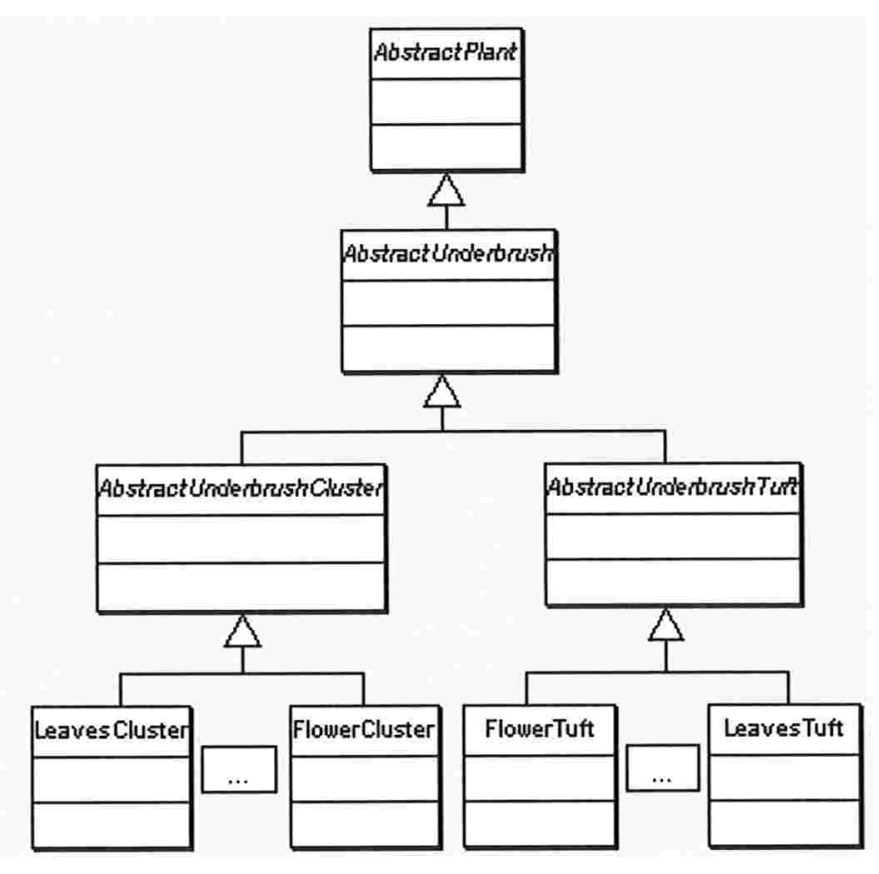

Figura A.8: Diagrama UML do pacote ecosys . plant . underbrush.

É definida uma classe AbstractUnderbrush que estende AbstractPlant, ou seja, irá determinar uma planta do sistema. Esta classe define um método que será chamado para incluir a planta na cena, por classes relacionadas à visualização, todas sub-classes devem implementá-lo.

As classes AbstractCluster e AbstractTuft criam plantas distribuídas de modo livre ou em forma de tufo, implementando algoritmos para a posição de cada planta. As classes que estendem estas devem descrever a forma das instâncias deste tipo de vegetação, por exemplo, a classe FlowerTuft deve descrever uma flor que será adicionada à vegetação e posicionada como um tufo, pois ela estende AbstractTuft. 


\section{A.3.7 Pacote ecosys.plants.bush}

Este pacote contém classes que são responsáveis pela criação de arbustos e árvores nas cenas. Foram implementadas classes parametrizadas, capazes de representar uma grande variedade de arbustos. $\mathrm{O}$ Diagrama A.9 ilustra as principais classes deste pacote.

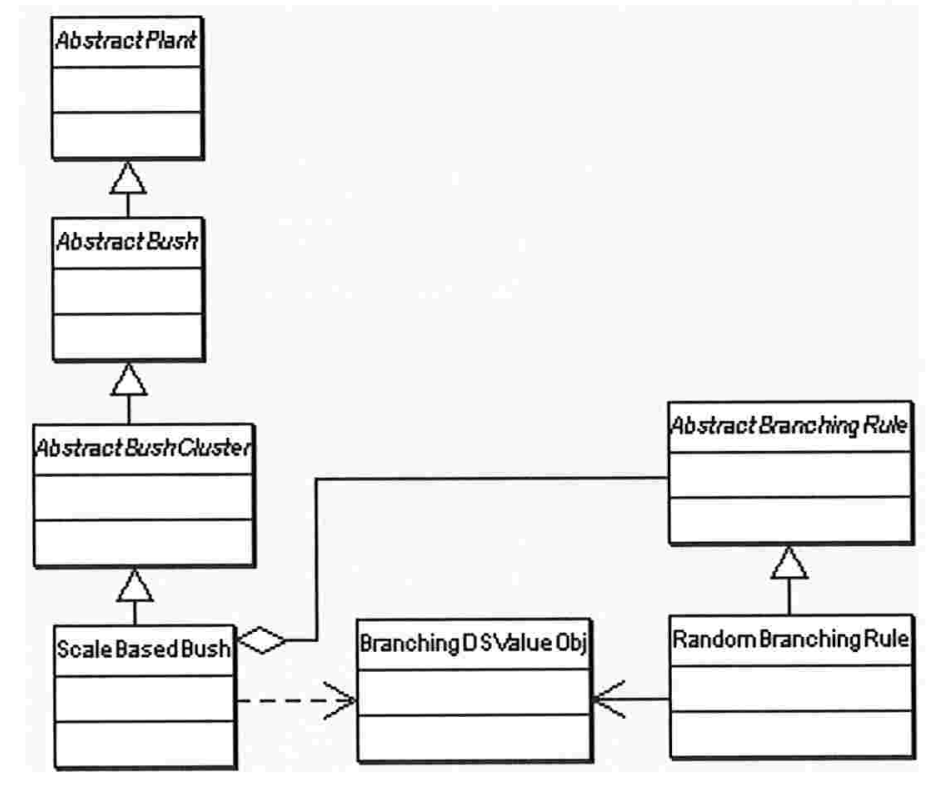

Figura A.9: Diagrama UML do pacote ecosys . plant . bush.

Como no pacote ecosys.plant. underbrush, é definida uma classe AbstractBush que estende AbstractPlant e define um arbusto do sistema. Esta classe define um método utilizado para inclusão do arbusto na cena, em caso de necessidade de criação de arbustos diferentes dos definidos, basta estender esta classe para integração com o sistema.

Neste arcabouço definimos uma classe simples para criação de arbustos. A classe AbstractBushcluster é responsável pela criação de um arbusto em uma certa região do terreno, adicionando todos componentes do arbusto na cena, utilizando o método addChildToGroup ( ) definido em AbstractBush. A classe ScaleBasedBush estende a classe AbstractBushcluster e cria um arbusto baseado em uma regra simples e nas informações dos galhos. Para um galhos principal são criados outros componentes de plantas em sua extensão, estes componentes podem ser inclusive outros galhos. A classe RandomBranchingRule é responsável por indicar o tipo de componente e a posição em que este deve ser inserido em um certo galho, para isso utiliza um algoritmo simples de escolha aleatória de componentes. 


\section{A.4 Pacote ecosys.naturalphenomena}

\section{A.4.1 Pacote ecosys.naturalphenomena.wind}

Este pacote encapsula todas classes relacionadas à geração e ação do vento sobre o campo de forças. Como veremos as funcionalidades implementadas neste pacote refletem diretamente sobre o campo de forças. A técnica para definição da ação do vento já foi discutida na seção 3.7.1 e é implementada por classes deste pacote.

A thread ForceField utiliza um objeto ForceFieldActionManager para atualizar todos objetos que agem sobre o campo de forças. Neste momento a classe Windobserver é chamada para fazer a atualização da simulação do vento e ação sobre o campo de forças, conforme já descrito pelos algoritmos da seção 3.7.1. A atualização do vento, portanto, é efetuada sob demanda quando o campo de forças for atualizado.

O Diagrama A.10 descreve as classes do pacote ecosys . naturalphenomena .wind. A classe Windobserver atualiza o WindManager, gerenciador de fluxos que iniciam ou se extinguem, o WindFlowManager, que gerencia os fluxos ativos, e as partículas já existentes chamando a classe WindParticleManager. Além disso, esta classe atualiza a lista de fluxos ativos. Como o componente deve ser bastante eficiente, algumas estruturas de dados auxiliares foram definidas para otimização do sistema, como as classes FFActionLinkedList e FFActionLinkedList que são lista de fluxos.

A classe WindData armazena dados relativos a um fluxo, como a velocidade média que os fluxos são criados, sua dimensão do fluxo (área de ação) e seu tempo de vida. Além disso, ela armazena a primitiva que descreve a forma do fluxo. Para criação desta primitiva deve ser definido um objeto que implementa a interface WindPrimitiveInterface. Três opções foram implementadas pelo sistema WindPrimitiveUniform, WindPrimitiveSink e WindPrimitiveSource que definem os fluxos uniforme, de atração e repulsão. Podem ser implementadas outras primitivas para geração de fluxos diferentes, para isto basta seguir as regras definidas pela interface.

A classe WindFlow trata as ações de um fluxo criado, definindo a velocidades dos fluxos. Este objeto também estima o vetor direção de ação de força que o fluxo exerce em um ponto definido. A classe WindFlowManager gerência os objetos WindFlow, simulando o vento por aproximação ou utilizando partículas. O valor de ação de forças externas na célula que o fluxo age é atualizado após a simulação. 


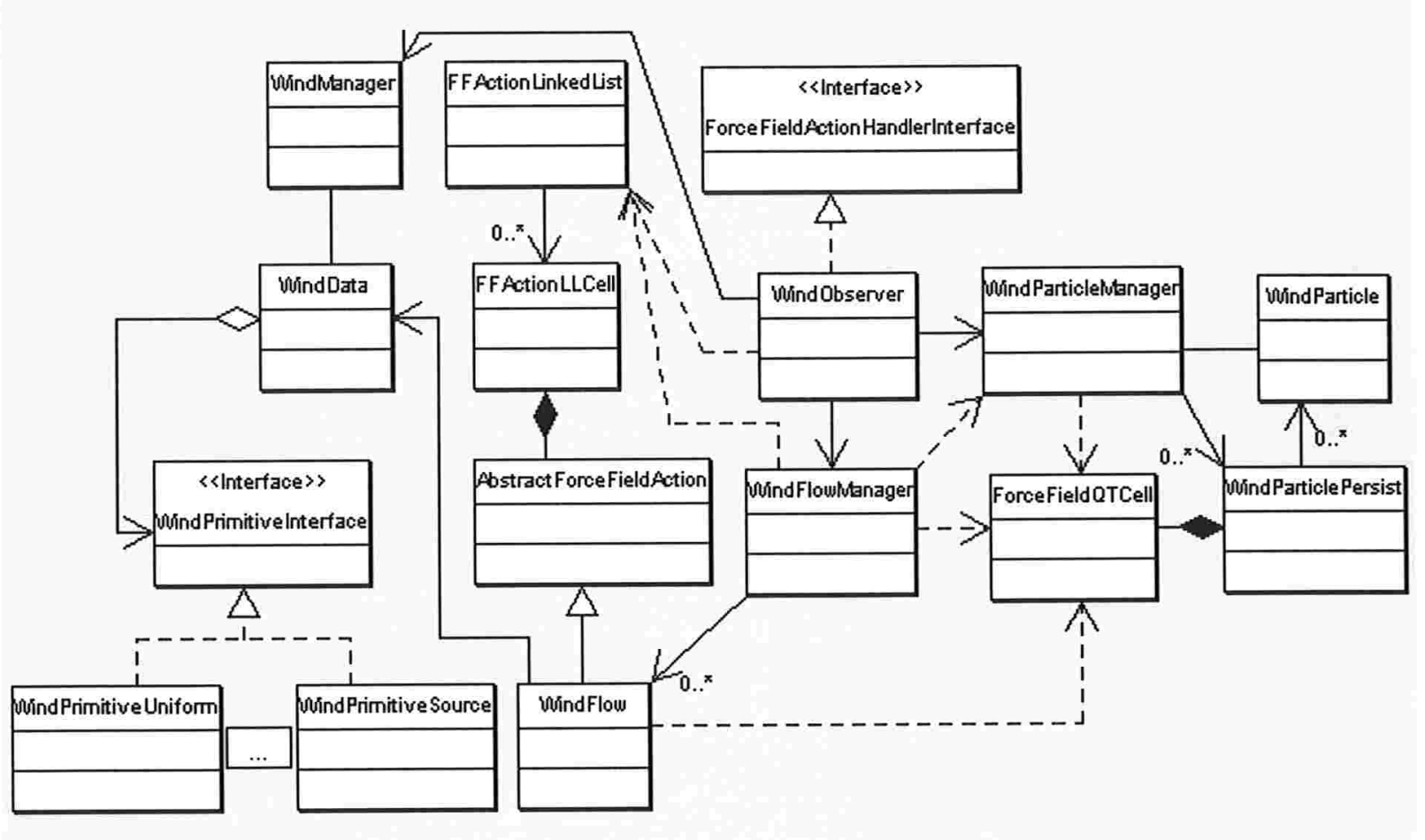

Figura A.10: Diagrama UML do pacote ecosys.naturalphenomena.wind. As classes do pacote ecosys.interaction, ForceFieldQTCell e ForceFieldActionHandlerInterface são exibidas para ilustrar o relacionamento das classes de geração de vento, com a interação com os objetos do sistema.

\section{A.5 Pacote ecosys.visualization}

O pacote ecosys . visualization encapsula as operações de adição de conteúdo no grafo de cena do programa. É um pacote composto por poucas classes, porém em caso de adicionar novos tipos de vegetação ou objetos ao sistema, novas classes podem ser criadas.

A classe EcosysVisualization cuida da geração do BranchGroup que será adicionado ao conteúdo do grafo da cena. Ele possui uma lista de objetos de visualização que geram todos grupos que irão compor a cena. Os objetos de visualização implementam a interface EcosysVisualizationInterface que define o método getVisualizationGroup (). Os objetos de visualização devem implementar este método de modo que ele retorne um objeto Group da API do Java 3D. Este objeto deve ter o conteúdo definido para cada tipo de visualização.

Ao se criar um objeto de visualização ele deve ser adicionado à lista do objeto EcosysVisua- 
lization, utilizando-se o método addVisualization(). Deste modo ele será adicionado ao grafo da cena automaticamente pelo objeto EcosysVisualization. O Diagrama A.11 ilustra as ações deste pacote.

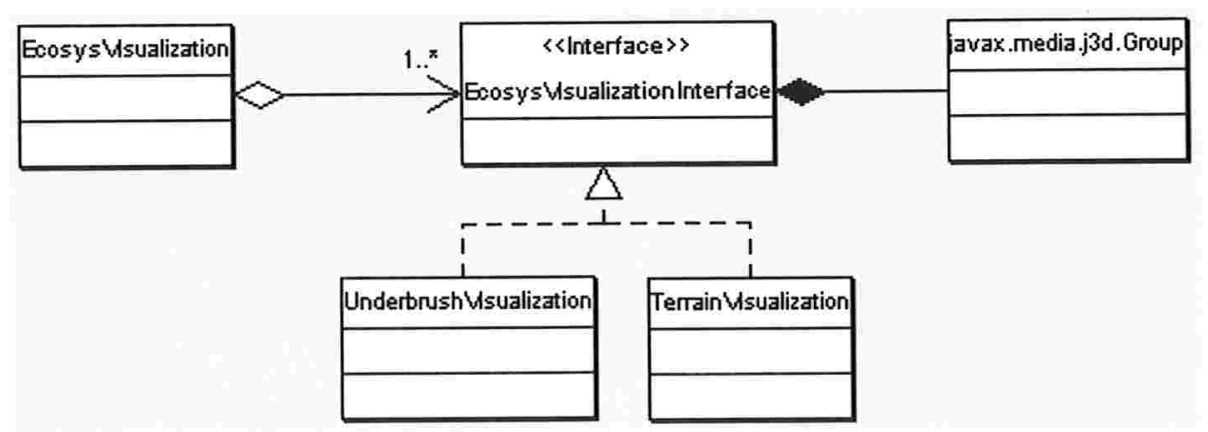

Figura A.11: Diagrama UML do pacote ecosys . visualization.

\section{A.6 Pacote ecosys.ui}

O pacote ecosys . ui encapsula funcionalidades relacionadas à interface do sistema com o usuário. Este pacote contém três subpacotes, um relacionado às informações do observador, um para interface gráfica do sistema e outro que implementa o interpretador da linguagem ESL. Discutimos as informações mais relevantes nas próximas subseções.

\section{A.6.1 Pacote ecosys.ui.gui}

Concentra classes relacionadas à interface gráfica do sistema com o usuário. Atualmente se restringe à classe que cria a janela da aplicação e ao diálogo de seleção de arquivo ESL.

\section{A.6.2 Pacote ecosys.ui.parser}

Como já foi dito, foi implementada uma linguagem para descrição das informações necessárias para criação da cena do sistema. Este pacote é responsável por interpretar este arquivo e criar os objetos necessários para que o sistema seja executado.

Os comandos da linguagem definem como e quais dados são analisados e utilizados para criação dos objetos que recebem as informações e as utilizam para uma determinada finalidade. Por exemplo, para criar uma planta são necessários comandos que definem propriedades das folhas e galhos da mesma. Os 
comandos tem atributos próprios, que definem as informações que o usuário disponibiliza para geração da cena.

Existem dois tipos de comandos que podem ser definidos pela linguagem: comandos terminais e comandos não terminais. A diferença entre os dois é que os comandos do tipo terminais não possuem subcomandos, enquanto os não terminais podem depender ou ser compostos por outros comandos. Este conceito vem da idéia do padrão "Interpreter".

O Diagrama A.12 mostra um modelo do pacote ecosys .ui parser. Comandos terminais da linguagem devem estender a classe ESLAbstract Command, enquanto os não terminais, por sua vez, devem estender a classe ESLAbstractNonTerminal Command.

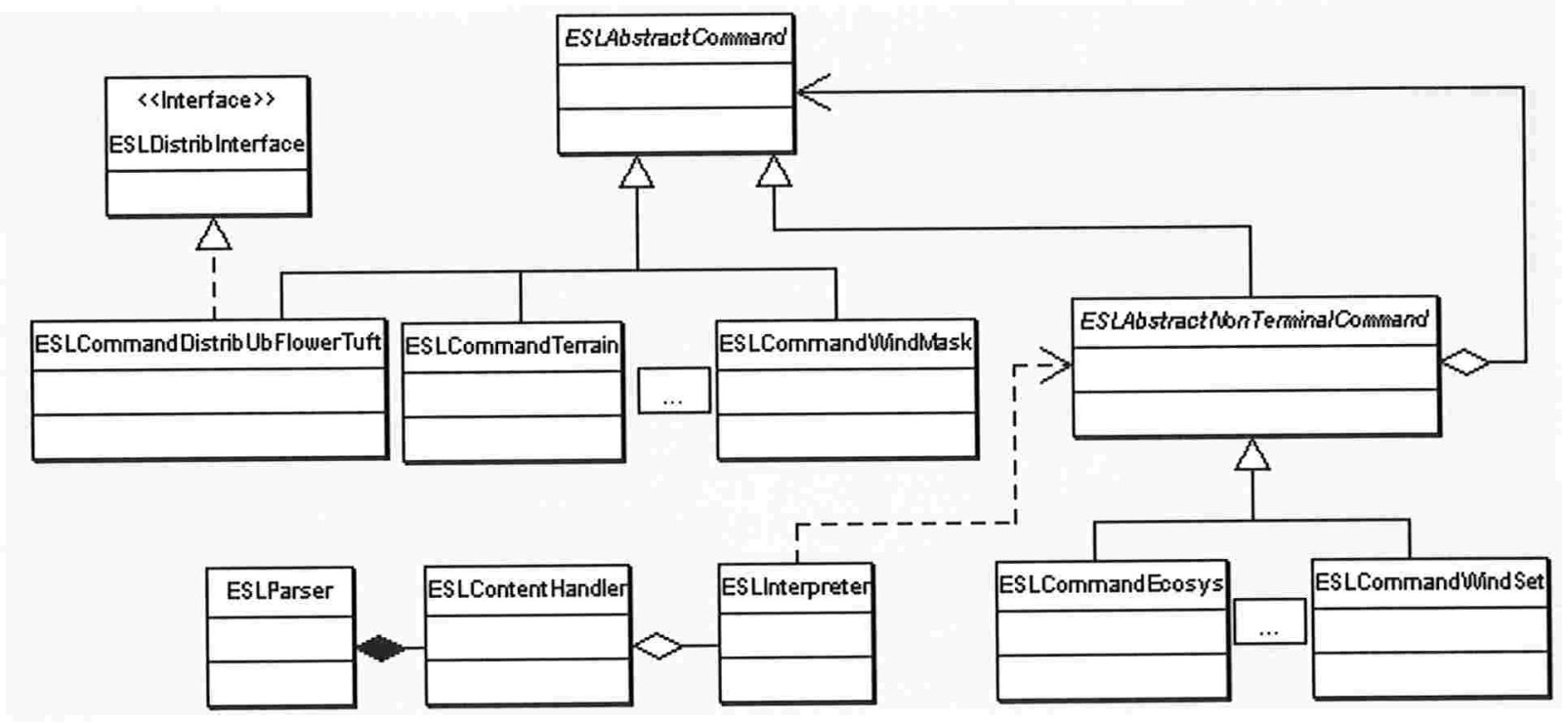

Figura A.12: Diagrama UML do pacote ecosys .ui . parser.

No exemplo da linguagem, que é descrito na seção, podemos ver que comandos que definem o terreno ou uma máscara de vento são do tipo terminais, como estão representados no diagrama. Um conjunto de vento é um comando que é composto por comandos que descrevem fluxos e máscaras de vento. Logo ele é um comando do tipo não terminal.

Todos os comandos definidos na linguagem estendem ou ESLAbstractCommand ou ESLAbs tractNonTerminal Command. Podemos ver pelo diagrama, que comandos não terminais estendem comandos, logo todos comandos estendem ESLAbstractCommand.

Em caso de criação de novas funcionalidades para o sistema, para incluir comandos que interpretem 
as informações necessárias para criação dos novos objetos, devem ser criados comandos para o interpretador também. Os comandos devem seguir a regra de estender um dos dois tipos de comandos da linguagem, para que possa ser interpretado corretamente.

\section{A.6.3 Pacote ecosys.ui.user}

Encapsula as classes relativas ao usuário ou ao observador. Atualmente a única classe deste pacote é a UserProps, que tem informações sobre o campo de visão do usuário. Utiliza conceitos de posição e orientação, que foram discutidos na seção 2.3.1, para determinar a posição e a direção de visão do observador. Estes dados são constantemente atualizados e são fundamentais para o algoritmo de atualização do campo de forças.

\section{A.7 Pacote ecosys.j3d}

Para construção do arcabouço foi necessária a criação de classes que facilitam a utilização de algumas funcionalidades disponíveis na API do Java 3D. Estas classes têm o objetivo de estender funcionalidades da API ou restringir funcionalidades complexas para que satisfaçam o apenas o que é necessário para o arcabouço (seguindo a idéia do padrão "Facade").

\section{A.8 Pacote ecosys. 1 ib}

Implementa uma mini biblioteca dentro do arcabouço. Classes deste pacote definem padrões para o sistema ou implementam funcionalidades utilizadas em todo sistema.

Dentre as classes deste pacote, a classe EcosysMulti ThreadManager tem uma funcionalidade bastante importante. Esta classe é responsável por iniciar as threads do sistema, que executam de forma concorrente. Dentre as threads temos o campo de forças, as classes para simulação da ação do campo sobre as plantas e a thread responsável pela animação das plantas.

\section{A.9 Pacote ecosys.util}

Contém classes utilitárias, na sua maioria relacionadas à geometria. Contém objetos de listas, matrizes bidimensionais e tridimensionais de primitivas como pontos, vetores e cores, que utilizam objetos disponibilizados pela API do Java 3D. Também podem ser encontradas classes que implementam algumas operações geométricas, vetoriais e físicas que foram necessárias para construção do sistema. Além da "bounding box" que é bastante utilizada nos algoritmos de aproximação do sistema. 


\section{Apêndice B}

\section{ESL - A Linguagem de Descrição de Cenas}

Neste apêndice apresentamos a linguagem ESL (EcoSystem Language), criada com o objetivo de descrever as cenas que o arcabouço pode gerar. As informações necessárias para criação da cena são descritas por um arquivo XML, suas "tags" e possíveis atributos são descritos nesta seção.

O interpretador para linguagem foi desenvolvido no pacote ecosys.ui.parser, descrito na seção A.6.2. Caso novas "tags" e atributos tenham que ser adicionados, para a extensão do sistema, deve-se seguir o procedimento descrito nesta seção para interpretação dos dados.

A seção abaixo explica as "tags" e atributos definidos na linguagem. A seção B.2 descreve um exemplo para geração de uma cena simples com a linguagem ESL, demonstrando assim a facilidade para se definir uma cena que simula diferentes espécies de vegetação utilizando este sistema.

\section{B.1 Descrição da linguagem}

Como todas linguagens baseadas em XML, a linguagem ESL é composta por "tags" e atributos que definem informações sobre objetos. Foram definidos alguns tipos para essas informações, como na maioria das linguagens de computador. As informações de cada atributo devem ser passadas no formato exigido pelo tipo definido, caso contrário o interpretador lançará uma exceção.

Vamos listar os tipos definidos no próximo parágrafo e a seguir descrevemos as "tags" e atributos indicando qual tipo deve ser utilizado para passar a informação. 


\section{B.1.1 Tipos definidos}

- Booleano (BOOL) - Aceita dois valores: TRUE e FALSE, em caso da informação requerida pelo atributo ser verdadeira ou falsa, respectivamente.

- Número Inteiro (INT) - Devem ser passados números inteiros. Exemplos: $-1,0,1,9$, etc.

- Número Real (REAL) - Devem ser passados números reais. Exemplos: $-1.2,0.9,1.5,9$, etc.

- Vetores ou pontos 3D (VEC) - O formato para representar um vetor ou ponto 3D é "(NUM1,NUM2, NUM3)", onde NUM1 representa o valor do eixo X, NUM2 do eixo Y e NUM3 do eixo Z. Os números devem ser do tipo real. Exemplos: $(0.0,0.0,0.0),(33.4,-5.0,2.0),(10.0,-90.0,1.5)$.

- Cor (COR) - A representação de cores deve seguir o seguinte formato: "(RVAL,GVAL,BVAL, AVAL)", onde RVAL, GVAL, BVAL representam os valores das tonalidades de vermelho, verde e azul e AVAL o valor alfa. Todos os valores devem ser definidos com valores no intervalo de 0.0 até 1.0. Exemplos: $(0.43,0.57,0.21,0.8),(0.19,0.27,0.06,0.8)$.

- Lista de inteiros (LINT) - Representa uma sequência de inteiros. Deve-se seguir o seguinte formato: “[NUM1,NUM2, ...,NUMX]”. Ex: [0, 1, 2, 3], [0, 4, 6, 15].

- Lista de reais (LREAL) - Representa uma sequência de números reais. Deve-se seguir o seguinte formato: “[NUM1,NUM2, ,..,NUMX]”. Ex: [0.0, 1.3, 0.2, 3.5], [0, 4.2, 6.6, 15].

- Palavras (PAL) - Sequência de alfanuméricos.

- Coordenadas 2D (COORD2D) - Coordenadas 2D, o formato deve ser o seguinte: "(COORD1, COORD2)". Exemplos: $(0,1),(30,40)$, etc.

\section{B.1.2 Tags e atributos}

Definidos os tipos que podem ser utilizados, listamos nesta seção todas as "tags" e atributos definidas na linguagem ESL. Adotamos as unidades de medida padrões (SI) no sistema, ou seja, é utilizado o metro (m) para distância, segundo (s) para tempo e quilograma $(\mathrm{kg})$ para massa. Caso utilizarmos outra unidade diferente das padrões adotadas, esta será explicitada na própria definição do atributo. Todos atributos são obrigatórios. 


\section{- ecosys}

É a "tag" que inicia a linguagem, todas outras tags deverão estar dentro desta. Esta "tag" define propriedades gerais do ecossistema.

Seus atributos são os seguintes:

o normal [VEC] Vetor que indica a normal da cena.

○ winlen [INT] Largura da janela onde a cena será renderizada.

○ winhei [INT] Altura da janela onde a cena será renderizada.

As "tags" que podem ser definidas dentro desta são as seguintes:

\section{- windset}

Define o conjunto de fluxos de vento que irão interagir sobre as plantas.

As "tags" que podem ser definidas dentro de windset são listadas abaixo.

\section{- windmask}

Define um formato (máscara) para o fluxo. Os possíveis atributos são listados abaixo:

o name $[\mathrm{PAL}]$ Define o nome da máscara. Este nome será utilizado para definir um fluxo.

- type [PAL] O tipo de máscara. Pode assumir os valores: uni form, source ou sink, que correspondem aos tipos de fluxos definidos na seção 3.7.2.

○ winddir [VEC] Direção do fluxo, obrigatório apenas para o fluxo do tipo uni form.

- sidelen [REAL] Largura de ação do fluxo, obrigatório apenas para o fluxo do tipo uni form.

- wind

Define uma fonte de fluxos de vento. O processo de geração de fluxos requer diversos parâmetros, dentre eles a máscara que será utilizada e outros atributos listados abaixo:

- name $[\mathrm{PAL}]$ Nome da fonte de fluxos.

○ wmask [PAL] Nome da máscara que será utilizada. Esta máscara deve já ter sido definida anteriormente.

o sourcelifetime [INT] Período de tempo que a fonte gerará fluxos, em milisegundos.

- borntime [INT] Momento em que a fonte começa a atuar (gerar fluxos), em milisegundos. 
o freqflowgen [INT] Frequência de geração de novos fluxos, em milisegundos.

- freqflowgenoffset [INT] Variação máxima no tempo de geração de novos fluxos, em milisegundos.

o genfixed [BOOL] Indica se a fonte pode se mover pela ação de outros fluxos.

- gencenterposition [VEC] Posição inicial da fonte.

- velocityflow [REAL] Norma da velocidade dos fluxos gerados.

o velocityflowoffset [REAL] Variação na norma da velocidade dos fluxos gerados.

- flowmovevelocity [VEC] Velocidade de movimento do fluxo, o atributo genfixed deve estar habilitado.

o flowlifetime [INT] Tempo de vida dos fluxos gerados, em milisegundos.

\section{- forcefield}

Define os atributos do Campo de forças, estes seguem listados abaixo:

o inipt [VEC] Ponto inicial em que será criado o Campo de forças.

○ qtlen [REAL] Dimensão de ação do Campo de forças.

o maxlevel [INT] Número máximo de níveis que a quadtree poderá ter.

- lodboundaries [LREAL] Lista de distâncias para o algoritmo de nível de detalhe por distância do Campo de forças descrito em 3.4.3.

\section{- plantcomponents}

Define os componentes das plantas que são definidas na cena. As "tags" que definem os tipos de componentes são listadas abaixo:

\section{- leaf}

Define os atributos de uma folha, todos listados abaixo.

- name $[P A L]$ Nome da folha.

- constraint [REAL] Valor da constante de controle para animação.

o modellength [REAL] Dimensão do modelo da folha.

o maxlength [REAL] Comprimento máximo da folha. 
o offsetlength [REAL] Maior variação possível para o comprimento máximo da folha.

o nutrientmin [INT] Quantidade mínima de nutrientes necessária para alimentar a folha.

o nutrientmax [INT] Quantidade máxima de nutrientes que a folha suporta.

o watermin [INT] Quantidade mínima de irrigação necessária para sustentar a folha.

○ watermax [INT] Quantidade máxima de irrigação que a folha suporta.

o cachebendangleoffset [INT] Diferença de ângulos para o cache do modelo da folha na vertical.

o cacherotangleoffset [INT] Diferença de ângulos para o cache do modelo da folha em diferentes ângulos de rotação.

- numanimangoffset [INT] Número de intervalos de ângulo utilizado na pré-computação da animação.

As seções da folha devem ser definidas, na ordem em que estarão na folha, as primeiras "tags" definem as seções mais próximas à base da folha. Pode ser definida uma "tag" de nível de detalhes para folha também como veremos a seguir:

\section{- leafsection}

Define atributos das seções de uma folha. Seus atributos são listados abaixo:

- color [COR] Cor da seção.

o mass [REAL] Massa da seção.

o thickness [REAL] Grossura do talo da folha na seção

- length [REAL] Largura da seção. Deve ser proporcional ao atributo modellength da "tag" leaf

\section{- leaflod}

Deve definir as distâncias para os níveis de detalhes definidos dentro desta "tag".

o dist [LREAL] Uma lista de distâncias que determinam os intervalos em que cada nível de detalhe definido será utilizado.

A seguinte "tag" pode ser utilizada para se definir os níveis de detalhes da folha.

- leaflodinfo

○ index [LINT] Lista de inteiros que definem os índices das seções que serão utilizadas no nível de detalhe definido pela "tag".

- type [PAL] Pode assumir dois valores: triangles ou lines, para representação por triângulos ou linhas, respectivamente. 
- branch

Define os atributos de um galho. Segue a mesma idéia de seções da folha. Os atributos desta "tag" são listados abaixo.

o name [PAL] Nome do galho.

o numedges [INT] Número de polígonos utilizados para criação das bases do galho.

- symmetric [BOOL] Indica se o galho tem formato simétrico nas bases.

- tropism [REAL] Nível de fototropismo.

o nutrientmin [INT] Quantidade mínima de nutrientes necessária para alimentar o galho.

o nutrientmax [INT] Quantidade máxima de nutrientes que o galho suporta.

o watermin [INT] Quantidade mínima de irrigação necessária para sustentar o galho.

o watermax [INT] Quantidade máxima de irrigação que o galho suporta.

- cachebendangleoffset [INT] Diferença de ângulos para o cache do modelo do galho na vertical.

o cacherotangleoffset [INT] Diferença de ângulos para o cache do modelo do galho em diferentes ângulos de rotação.

o constraint [REAL] Valor da constante de controle para animação.

o numanimangoffset [INT] Número de intervalos de ângulo utilizado na pré-computação da animação.

São definidos duas "tags" relativas às seções e níveis de detalhes:

\section{- branchsection}

Define atributos das seções de um galho. Seus atributos são listados abaixo:

o color [COR] Cor da seção.

- mass [REAL] Massa da seção.

- thickness [REAL] Grossura da seção.

o strength [REAL] Resistência da seção.

\section{- branchlod}

Deve definir as distâncias para os níveis de detalhes definidos dentro desta "tag".

o index [LINT] Lista contendo os índices das seções utilizadas em cada nível de detalhe.

o type [PAL] Pode assumir dois valores: triangles ou lines. 
- flower

Este componente representa informações sobre flores. A flor implementada utiliza um objeto leaf como pétala. Este objeto deve ter sido definido anteriormente. Os atributos da flor seguem abaixo:

o name $[\mathrm{PAL}]$ Nome da flor.

o vangles [LINT] Lista de ângulos verticais de cada pétala.

- rotangles [LINT] Lista de ângulos de rotação de cada pétala.

- leafinfo [PAL] Nome da folha utilizada como pétala.

\section{- terrain}

Define a malha do terreno e suas propriedades. Os atributos são listados abaixo:

o ini tpoint [VEC] Ponto inicial do terreno que será gerado.

○ numlines [INT] Número de linhas da malha do terreno.

o numcols [INT] Número de colunas da malha do terreno.

o sectiondist [REAL] Distância entre os pontos da malha.

o maxheigthvar [REAL] Máxima variação de altura entre pontos adjacentes da malha.

o nutrients [INT] Quantidade de nutrientes definido em cada ponto da malha.

o nutrientsvar [INT] Variação máxima na quantidade de nutrientes.

o irrigation [INT] Nível de irrigação definido em cada ponto da malha.

○ irrigationvar [INT] Variação máxima na irrigação.

\section{- plantdistribution}

Define os conjuntos de distribuições de plantas. Pode ter dois tipos de conjuntos:

\section{- bushdistribution}

Conjunto de distribuição de árvores ou arbustos. Apenas um tipo de distribuição foi implementado:

- bushscalebaseddistribution

Cria a distribuição de árvores e arbustos. Os atributos das árvores seguem: 
- bushheight [REAL] Altura dos arbustos.

o bushheightvar [REAL] Variação na altura dos arbustos.

o proppt [COORD2D] Posição inicial de distribuição na malha do terreno.

o maxelements [INT] Número máximo de elementos criados na distribuição.

- branchinfo [PAL] Nome do galho que será utilizado para criação das árvores.

- leafinfo [PAL] Nome do tipo de folha que será utilizada no arbusto.

o flowerinfo [PAL] Nome do tipo de flor que será utilizada no arbusto.

- distribseed [INT] Número utilizado como semente do algoritmo aleatório de geração de distribuição.

o numbushespercluster [INT] Números de arbustos definidos numa região de distribuição.

o offsetnumbushes [INT] Variação no número de arbustos por região.

o clusterdimension [REAL] Dimensão da região de distribuição de um arbusto.

- maxdistanceforpropagation [INT] Número máximo de pontos no terreno que pode ser utilizado para expansão da vegetação no algoritmo de distribuição.

- branchcachekey [PAL] Palavra chave para o cache de galhos desta distribuição, pode assumir qualquer valor definido pelo usuário.

- compsprop [LINT] Proporção entre folhas, galhos e flores geradas na criação do arbusto. Por exemplo, $[40,50,10]$ indica que a chance de criação de uma folha é de $40 \%$, de um galho é de $50 \%$ enquanto o de uma flor é de $10 \%$ no algoritmo de ramificação do arbusto.

○ numlevels [INT] Número de níveis que serão criadas novas ramificações.

- numonlybranchlevels [INT] Número de níveis onde apenas galhos são criados como novas ramificações. Nos níveis após este valor é utilizada a proporção definida em compsprop.

- numcomppersection [INT] Número de componentes gerados por seção de um galho no algoritmo de ramificação.

o numcomppersectionvar [INT] Variação do número de componentes gerados por seção.

- underbrushdistribution

Conjunto de distribuição de vegetação rasteira. Os tipos de distribuição são os seguintes:

- flowerclusterdistribution 
Define a distribuição de um agrupamento de flores. Os atributos desta distribuição são listados abaixo:

- flowerheight [REAL] Altura das flores.

- flowerheightvar [REAL] Variação na altura das flores.

o proppt [COORD2D] Posição inicial de distribuição na malha do terreno.

o maxelements [INT] Número máximo de agrupamentos criados na distribuição.

o branchinfo [PAL] Nome do galho utilizado.

- leafinfo [PAL] Nome do tipo de folha utilizada.

o flowerinfo [PAL] Nome do tipo de flor utilizada.

o distribseed [INT] Número utilizado como semente do algoritmo aleatório de geração de distribuição.

o numflowerpercluster [INT] Número de folhas definidos por agrupamento.

o offsetnumflowers [INT] Variação no número de folha por agrupamento.

- clusterdimension [REAL] Dimensão da região de distribuição do agrupamento.

- maxdistanceforpropagation [INT] Número máximo de pontos no terreno que pode ser utilizado para expansão da vegetação no algoritmo de distribuição.

- branchcachekey [PAL] Palavra chave para o cache de galhos desta distribuição, pode assumir qualquer valor definido pelo usuário.

- leafclusterdistribution

Define a distribuição de um agrupamento de folhas sobre o solo. Os atributos desta distribuição são listados abaixo:

o proppt [COORD2D] Posição inicial de distribuição na malha do terreno.

o maxelements [INT] Número máximo de agrupamentos criados na distribuição.

- leafinfo [PAL] Nome do tipo de folha utilizada.

o distribseed [INT] Número utilizado como semente do algoritmo aleatório de geração de distribuição.

o numleavespercluster [INT] Número de folhas definidos por agrupamento.

- offsetnumleaves [INT] Variação no número de folha por agrupamento.

- clusterdimension [REAL] Dimensão da região de distribuição do agrupamento.

- maxdistanceforpropagation [INT] Número máximo de pontos no terreno que pode ser utilizado para expansão da vegetação no algoritmo de distribuição. 


\section{B.2 Exemplo}

O código ESL abaixo descreve a especificação de uma cena simples.

$<$ !-- Propriedades do ecossistema. - $>$

$2<$ ecosys normal $="(0.0,1.0,0.0)$ " winlen $=" 400 "$ winhe $i=" 400 ">$

$<$ !-- Propriedades dos fluxos de vento. $-->$

$<$ windset $>$

$<$ windmask name $=$ "WUNIF" type $=$ "UNIFORM" wind dir $="(0.0,0.0,1.0) "$ sidelen $=" 5.0 " />$

$<$ wind name="WDUNIF" wmask="WUNIF" sourcelifeTime="100000" bornTime $=" 5000 "$ freqFlowGen $=" 300 "$ freqFlowGenOffset $=" 50 "$ genFixed="TRUE" genCenterPosition $="(0.5,-4.0,0.0)$ " velocityFlow $=" 10.0 "$ velocityFlow Offset $=" 1.0 "$ flowMoveVelocity $="(1.0,0.0,0.0) "$ flowLifeTime $=" 10000 " />$ $</$ windset $>$

$<$ !-- Propriedades do campo de forcas. $->>$

$<$ forcefield inipt $="(-25.0,-5.0,-25.0)$ " qtlen $=" 64.0 "$

maxlevel $=" 5 "$ lodboundaries $="[10.0,30.0] " />$

$<$ !-- Propriedades dos componentes das plantas. $-->$

$<$ plantcomponents $>$

$<$ !-- Folha de grama. $-->$

$<$ leaf name $="$ gleaf " constraint $=" 100.0 "$ modelLength $=" 5.0 "$

maxLength $=" 0.15 "$ offsetLength $=" 0.015 "$ nutrientMin $=" 10 "$

nutrientMax $=" 2000 "$ waterMin="10" waterMax $=" 2000 "$

cacheBendAngleOffset $=$ " 5 " cacheRotAngleOffset $=" 10 "$ numanimangoffset $=" 4$ " $>$

$$
\begin{aligned}
& <\text { leafsection color }="(0.45,0.56,0.14,0.8) \text { " mass }=" 0.00005 " \\
& \text { thickness }=" 0.27 \text { " length }=" 0.15 " /> \\
& <\text { leafsection color }="(0.47,0.60,0.16,0.8) " \text { mass }=" 0.000075 " \\
& \text { thickness }=" 0.019 \text { " length }=" 0.23 " /> \\
& <\text { leafsection color }="(0.48,0.62,0.17,0.8) " \text { mass }=" 0.0001 " \\
& \text { thickness }=" 0.006 " \text { length }=" 0.16 " /> \\
& <\text { leafsection color }="(0.48,0.63,0.19,0.8) " \text { mass }=" 0.0001 " \\
& \text { thickness }=" 0.002 \text { "length }=" 0.08 " /> \\
& <\text { leafsection color }="(0.49,0.65,0.21,0.8) " \text { mass }=" 0.0001 " \\
& \text { thickness }=" 0.001 " /> \\
& <\text { leaflod dist }="[15.0] "> \\
& <\text { leaflodinfo index }=\text { " }[0,1,2,3] \text { " type="triangles"/> } \\
& <\text { leaflodinfo index }="[0,1,2,3] \text { " type="lines"/> }
\end{aligned}
$$




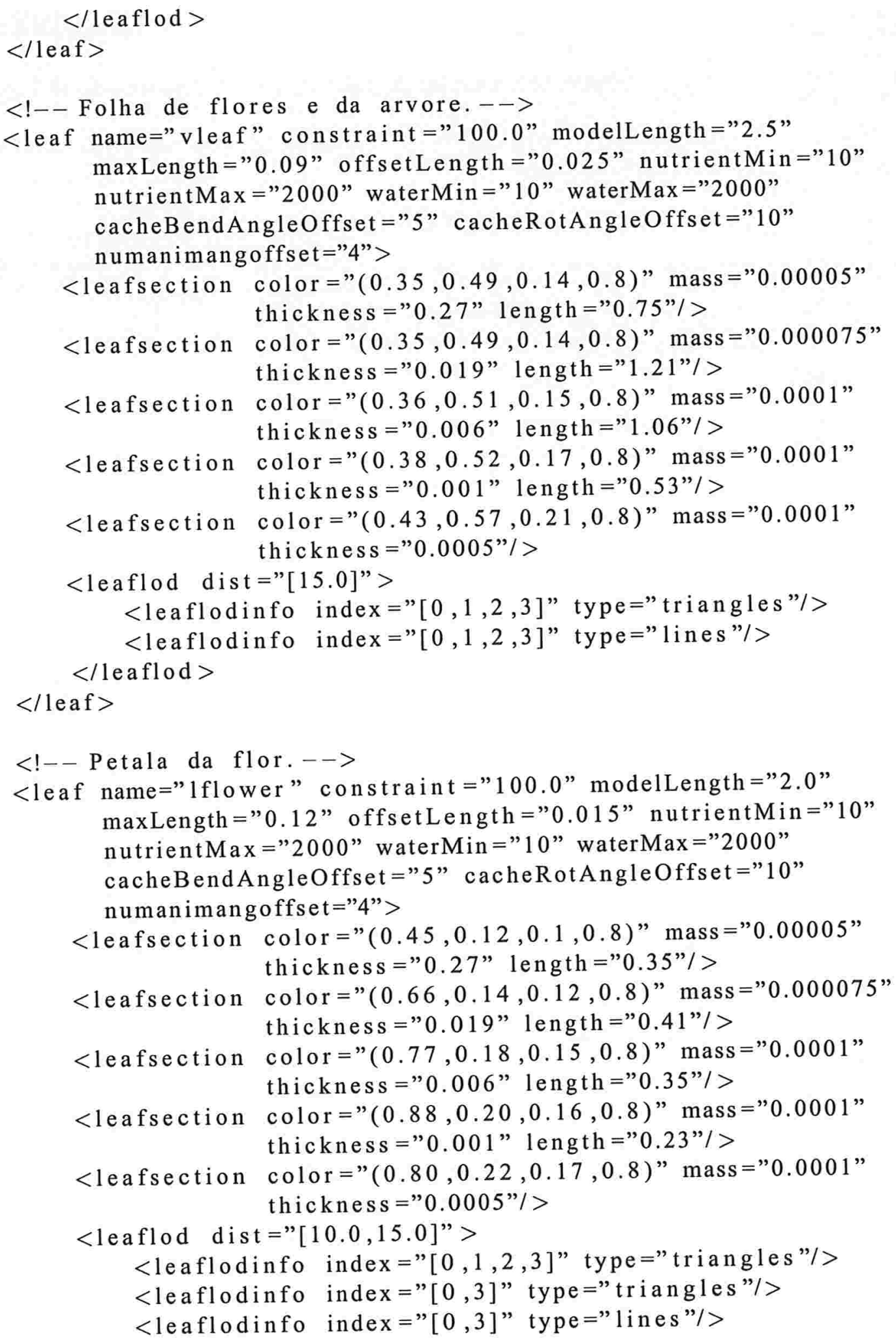




$$
\begin{aligned}
& </ \text { leaflod }> \\
& </ \text { leaf }>
\end{aligned}
$$

$<$ ! - Galhos utilizados pelas flores e arvore. $-->$

$<$ branch name $=$ "vbranch" numedges $=" 5$ " symmetric $=$ "true"

tropism $=" 0.1 "$ nutrientMin="10" nutrientMax="2000"

waterMin ="10" waterMax ="2000" cacheBendAngleOffet ="5" cacheRotAngleOffset $=" 10 "$ constraint $=" 100.0 "$ numanimangoffset $=" 4$ ">

<branchsection color $="(0.19,0.16,0.06,0.8) " \quad$ mass $=" 0.0001 "$

thickness $=" 0.02 "$ strength $=" 1.0 " />$

<branchsection color $="(0.19,0.21,0.06,0.8) " \quad \operatorname{mass}=" 0.0001 "$

thickness ="0.02" strength $=" 1.0 " />$

<branchsection color $="(0.19,0.27,0.06,0.8) " \quad \operatorname{mass}=" 0.0001 "$

thickness $=" 0.02 "$ strength $=" 1.0 " />$

$<$ branchlod dist $="[15.0] ">$

$<$ branchlodinfo index $="[0,1,2] "$ baseIndex $="[0,1,2,3,4] "$

type="triangles"/>

$<$ branchlodinfo index $="[0,1,2] "$ baseIndex $="[0] "$

type="1ines"/>

$<$ /branchlod $>$

$</$ branch $>$

$<$ !-- Propriedades da flor. $-->$

$<$ flower name="flower" vangles $="[25,25,25,25,25] "$

rotangles $="[0,75,150,225,300] "$ leafinfo="lflower" $/>$

$</$ plantcomponents $>$

$<$ !-- Propriedades do terreno. $-->$

$<$ terrain initpoint $="(-25.0,-5.0,-25.0) "$ numlines $=" 70 "$

numcols $=" 70 "$ sectiondist $=" 0.5 "$ maxheigthvar $=" 0.1 "$

nutrients $=" 32$ " nutrientsvar $=" 2 "$

irrigation $=" 32 "$ irrigationvar $=" 2 " />$

$<$ !-- Distribuicoes de plantas. $-->$

$<$ plantdistribution $>$

$<$ !- - Distribuicoes de arvores. $-->$

$<$ bushdistribution $>$

$<$ !- - Exemplo de distribuicao de arvore. $->$

$<$ bushscalebaseddistribution name="tree"

bushheight =" $3.2 "$

bushheightvar $=$ " 0.2 "

proppt $="(43,33) "$ 


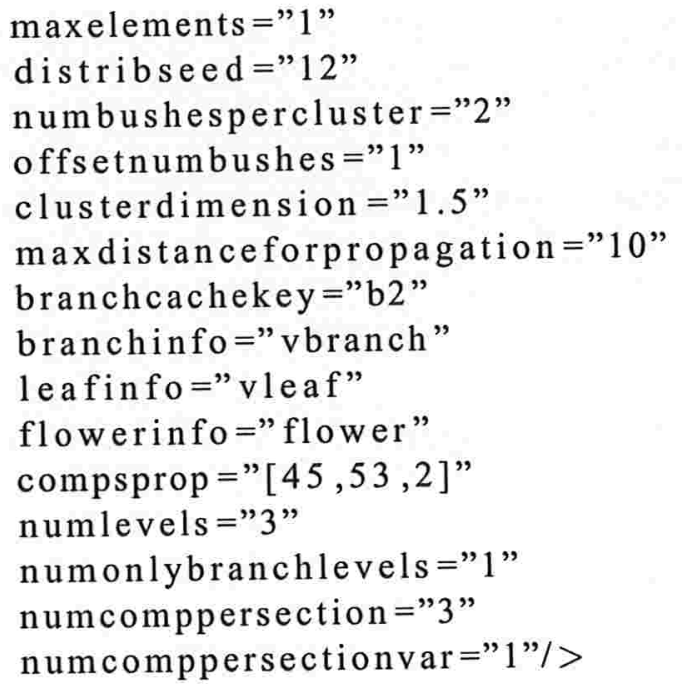

$</$ bushdistribution $>$

$<$ !-- Distribuicoes de vegetacao rasteira. $->$

$<$ underbrushdistribution $>$ $<$ !-- Exemplo de distribuicao de flores. - $>$ $<$ flowerclusterdistribution name=" simpleflowers"

flowerheight $=" 0.8 "$

flowerheightvar $=" 0.2$ "

proppt $="(45,35) "$

maxelements $=" 5$ "

distribseed $=" 12 "$

numflowerpercluster $=$ " 3 "

offsetnumflowers $=$ " 1 "

clusterdimension $=" 1.5 "$

maxdistanceforpropagation $=$ " $10 "$

branchcachekey="b1"

branchinfo="vbranch"

leafinfo="vleaf"

flowerinfo="flower"/>

$<$ !-- Exemplo de distribuicao de grama. - $>$

$<$ leafclusterdistribution name="grass"

proppt $="(42,32) "$

maxelements $=" 15$ "

distribseed $=" 12 "$

numleavespercluster $=" 20 "$

offsetnumleaves $=" 5$ "

clusterdimension $=" 1.5$ "

maxdistanceforpropagation $=" 7 "$

leafinfo="gleaf"/> 
176

$</$ underbrushdistribution $>$ $</$ plantdistribution $>$

$178</$ ecosys $>$

Este exemplo de código ESL gera a cena ilustrada na Figura B.1.

Apenas três tipos de folhas são criados. A folha "gleaf", descrita na linha 23, é utilizada na distribuição de folhas definida na linha 167 e contém informações que geram uma folha similar a uma folha de grama. A folha "vleaf", descrita na linha 45, descreve uma folha que é usada para definir a folha tanto na distribuição de flores (linha 151) quanto na de arbustos (linha 127). A folha "lflower", descrita na linha 67, descreve a pétala das flores. A flor definida na linha 110 utiliza esta folha como pétala.

As fontes de vento são definidas na linha 5, e utilizam uma máscara uniforme (linha 6). As propriedades do campo de forças são configuradas na linha 16. O terreno, por sua vez, é definido na linha 116.

Note que apesar das distribuições de flores e arbustos definidas utilizarem os mesmos componentes de folha e flor, a linguagem permite que sejam definidos outros componentes de modo a criar flores e folhas diferentes para cada distribuição. Utilizamos os mesmos componentes apenas para não criarmos um exemplo muito grande e complexo. 


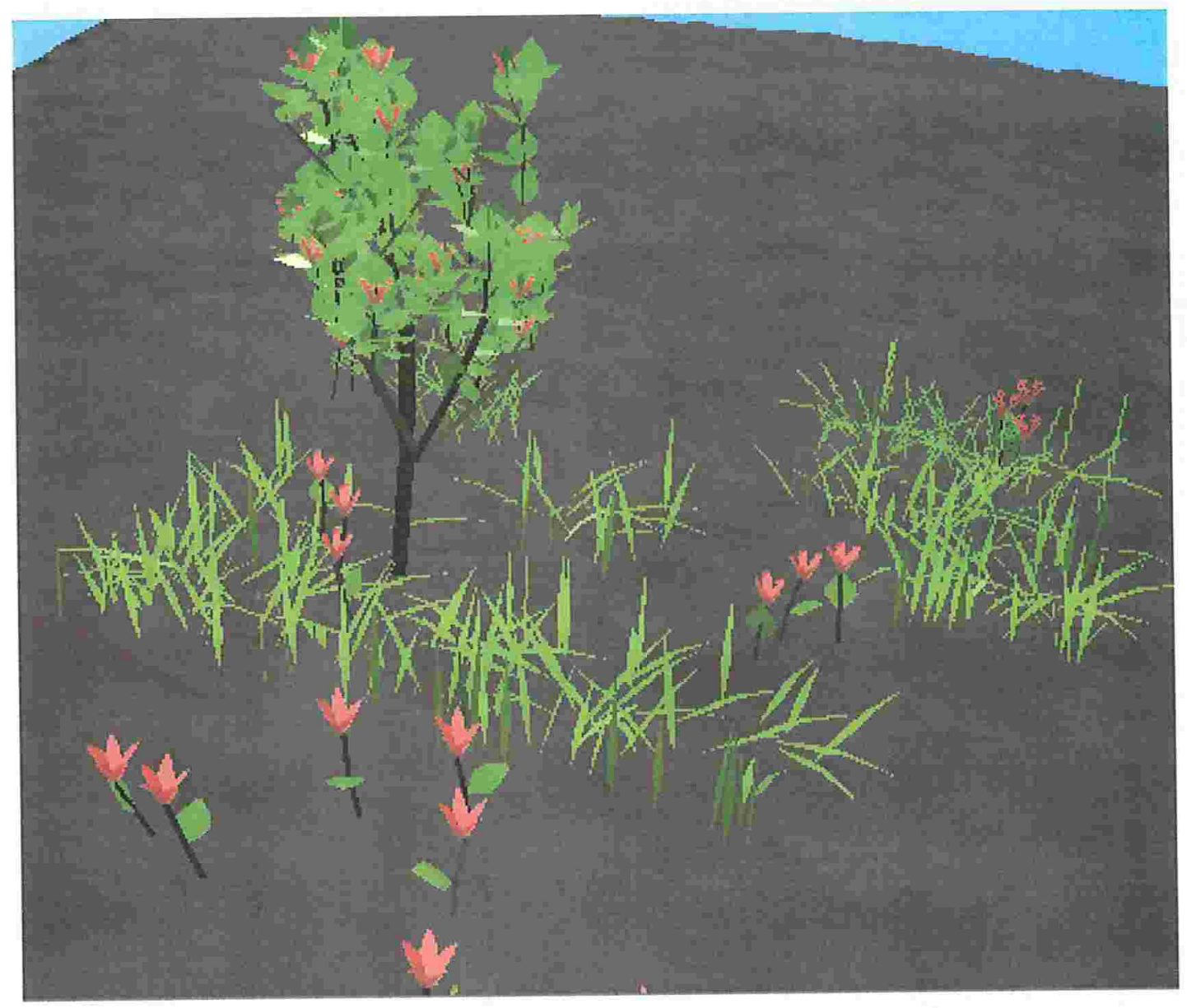

Figura B.1: Cena gerada pelo ESL exemplo. 


\section{Bibliografia}

[AC96] ARnold K., Cosling J.: The Java Programming Language. Addison Wesley, 1996.

[Alh98] ALHIR S. S.: UML in a Nutshell. O’Reilly, 1998.

[BB88] BARzel R., BARR A. H.: A Modeling System Based On Dynamic Constraints. Computer Graphics - ACM SIGGRAPH 22, 4 (Agosto 1988), 179-188.

[BFWS78] Barrett J. R., Foster J. E., Wong G. A., Stanley E. C.: Insect population simulation. In Winter Simulation Conference (1978), vol. 2, pp. 485-492.

[CH97] CARlson D. A., Hodgins J. K.: Simulation Levels of Detail for Real-time Animation. In Proceedings of Graphics Interface (1997).

[Che01] CHENNEY S.: Simulation Level-Of-Detail. In Web (http://citeseer.nj.nec.com/ 488321.html) (2001).

[Cla75] Claudson R. M.: The digital simulation of river plankton population dynamics. In Communications of the ACM (1975), pp. 517-523.

[DCSD02] Deussen O., Colditz C., Stamminger M., Drettakis G.: Interactive Visualization of Complex Plant Ecosystems. Proceedings of the IEEE Visualization Conference (Outubro. 2002).

[DHL*98] Deussen O., Hanrahan P., Lintermann B., MĚch R., Pharr M., PRUSINKIEWICZ P.: Realistic Modeling and Rendering of Plant Ecosystems. Computer Graphics - ACM SIGGRAPH 32 (1998), 275-286.

[Ebe96] EBERT D. S.: Advanced Modeling Techniques for Computer Graphics. ACM Computing Surveys 28 (Março 1996), 153-156. 
[EMF] Endo L. C. Y., Morimoto C. H., FABris A. E.: JEcoSys: A Framework for Interactive Plants Simulation. a ser publicado.

[EMF03] ENDo L. C. Y., Morimoto C. H., FABRis A. E.: Real-time Animation of Underbrush. WSCG Short Papers Proceedings - The 11th International Conference in Central Europe on Computer Graphics, Visualization and Computer Vision'2003 11 (2003), 41-48.

[FGL03] Fuhrmann A., GROB C., LuCKAS V.: Interactive animation of cloth including self collision detection. Journal of WSCG - The 11th International Conference in Central Europe on Computer Graphics, Visualization and Computer Vision'2003 11, 1 (2003), 141-148.

[FPB92] Fowler D. R., Prusinkiewicz P., Battjes J.: A Collision-based model of spiral phyllotaxis. Computer Graphics 26, 2 (1992), 361-368.

[FvDFH97] Foley J. D., van Dam A., Feiner S. K., Hughes J. F.: Computer Graphics: Principles and Practice, 2nd edition in C. Addison-Wesley, 1997.

[GCF01] Giacomo T. D., CAPO S., FAURE F.: An Interactive Forest. In Eurographics Workshop on Computer Animation and Simulation (Setembro. 2001), pp. 65-74.

[GHJV95] Gamma E., Helm R., Johnson R., Vlissides J.: Design Patterns - Elements of Reusable Object-Oriented Software. Addison Wesley, 1995.

[Gre] Green M.: Topics in Virtual Reality and Interactive 3D Graphics, Part two.

[GV98] Gomes J., Velho L.: Computação Gráfica Volume 1. Instituto de Matemática Pura e Aplicada - IMPA - Série de Computação e Matemática, 1998.

[Jak00] JakUlin A.: Interactive Vegetation Rendering with Slicing and Blending. In Proc. Eurographics 2000 (Short Presentations) (Agosto 2000), Eurographics.

[jav] Sun Microsystems. Java 3DTM API Tutorial.

[Ki178] KILlus J.: SIMPLE: A SIMPLIFIED ECOSYSTEM MODEL FOR LAKE GEORGE, NEW YORK. In Winter Simulation Conference (1978), vol. 2, pp. 641-646.

[Man88] Mantyla M.: Introduction to Solid Modeling. Computer Science Press, 1988.

[MC95] MASSElot A., ChOpard B.: Cellular Automata Modeling of Snow Transport by Wind. In PARA (1995), pp. 429-435. 
[McC93] MCCORMACK J. P.: Interactive evolution of L-system grammars for computer graphics modelling. In Complex Systems: from biology to computation, Green D. G., Bossomaier T., (Eds.). ISO Press, Amsterdam, 1993, pp. 118-130.

[McL00] McLaughlin B.: Java and XML. O'Reilly, 2000.

[Met02] Metsker S. J.: Design Patterns Java Workbook. Addison Wesley, 2002.

[MFAC97] Marshall D., Fussell D. S., A.T. Campbell I.: Multiresolution rendering of complex botanical scenes. In Graphics Interface (Maio 1997), Davis W., Mantei M.,, Klassen V., (Eds.), pp. 97-104.

[MMK*00] Markosian L., Meier B., Kowalski M., Holden L., Northrup J., Hughes J.: Art-based Rendering with Continuous Levels of Detail. In In Proceedings of the First International Symposium on Non Photorealistic Animation and Rendering (NPAR) for Art and Entertainment (2000).

[MT92] Metaxas D., Terzopoulos D.: Dynamic Deformation of Solid Primitives with Constraints. Computer Graphics - ACM SIGGRAPH 26, 2 (1992), 309-312.

[NIDN97] Nishita T., Iwasaki H., Dobashi Y., Nakamae E.: A Modeling and Rendering Method for Snow by Using Metaballs. Computer Graphics Forum 16, 3 (1997), C357C364.

[OH95] O'Brien J. F., Hodgins J. K.: Dynamic Simulation of Splashing Fluids. In Computer Animation '95 (1995), pp. 198-205.

[PC01] Perbet F., CANi M. P.: Animating Prairies in Real-Time. In ACM Interactive 3D Graphics (Março 2001).

[PHHM96a] Prusinkiewicz P., Hammel M., Hanan J., MĚch R.: L-Systems: From the Theory to Visual Models of Plants. In Proceedings of the 2nd CSIRO Symposium on Computational Challanges in Life Sciences (1996), CSIRO Publishing.

[PHHM96b] Prusinkiewicz P., Hammel M., Hanan J., Mech R.: Visual models of plant development. In Handbook of formal languages, Rozenberg G., Salomaa A., (Eds.). SpringerVerlag, 1996.

[PHM] Prusinkiewicz P., Hammel M., MĚch R.: Visual Models of Morphogenesis: A Guided Tour. In Web (http://www.cpsc.ucalgary.ca/projects/bmv/vmm/title.html). 
[Pru93] PRUSINKIEwICZ P.: Modeling and Visualization of Biological Structures. In Graphics Interface '93 (Maio 1993), pp. 128-137.

[RB85] REEves W. T., BLAN R.: Approximate and Probabilistic Algorithms for Shading and Rendering Structured Particle Systems. Computer Graphics - ACM SIGGRAPH 19, 3 (1985), 313-322.

[Ree83] ReEves. W. T.: Particle Systems - A Technique for Modeling a Class of Fuzzy Objects. In ACM Transactions of Graphics (Abril 1983), pp. 91-108.

[Req80] REQuicha A.: Representations for rigid solids: Theory, methods and systems. $A C M$ Computing Surveys 12, 4 (1980), 437-464.

[SF93] StAm J., FiUme E.: Turbulent Wind Fields for Gaseous Phenomena. Computer Graphics - ACM SIGGRAPH 27, Annual Conference Series (1993), 369-376.

[Sim90] Sims K.: Particle Animation and Rendering Using Data Parallel Computation. Computer Graphics - ACM SIGGRAPH 24, 4 (Agosto 1990), 405-413.

[Tan01] TANKARD G.: Pratical Modeling of Realistic Plants for Real-Time 3D Environment. In Web (http://citeseer.ist.psu.edu/tankard01 practical.html) (2001).

[TPBF87] Terzopoulos D., Platt J., BARr A., Fleischert K.: Elastically Deformable Models. Computer Graphics - ACM SIGGRAPH 21, 4 (Julho 1987), 205-214.

[TTG94] Terzopoulos D., Tu X., Grzeszczuk R.: Artificial Fishes: Autonomous Locomotion, Perception, Behavior, and Learning in a Simulated Physical World. Artificial Life 1, 4 (1994).

[VF03] Velha P. L. E., FABRis A. E.: A Global Signal Propagation Technique for the Modeling of Plants. Journal of WSCG - The 11th International Conference in Central Europe on Computer Graphics, Visualization and Computer Vision'2003 11 (2003).

[Wat93] WATt A.: 3D Computer Graphics, Second Edition. Addison-Wesley, 1993.

[WB] Witkin A., BARAFF D.: Physically Based Modeling: Principles and Practice (SIGGRAPH'97 Course Notes).

[WFB87] Witkin A., Fleischer K., BARR A.: Energy Constraints on Parameterized Models. Computer Graphics - ACM SIGGRAPH 21, 4 (1987), 225-232. 
[WH91] WeJChert J., HAUMANn D.: Animation Aerodynamics. Computer Graphics - ACM SIGGRAPH (Julho 1991), 19-22. 